\author{
Universidade de São Paulo \\ Instituto de Física
}

\title{
Sistema para Medida de Estados Isoméricos
}

\author{
Dennis Lozano Toufen
}

Orientador: Prof. Dr. Nilberto Heder Medina

Dissertação de mestrado apresentada ao Instituto de Física da Universidade de São Paulo para a obtenção do título de Mestre em Ciências

Banca Examinadora:

Prof. Dr. Nilberto Heder Medina (IFUSP)

Prof. Dr. Roberto Meigikos do Anjos (UFF)

Dr. Eduardo Luiz Augusto Macchione (IFUSP) 
FICHA CATALOGRÁFICA

Preparada pelo Serviço de Biblioteca e Informação do Instituto de Física da Universidade de São Paulo

Toufen, Dennis Lozano

Sistema para medida de estados isométricos - São Paulo - 2008

Dissertação (Mestrado) - Universidade de São Paulo. Instituto de Física - Depto. de Física Nuclear

Orientador: Prof. Dr. Nilberto Heder Medina

Área de Concentração: Física Nuclear

Unitermos: 1. Física Nuclear; 2. Estrutura Nuclear; 3. Modelo Nuclear.

USP/IF/SBI-080/2008 
"Para ser grande, sê inteiro: nada Teu exagera ou exclui. Sê todo em cada coisa. Põe quanto és

No mínimo que fazes. Assim em cada lago a lua toda Brilha, porque alta vive."

(Ricardo Reis) 


\section{AGRADECIMENTOS}

Ao Prof. Dr. Nilberto Heder Medina, pela sincera amizade e pela dedicação e vontade com que tem me orientado.

Aos meus pais, Carlos e Aparecida, pois tudo que sou devo a eles.

Ao meu irmão, Carlos Jr, pelo companheirismo, incentivo e permanente inspiração.

A Paula, pela cumplicidade e apoio em todas as situações.

Ao Prof. Dr. José Roberto (Zero), pela valiosíssima ajuda na instrumentação e por sempre responder sim para a minha constante pergunta: "Zero, você tem 5 minutos para tirar uma dúvida?".

Aos Professores do grupo Gama: Ribas, Ewa e Wayne, pela ajuda sempre atenciosa e pelo apoio em períodos de máquina.

Aos alunos e ex-alunos de pós-graduação do grupo Gama: Roberto, Shila e Kenia pelo coleguismo e apoio em períodos de máquina.

Ao Prof. Dr. Nemitala Added, pelos conselhos referentes às peças mecânicas.

A todos os colegas e funcionários do Pelletron, por fornecerem a infra-estrutura que permitiu a realização deste trabalho.

Ao CNPq e a FAPESP pelo apoio financeiro. 


\section{ABSTRACT}

A system, called SISMEI (Isomeric State Measurement System), was developed for the detection and measurement of isomeric states with half-lives in the range of $10 \mathrm{~ns}$ to $10 \mu \mathrm{s}$ without the use of a pulsed beam. This system mainly uses the technique of charged particles and $\gamma$-ray delayed coincidences. In SISMEI, the statistical background is reduced by the separation between the target region, where charged particles are evaporated, and the "stopper" region, where the delayed $\gamma$-rays are emitted.

SISMEI was tested in two experiments with the reaction ${ }^{46} \mathrm{Ti}\left({ }^{11} \mathrm{~B}, 1 \mathrm{p} 2 \mathrm{n}\right){ }^{54} \mathrm{Fe}, \mathrm{E}_{\text {beam }}=$ $30 \mathrm{MeV}$ and $\mathrm{E}_{\text {beam }}=33 \mathrm{MeV}$. In these experiments, the experimental lifetime of the ${ }^{54} \mathrm{Fe}$ nucleus $10^{+}$isomeric state was $\mathrm{T}_{1 / 2}=375$ (16) ns, which is consistent with the known experimental value $\left(\mathrm{T}_{1 / 2}=364(7) \mathrm{ns}\right)$. Using the ${ }^{54} \mathrm{Fe} 10^{+}$isomeric state time spectrum as calibration, the half life of the ${ }^{19} \mathrm{~F} 5 / 2^{+}$state was measured. The experimental lifetime $\left(\mathrm{T}_{1 / 2}=\right.$ $100(36) \mathrm{s})$ is consistent with the known value $\left(\mathrm{T}_{1 / 2}=89.3(10) \mathrm{ns}\right)$. The results also indicate that the system is capable of identifying the transitions to the isomeric state through the delayed $\gamma-\gamma$ coincidence method.

The ${ }^{54} \mathrm{Fe}$ nucleus $10^{+}$isomeric state was calculated in the framework of the Large Scale Shell Model. The energy and B (E2) experimental values were very well reproduced for a sufficient number of free particles in the full pf shell. 


\section{RESUMO}

Com o objetivo de permitir a detecção e a medida de estados isoméricos com meias vidas na faixa de 10 ns a $10 \mu$ s sem a utilização de feixe pulsado, desenvolveu-se um sistema, batizado de SISMEI (SIStema de Medida de Estados Isoméricos). Este sistema utiliza principalmente a técnica de coincidência atrasada entre partículas carregadas e raios $\gamma$. No SISMEI há uma separação espacial entre a região do alvo, onde as partículas carregadas são emitidas, e a região do "stopper", onde os raios $\gamma$ atrasados são emitidos, permitindo assim uma diminuição do fundo estatístico.

Para o teste do SISMEI foram realizadas duas experiências com a reação de fusão evaporação ${ }^{46} \operatorname{Ti}\left({ }^{11} \mathrm{~B}, 1 \mathrm{p} 2 \mathrm{n}\right){ }^{54} \mathrm{Fe}, \mathrm{E}_{\text {feixe }}=30 \mathrm{MeV}$ e $\mathrm{E}_{\text {feixe }}=33 \mathrm{MeV}$. Nestas experiências o estado isomérico conhecido $10^{+}$do ${ }^{54} \mathrm{Fe}\left(\mathrm{T}_{1 / 2}=364(7) \mathrm{ns}\right)$ foi medido, sendo o resultado encontrado $\left(\mathrm{T}_{1 / 2}=375(16) \mathrm{ns}\right)$ compatível com o conhecido. Utilizando o espectro de tempo do estado isomérico $10^{+}$do ${ }^{54} \mathrm{Fe}$ como calibração, mediu-se a meia vida do estado isomérico $5 / 2^{+}$do ${ }^{19} \mathrm{~F}$ $\left(\mathrm{T}_{1 / 2}=89,3(10) \mathrm{ns}\right)$ e a meia vida encontrada $\left(\mathrm{T}_{1 / 2}=100(36) \mathrm{ns}\right)$ é compatível com o valor conhecido. O sistema também foi capaz de identificar transições que populam o estado isomérico $10^{+}$através da técnica de coincidência $\gamma-\gamma$ atrasada.

O Modelo de Camadas de Larga Escala foi utilizado para interpretar o estado isomérico $10^{+}$do ${ }^{54} \mathrm{Fe}$. Este modelo foi capaz de reproduzir bem os valores experimentais de energia do nível e da probabilidade de transição reduzida B(E2), desde que seja utilizado um número suficiente de partículas livres na camada pf. 


\section{Lista de Ilustrações}

Figura 1.1: Faixas de meias vidas de utilização de diversas técnicas de medidas de meias vidas, incluindo o SIStema de Medidas de Estados Isoméricos (SISMEI), abordado no subitem 1.2............................................ 12 Figura 1.2: Espectro de raios $y$ utilizado para a medida da meia vida do estado $2^{+}(E=1494,8(8) k e V$, $\left.T_{1 / 2}=0,9(2) p s\right)$ do ${ }^{54}$ Ti através do método por excitação coulombiana (DINCA, 2005). 14 Figura 1.3: Formas de linha dos picos de raios $y$ de $662 \mathrm{keV} \mathrm{do}{ }^{50} \mathrm{Cr}$, obtido com detector posicionado a 34ㅇ e 146․ O ajuste da forma de Linha permite extrair o valor da vida média do estado. Nota-se que para o ângulo de

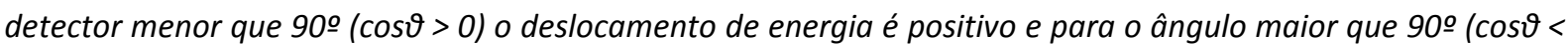
0) o deslocamento de energia é negativo (BRANDOLINI, 1998).

Figura 1.4: Princípio de funcionamento da técnica de medida de vidas médias utilizando um Plunger. Observa-se um exemplo de montagem experimental em (a) e o espectro de raios $y$ em (b) (MORINAGA, 1976).

Figura 1.5: Exemplo de espectros de tempo obtidos através da técnica de medida de vidas médias utilizando feixe pulsado para o estudo do ${ }^{136}$ Pr. O ajuste do decaimento exponencial desses dados permite a medida da meia vida do estado isomérico (BAZZACCO, 1993).

Figura 1.6: Perfil típico de um feixe pulsado, cujas principais características são: a largura do pulso de feixe e a diferença em tempo, período, entre dois pulsos consecutivos...................................................................... 19 Figura 1.7: Espectrômetro de raios y SACI-PERERE montado na canalização 30a do acelerador Pelletron.......... 21 Figura 1.8: Sistema de Medidas de Estados Isoméricos (SISMEI) à direita e diagrama esquemático do SISMEI, à esquerda.

Figura 2.1: SISMEI visto por cima. Pode se observar: uma peça cônica (1), cuja extremidade menor fica acoplada ao SACl, um detector cintilador de raios $\gamma$ de $\mathrm{Nal}(\mathrm{TI})$ (2), um detector semicondutor de raios $\gamma$ de GeHP com supressor Compton (3), duas peças de chumbo com $5 \mathrm{~cm}$ e $7 \mathrm{~cm}$ de espessura que blindam os detectores de GeHP e NaI(TI), respectivamente (4) e (5) e o Sistema Ancilar de Cintiladores (SACI) (6). O alvo é posicionado no centro do SACI.

Figura 2.2: Curva de absorção do chumbo em função da energia do fóton. (HUBBELL, 2004).............................25

Figura 2.3: Parador de feixe do SISMEI montado em sua flange. Observa-se que o parador é composto por um disco de chumbo colado em um disco maior de alumínio. ...............................................................................2 27

Figura 2.4: Corte horizontal, em escala, do cone de alumínio do SISMEI acoplado ao SACI. ..............................2 27

Figura 2.5: Diagrama em blocos funcionais da eletrônica modular do SISMEI. ................................................. 30

Figura 2.6: Exemplo de circuito de energia de um dos detectores de raios $\gamma$. O detector é representado como um

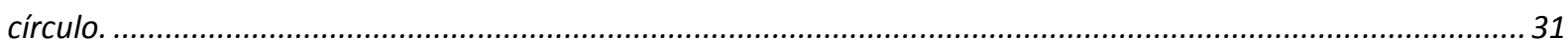

Figura 2.7: Exemplo de circuito de tempo de um dos detectores de raios $\gamma$........................................................32

Figura 2.8: Circuitos de Supressão Compton dos detectores de raios $\gamma$ de GeHP............................................. 33

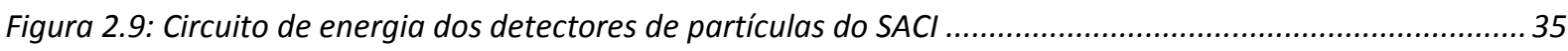

Figura 2.10: Circuito de tempo dos detectores de partículas do SACI ............................................................37

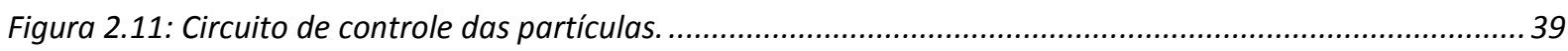

Figura 2.12: Circuito de coincidência atrasada $\gamma$-partícula ............................................................................ 41

Figura 2.13: Diagrama dos pulsos lógicos de entrada (raio re partícula) e saída do módulo AND 2 (coincidência $\gamma$-partícula) para a condição em que raio $\gamma$ e partícula são detectados simultaneamente................................. 42

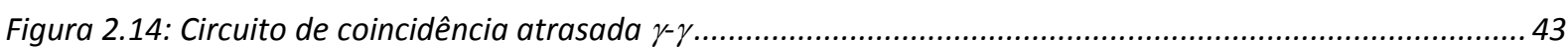

Figura 2.15: Circuito de medida de tempo de decaimento.............................................................................44

Figura 2.16: Sinais de START e STOP dos módulos TAC para a condição em que a partícula, por exemplo, foi

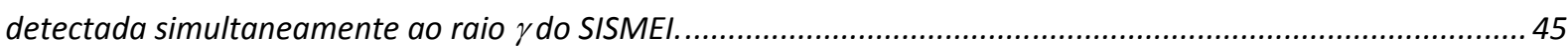

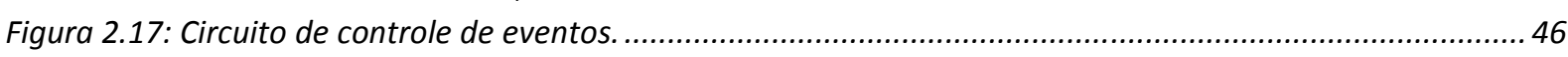

Figura 2.18: Diagrama completo da eletrônica modular do SISMEI. ..............................................................48

Figura 3.1: Seções de choque previstas para a experiência ${ }^{11} B+{ }^{46} T i$, utilizada para testar o SISMEI. A energia utilizada na experiência está marcada com uma barra vertical. 
Figura 3.2: Esquema de níveis conhecido do ${ }^{54} \mathrm{Fe}$ (RUDOLPH, 1999), o estado isomérico $10^{+}\left(E_{L}=6526 \mathrm{keV}\right.$, $T_{1 / 2}=364(7)$ ns) se encontra destacado à direita.

Figura 3.3: Diagrama em blocos funcionais da eletrônica modular utilizada na primeira experiência de teste do SISMEI..

Figura 3.4: Curvas de calibração em energia (a) utilizando as principais transições do ${ }^{54} \mathrm{Fe}\left(E_{V}=146,2(2) \mathrm{keV}\right.$, $411,4(5) \mathrm{keV}, 1129,9(3) \mathrm{keV}, 1408,1(2) \mathrm{keV}$ e 3432,0(18) keV) e em tempo (b) utilizando um módulo GG calibrado com um osciloscópio para vários atrasos distintos.

Figura 3.5: Histograma referente a diferença em tempo entre a coleta da partícula carregada nos detectores do $\mathrm{SACl}$ e o instante de chegada do raio y no detector de GeHP (a). E espectro de raios y adquirido pelo detector de GeHP (b). O picos marcados com um ponto indicam transições pertencentes ao ${ }^{54} \mathrm{Fe}$ que depopulam o estado isomérico $10^{+}$, vide Figura 3.2.

Figura 3.6:Matriz $\gamma$-tempo do detector de GeHP obtida em coinidência $\gamma$ - $\gamma$ com o detector de Nal(TI). Nesta matriz os raios gama que depopulam os estados abaixo do estado isomérico $10^{+}$, vide Figura 3.2, podem ser facilmente identificados como linhas verticais.

Figura 3.7: Espectros de raios $\gamma$ do detector GeHP em coincidência $\gamma$-p atrasada, delay, (a) e em coincidência $\gamma$-p instantânea, prompt, (b). Nota-se que as transições abaixo do estado isomérico $10^{+}$são observadas apenas no espectro delay, mostrando assim que o sistema é capaz de identificar transições ligadas a estados isoméricos. Os picos identificados no espectro delay foram numerados e estão descritos na Tabela 3.1..............................5 56 Figura 3.8: Espectro de tempo em coincidência com as transições do ${ }^{54} \mathrm{Fe}$ com energias de 146, 411, 1130, 1408 e $3434 \mathrm{keV}$. As linhas tracejadas representam a região escolhida para estimar o fundo estatístico enquanto as linhas pontilhadas representam a região escolhida para a medida da meia vida.

Figura 3.9: Ajuste exponencial para a determinação da meia vida do estado isomérico $10^{+}$do núcleo ${ }^{54} \mathrm{Fe} . . . . .59$ Figura 3.10: Figura esquemática do SISMEI completo, com um detector de raios y de GeHP posicionado no SACI, além dos dois detectores de raios y posicionando no fim do cone do SISMEI.

Figura 3.11: Espectro de raios $\gamma$ em coincidência $\gamma$-p atrasada, delay. Neste espectro pode ser observadas todas as transições abaixo do estado isomérico $10^{+}$do ${ }^{54} \mathrm{Fe}$...

Figura 3.12: Espectro de tempo em coincidência com as transições de $146 \mathrm{keV}, 411 \mathrm{keV}, 1130 \mathrm{keV}, 1408 \mathrm{keV} \mathrm{e}$ $3431 \mathrm{keV} \mathrm{do}{ }^{54} \mathrm{Fe}$.

Figura 3.13: Espectro de tempo em coincidência com a transição de $197 \mathrm{keV}$ proveniente do estado 5/2 $\left(T_{1 / 2}=89,3(10) n s\right)$ do ${ }^{19} \mathrm{~F}$.

Figura 3.14: Espectro de tempo em coincidência com a transição de $351 \mathrm{keV} \mathrm{do}{ }^{21} \mathrm{Ne}$. Esta transição apresenta meia vida longa, já que $o^{21} \mathrm{Ne}$ é produzido por processos de decaimento $\mathrm{B}^{-}$, que possuem meia vida da ordem de segundos.

Figura 3.15: Espectro do detector de raios $\gamma$ de GeHP posicionado no SACl em coincidência $\gamma-\gamma$ atrasada com as transições: 146, 411, 1130, 1408 e $3431 \mathrm{keV}$, provenientes do estado isomérico $10^{+}$do ${ }^{54} \mathrm{Fe}$. Neste espectro é possivel identificar, três transições que populam o estado isomérico $10^{+}$(vide Figura 3.2).

Figura 4.1: Energia do primeiro estado excitado normalizada por $A^{1 / 3}$ para os núcleos conhecidos com meia vida maior que $10^{15} \mathrm{~s}$ em função do número de prótons $(\mathrm{Z})$ e do número de nêutrons $(\mathrm{N})$. Os núcleos com números mágicos de núcleons apresentam os valores mais altos, isso indica que a configuração interna destes núcleos é muito estável.

Figura 4.2: níveis de energia de partícula única para o oscilador harmônico esférico (S.H.O.), oscilador harmônico esférico modificado com um termo de momento angular $\left(I^{2}\right)$ e oscilador harmônico esférico modificado com um termo de momento angular, acrescido de tempo de interação spin órbita(l.s), retirado de CASTEN (2005)...

Figura 4.3: Níveis de energia de partícula única para o oscilador harmônico esférico, Woods-Saxon e WoodsSaxon acrescido de tempo de interação spin órbita(I.s), retirado de BRUSSAARD (1977).

Figura 4.4: Comparação entre as energias previstas pelo LSSM com 2, 4, 6 e 8 partículas livres na camada pf e as energias experimentais dos primeiros estados excitados pertencentes a mesma banda do estado isomérico $10^{+}$do ${ }^{54} \mathrm{Fe}$. Observa-se que a medida que se aumenta o número de partículas livres as previsões teóricas se aproximam do resultado experimental. 
Figura 4.5: Comparação entre os valores de B(E2) do estado isomérico $10^{+}$do ${ }^{54} \mathrm{Fe}$, experimental e os teóricos previstos através do LSSM. São apresentados os valores calculados em função do número de partículas livres na camada pf.

Figura A. 1. Circuito Elétrico para base ativa com 3 estágios ativos. 83

Figura A. 2. Layout do circuito impresso utilizado para a construção da base ativa (à esquerda) e posição dos componentes no layout (à direita). Os pontos marcados com " $n c$ " não devem ser conectados ao soquete que liga a base com a fotomultiplicadora.

Figura A. 3: Espectros da perda de energia das partículas carregas no detector plástico $\Delta E$ posicionado no ângulo de 0 o do SACI para 3 correntes de feixe diferentes. Observa-se que o ganho da base passiva, à esquerda, muda consideravelmente com a variação de corrente enquanto o novo modelo de base ativa, à direita, mantém o ganho constante para correntes de feixe de até $35 n A$. 85

Figura B. 1: Circuito do novo módulo de BUSY. .87 


\section{Sumário}

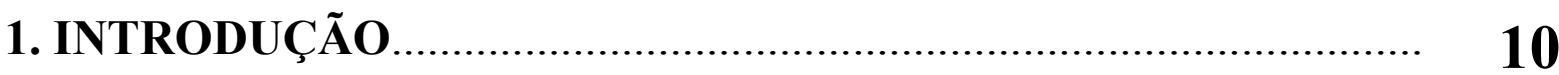

1.1 TÉCNICAS DE MEDIDAS DE VIDAS MÉDIAS...........................................

1.1.1 Método por Excitação Coulombiana............................................................. 12

1.1.2 Método por distância de Recuo (Recoil Distance Method-RDM)................. 14

1.1.2.1 Método através da Atenuação por Efeito Doppler (Doppler Shift Attenuation Method - DSAM) ..................................................................................................... 15

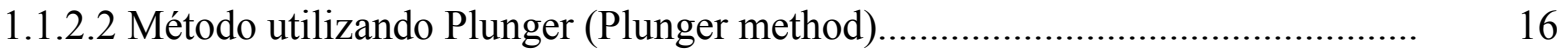

1.1.3 Método utilizando Feixe Pulsado (Pulsed Beam Method) .............................. 18

1.1.4 Métodos através da medida da atividade de uma amostra......................... 19

1.2 SISTEMA PARA MEDIDAS DE ESTADOS NUCLEARES ISOMÉRICOS

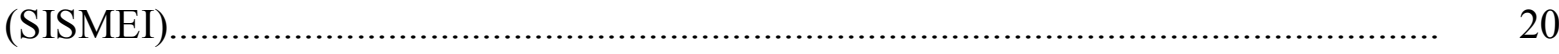

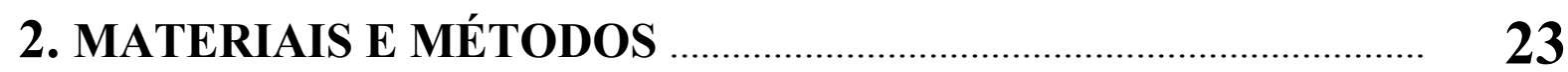

2.1 ASPECTOS MECÂNICOS DO SISMEI......................................................... 23

2.2 A ELETRÔNICA MODULAR DO SISMEI......................................................... 28

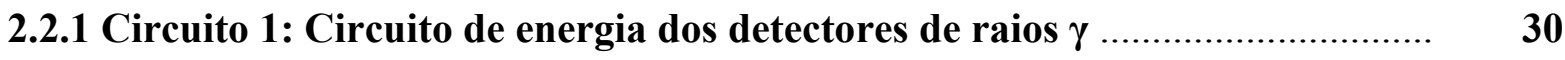

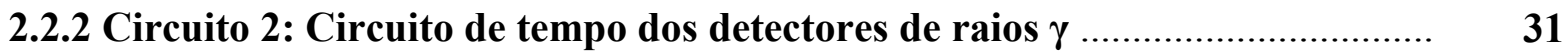

2.2.3 Circuito 3: Circuito de Supressão Compton........................................... 32

2.2.4 Circuito 4: Circuito de energia $(\Delta E-E)$ dos detectores de partículas

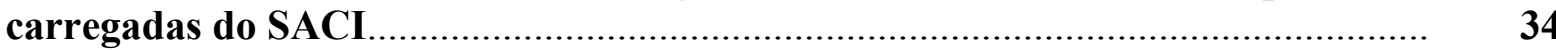

2.2.5 Circuito 5: Circuito de tempo dos detectores de partículas do SACI............ 36

2.2.6 Circuito 6: Circuito de controle do SACI....................................................... 39

2.2.7 Circuito 7: Circuito de coincidência atrasada $\gamma$-partícula................................. 41

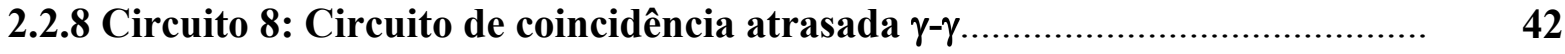

2.2.9 Circuito 9: Circuito de medida de tempo de decaimento............................... 43

2.2.10 Circuito 10: Circuito de controle de eventos................................................ 46

2.2.11 Eletrônica modular completa do SISMEI................................................... 47

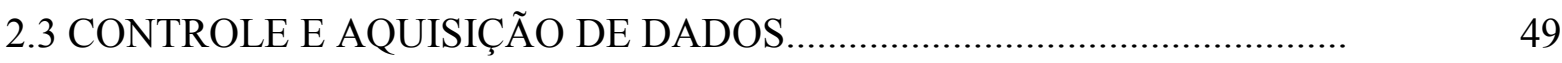


3. EXPERIÊNCIAS REALIZADAS E RESULTADOS OBTIDOS.... 50

3.1 A REAÇÃO DE FUSÃO-EVAPORAÇÃO ${ }^{46} \mathrm{Ti}\left({ }^{11} \mathrm{~B}, 1 \mathrm{p} 2 \mathrm{n}\right){ }^{54} \mathrm{Fe}, \mathrm{E}_{\mathrm{F}}=30 \mathrm{MeV} \ldots \ldots . . \quad 50$

3.1.1 Redução e Análise dos Dados.......................................................................... 52

3.1.2 Discussão dos resultados..............................................................................

3.2 A REAÇÃO DE FUSÃO-EVAPORAÇÃO ${ }^{46} \mathrm{Ti}\left({ }^{11} \mathrm{~B}, 1 \mathrm{p} 2 \mathrm{n}\right)^{54} \mathrm{Fe}, \mathrm{E}_{\mathrm{F}}=33 \mathrm{MeV} \ldots \ldots . . \quad 60$

3.2.1 Redução e Análise dos Dados.............................................................................

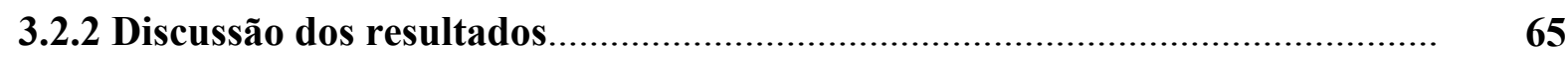

4. INTERPRETAÇÃO TEÓRICA DO ${ }^{54}$ Fe ATRAVÉS DO LSSM... 67

4.1 O MODELO DE CAMADAS DE LARGA ESCALA (LSSM)............................ 67

4.2 INTERPRETAÇÃO DO ESTADO $10^{+}$DO ${ }^{54} \mathrm{Fe}$ ATRAVÉS DO LSSM.............. 71

5. CONCLUSÕES E PERSPECTIVAS................................................. 76

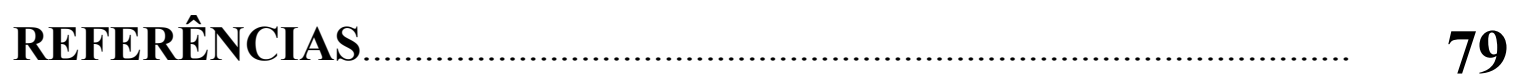

APÊNDICE A: Bases ativas para as fotomultiplicadoras dos

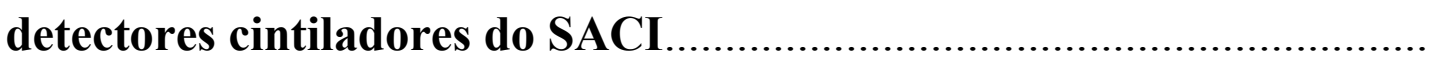

APÊNDICE B: Módulo CAMAC de BUSY comandado via arquivo de aquisição. 


\section{INTRODUÇÃO}

A estrutura dos núcleos, assim como a dos átomos, pode ser entendida a partir do estudo dos seus estados quânticos internos e suas interconexões. Conhecer os estados quânticos internos implica em determinar suas funções de onda, porém estas não podem ser medidas diretamente. Assim, devem-se estudar as propriedades de cada estado nuclear: energia, spin, paridade, vida média, probabilidades de transição reduzidas elétricas $(B(E \lambda))$ e magnéticas $(B(M \lambda))$, entre outras e a partir delas inferir informações a respeito da função de onda. Neste sentido, a espectroscopia de raios $\gamma$ destaca-se dentro da Física Nuclear como ciência experimental responsável por obter informações que levem ao entendimento da estrutura interna dos núcleos.

Dentre as propriedades dos estados nucleares, a vida média tem especial importância, pois é a partir dela que se pode determinar as probabilidades de transição reduzidas elétricas $(\mathrm{B}(\mathrm{E} \lambda))$ e magnéticas $(\mathrm{B}(\mathrm{M} \lambda))$. Tais probabilidades dependem fortemente da função de onda e por isso representam um teste robusto para modelos nucleares, visto que certos modelos podem prever bem as energias dos estados, porém não são capazes de determinar as funções de onda com precisão. Além disso, o conhecimento da vida média de um estado é ponto de partida para medidas de outras propriedades como o fator giromagnético (fator g) que pode ser utilizado para identificar a configuração de um determinado estado nuclear, como visto em IONESCU-BUJOR (2000).

Quando um estado nuclear é instável e decai através de uma transição eletromagnética com vida média muito longa, este estado é denominado isomérico (BOWLER, 1973). Ainda, segundo COHEN (1971), o termo isomérico é geralmente aplicado para estados com meias 
vidas da ordem de $10 \mathrm{~ns}$ ou mais. A meia vida de um estado nuclear $\left(\mathrm{T}_{1 / 2}\right)$ se relaciona com a vida média $(\tau)$ através da relação $\tau=\mathrm{T}_{1 / 2} * \ln (2)$.

Estados isoméricos geralmente ocorrem quando estes apenas decaem através de transições em que a variação de momento angular é maior ou igual a $3(\Delta 1 \geq 3)$, no entanto existem diversos casos de estados isoméricos que decaem através de transições com $\Delta 1 \leq 2$ mas cuja energia do raio $\gamma$ é pequena. TANIGAKI (1999), por exemplo, determinou a meia vida do primeiro estado excitado do ${ }^{64} \mathrm{Ga}$ em 21,9(7) $\mu$ s. Este estado isomérico decai através de uma transição E2 $(\Delta \mathrm{l}=2)$ cuja energia do raio $\gamma$ vale apenas: $\mathrm{E}_{\gamma}=42,89(10) \mathrm{keV}$ (SINGH, 2007).

\subsection{TÉCNICAS DE MEDIDAS DE VIDAS MÉDIAS}

As técnicas utilizadas para a determinação da vida média de estados nucleares variam de acordo com a ordem de grandeza da vida média que se deseja estudar, sendo que algumas das técnicas mais utilizadas são: Técnicas de distância de recuo (Recoil Distance Method RDM), que abrangem as técnicas de medida através da Atenuação por Efeito Doppler (Doppler Shift Attenuation Method - DSAM) e as técnicas utilizando Plunger (Plunger method), técnicas que utilizam um Feixe Pulsado (Pulsed Beam Method) e as técnicas por medida de atividade da amostra. Neste trabalho optou-se por considerar a técnica de DSAM como parte integrante das técnicas de RDM, no entanto vale ressaltar que em muitos casos a denominação de RDM é aplicada exclusivamente para as técnicas que utilizam o equipamento Plunger. A Figura 1.1 mostra as faixas de meias vidas de utilização destas técnicas, incluindo o SIStema de Medidas de Estados Isoméricos (SISMEI), abordado no subitem 1.2. 


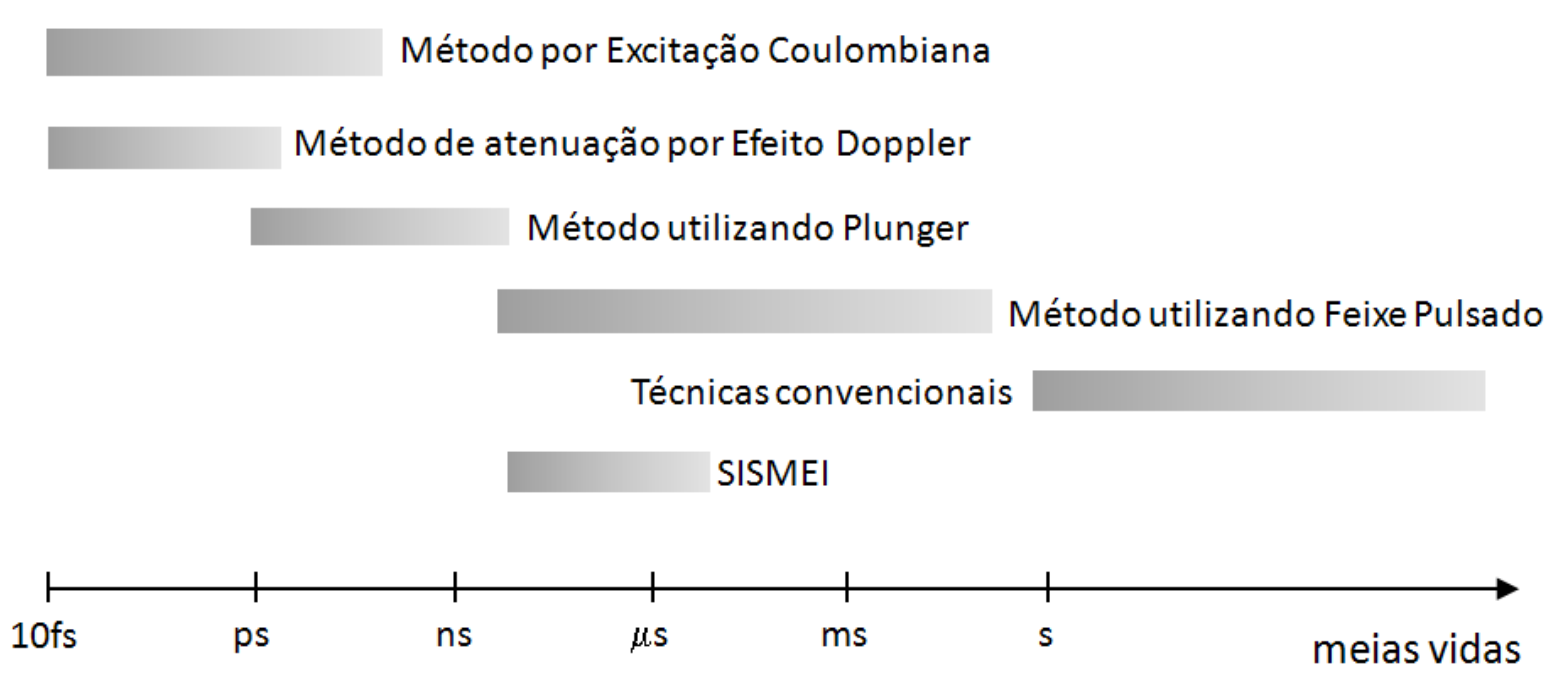

Figura 1.1: Faixas de meias vidas de utilização de diversas técnicas de medidas de meias vidas, incluindo o SIStema de Medidas de Estados Isoméricos (SISMEI), abordado no subitem 1.2.

\subsubsection{Método por Excitação Coulombiana}

No método por excitação coulombina, as probabilidades de transição eletromagnéticas são obtidas diretamente da medida da seção de choque de excitação coulombiana do núcleo. Para isso utiliza-se uma reação cuja energia do feixe incidente está abaixo da barreira coulombiana. Isto diminui muito as chances de penetração do núcleo feixe no núcleo alvo, o que elimina as interferências de interações nucleares mais complexas (ALDER, 1956).

Uma vez medida a probabilidade de transição reduzida e a energia do raio $\gamma$, a meia vida do estado pode ser facilmente calculada, como visto em WONG (1998). Este método é apropriado para a medida de vidas médias na faixa de 0,01 ps até 100 ps (KONDEV, 2008).

A seção de choque de excitação coulombiana experimental pode ser obtida através da Equação 1.1.

$$
\sigma=\frac{\mathrm{N}_{\gamma}}{\varepsilon} \frac{1}{N_{\text {alvo }} N_{\text {feixe }}}
$$


Onde: $\sigma$ é a seção de choque de excitação coulombiana experimental, $\mathrm{N}_{\gamma}$ é o número de raios $\gamma$ detectados, $\mathrm{N}_{\text {alvo }}$ é o número de átomos no alvo, $\mathrm{N}_{\text {feixe }}$ é o número de íons do feixe e $\varepsilon$ é a eficiência de detecção do raio $\gamma$.

Por outro lado, a seção de choque prevista teoricamente depende da probabilidade de transição reduzida, permitindo assim sua determinação a partir da medida da seção de choque de excitação coulombiana. A relação aproximada entre a seção de choque de excitação coulombiana relativística e a probabilidade de transição reduzida para uma transição quadrupolar elétrica é dada pela Equação 1.2 (WINTHER, 1979).

$$
\sigma_{0^{+} \rightarrow 2^{+}} \approx\left(\frac{Z_{a l v o} e^{2}}{\hbar c}\right)^{2} \frac{\pi}{e^{2} b_{\min }^{2}} B\left(E, 0^{+} \rightarrow 2^{+}\right)
$$

Onde: $\sigma_{0^{+} \rightarrow 2^{+}}$é a seção de choque de excitação coulombiana de um estado $0^{+}$para um estado $2^{+}, \mathrm{Z}_{\mathrm{alvo}}$ é o número atômico do alvo, $\mathrm{b}_{\min }$ é o parâmetro de impacto mínimo para o qual a interação nuclear é desprezível e $B\left(E, 0^{+} \rightarrow 2^{+}\right)$é a probabilidade de transição reduzida para uma transição quadrupolar elétrica de um estado $0^{+}$para um estado $2^{+}$.

Esta técnica foi utilizada recentemente por DINCA (2005) para a medida da meia vida do estado $2^{+}\left(\mathrm{E}=1494,8(8) \mathrm{keV}, \mathrm{T}_{1 / 2}=0,9(2) \mathrm{ps}\right)$ do ${ }^{54} \mathrm{Ti}$. A Figura 1.2 mostra o espectro utilizado para esta medida. Neste espectro está evidenciado o pico correspondente ao raio $\gamma$ de $1495 \mathrm{keV}$ cujo número de contagens indica o número de raios $\gamma$ detectados $\left(\mathrm{N}_{\gamma}\right)$. 


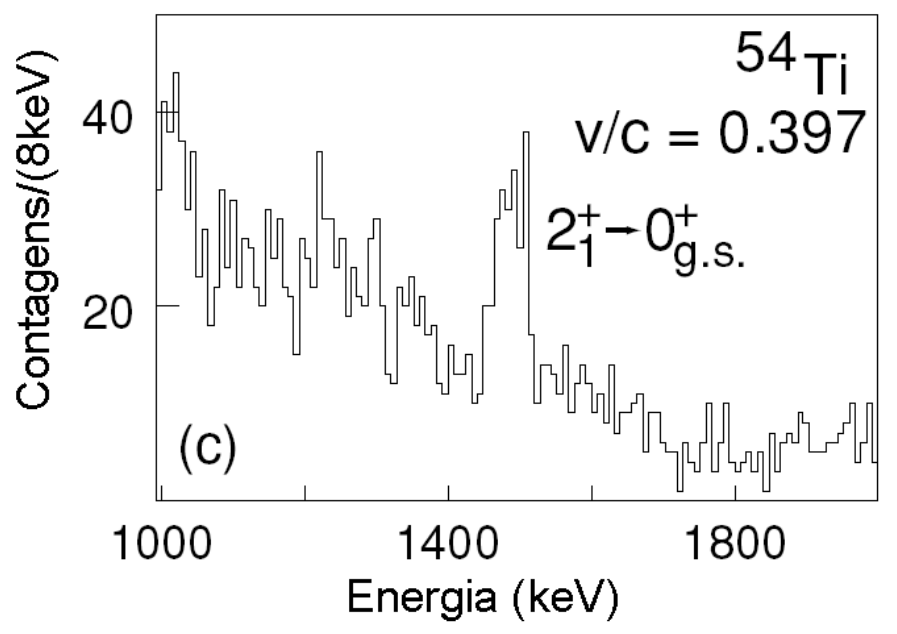

Figura 1.2: Espectro de raios $\gamma$ utilizado para a medida da meia vida do estado $2^{+}(\mathrm{E}=1494,8(8) \mathrm{keV}$, $\mathrm{T}_{1 / 2}=0,9(2) \mathrm{ps}$ ) do ${ }^{54} \mathrm{Ti}$ através do método por excitação coulombiana (DINCA, 2005).

\subsubsection{Método por distância de Recuo (Recoil Distance Method - RDM)}

As técnicas que utilizam distância de recuo caracterizam-se por utilizar o tempo de vôo do núcleo residual para determinar a vida média de seus estados excitados. Desde que o estado nuclear de interesse possua uma vida média da ordem de grandeza do tempo de vôo do núcleo residual, a probabilidade de que este núcleo decaia em vôo deve ser considerada.

Vejamos uma primeira hipótese: se fosse colocado um detector bem colimado e posicionado a um ângulo de $90^{\circ}$, em relação à direção do feixe, a intensidade medida em função da distância entre o alvo e o feixe, pelo detector seria dada pela Equação 1.3 (MORINAGA, 1976):

$$
\mathrm{I}_{\mathrm{d}}=\mathrm{I}_{\mathrm{o}} \mathrm{e}^{-\mathrm{d} /\left(\mathrm{v}^{*} \tau\right)}
$$

Onde: $\mathrm{I}_{\mathrm{d}}$ é a intensidade medida a uma distância d do alvo, $\mathrm{I}_{\mathrm{o}}$ é a intensidade medida no alvo, v é velocidade do núcleo residual e $\tau$ é vida média do estado nuclear.

A princípio seria possível determinar a vida média a partir da medida das intensidades $I_{d}$ e $I_{0}$. No entanto, o número de contagens dos picos de raios $\gamma$ seria muito pequeno para um 
detector bem colimado e muito impreciso para um detector com ângulo sólido maior, inviabilizando assim uma medida direta da vida média do estado nuclear.

Formas indiretas de se medir as intensidades $I_{d}$ e $I_{0}$ utilizam-se do fato de que a energia detectada de um raio $\gamma$, emitido em vôo, sofre um deslocamento Doppler que depende do ângulo entre a direção da velocidade de recuo do núcleo e a direção de detecção e da velocidade do núcleo residual. Em primeira aproximação, a energia detectada do raio $\gamma$ é dada pela Equação 1.4:

$$
\mathrm{E}_{\gamma} \cong \mathrm{E}_{\mathrm{o}}(1+\beta \cos \theta)
$$

Onde: $\mathrm{E}_{\gamma}$ é a energia do raio $\gamma$ detectada, $\mathrm{E}_{\mathrm{o}}$ é a energia do raio $\gamma$ no referencial do núcleo residual, $\beta$ é a razão entre a velocidade do núcleo residual e a velocidade da luz ( $\beta=\mathrm{v} / \mathrm{c})$ e $\theta$ é o ângulo de detecção.

1.1.2.1 Método através da Atenuação por Efeito Doppler (Doppler Shift Attenuation Method - DSAM)

O Método de medida de vidas médias de estados nucleares através da Atenuação por Efeito Doppler é aplicado para medidas de vidas médias na faixa de 10 fs à 1 ps. Neste método, utiliza-se um alvo com material freador, em geral chumbo ou ouro, de modo que o núcleo residual desacelere e atinja o repouso neste material freador. Com isso, se a vida média do estado nuclear for da ordem de grandeza do tempo de freamento do núcleo residual no alvo, o pico de energia do raio $\gamma$ detectado apresentará, dependendo da energia do raio $\gamma$ e do ângulo de observação, uma forma de linha similar às apresentadas na Figura 1.3. Neste espectro de raios $\gamma$ pode ser vista a contribuição dos raios $\gamma$ emitidos pelo núcleo residual em repouso (picos em $662 \mathrm{keV}$ ) e a contribuição dos raios $\gamma$ emitidos pelos núcleos freando no alvo (formas de linha à direita ou à esquerda do pico). $\mathrm{O}$ detector posicionado em $\theta=34^{\circ}$ 
observa raios $\gamma$ com energias maiores, pois $\cos 34^{\circ}>0$, já o detector posicionado em $\theta=146^{\circ}$ observa raios $\gamma$ com energias menores, pois $\cos 146^{\circ}<0$ (vide Equação 1.4).

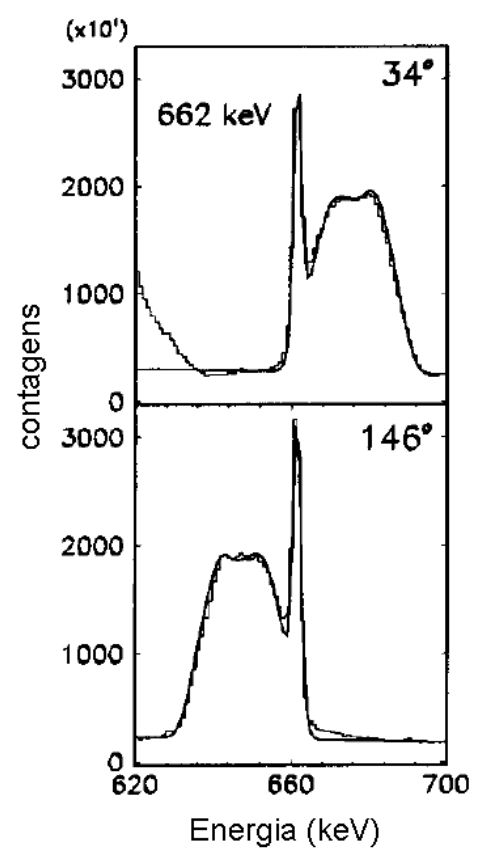

Figura 1.3: Formas de linha dos picos de raios $\gamma$ de $662 \mathrm{keV} \mathrm{do}{ }^{50} \mathrm{Cr}$, obtido com detector posicionado a $34^{\circ} \mathrm{e}$ $146^{\circ}$. O ajuste da forma de Linha permite extrair o valor da vida média do estado. Nota-se que para o ângulo de detector menor que $90^{\circ}(\cos \theta>0)$ o deslocamento de energia é positivo e para o ângulo maior que $90^{\circ}(\cos \theta<0)$ o deslocamento de energia é negativo (BRANDOLINI, 1998).

As formas de linha vistas na Figura 1.3 se alteram de acordo com a vida média do estado nuclear e do ângulo de observação. Para estados com vidas médias curtas o pico de energia detectado estará quase todo deslocado, já que o estado decai quase sempre quando o núcleo residual está com, praticamente, toda a sua velocidade inicial. Por outro lado, para estados muito lentos, o pico praticamente não apresenta deslocamento, pois quase sempre o estado excitado decai quando o núcleo residual está com velocidades próximas à zero. Assim, é possível inferir o valor da vida média através da análise da forma de linha do pico de raios $\gamma$ (SILVEIRA, 2004).

\subsubsection{Método utilizando Plunger (Plunger method)}

A técnica utilizando o equipamento chamado Plunger é apropriada para vidas médias entre 10 ps e 10 ns . Esta técnica consiste em posicionar um freador (Plunger) a uma distância 
d do alvo para parar o núcleo residual. Um detector de raios $\gamma$ é posicionado em ângulos dianteiros de modo a medir os raios $\gamma$ tanto dos núcleos que decaírem em vôo tanto dos núcleos que decaírem depois de atingir o freador. Assim, o espectro de raios $\gamma$ do detector apresentará dois picos, um deles com energia $\mathrm{E}_{\gamma}$ (raios $\gamma$ emitidos em vôo) e o outro com energia $E_{o}$ (raios $\gamma$ emitidos após serem freados). A relação entre as intensidades do pico deslocado $\left(I_{s}\right)$, composto por raios $\gamma$ emitidos com o núcleo em vôo, e não deslocado $\left(I_{u}\right)$, composto por raios $\gamma$ emitidos com o núcleo parado, depende diretamente da vida média $(\tau)$ do estado nuclear (MORINAGA, 1976). Esta relação é vista na Equação 1.5:

$$
\mathrm{F}(\mathrm{d})=\frac{\mathrm{I}_{\mathrm{u}}}{\mathrm{I}_{\mathrm{u}}+\mathrm{I}_{\mathrm{s}}}=\mathrm{e}^{-\mathrm{d} /\left(\mathrm{v}^{*} \tau\right)}
$$

Onde: $I_{u}$ é a intensidade medida dos raios $\gamma$ emitidos após o núcleo residual parar no plunger, $\mathrm{I}_{\mathrm{s}}$ é a intensidade medida dos raios $\gamma$ emitidos em vôo, v é velocidade do núcleo residual, d é a distância entre o alvo e o plunger e $\tau$ é vida média do estado nuclear.

Variando a distância entre o alvo e o freador é possível ajustar a função $F(d)$ e determinar $\tau$. A Figura 1.4 ilustra a técnica que utiliza um plunger.

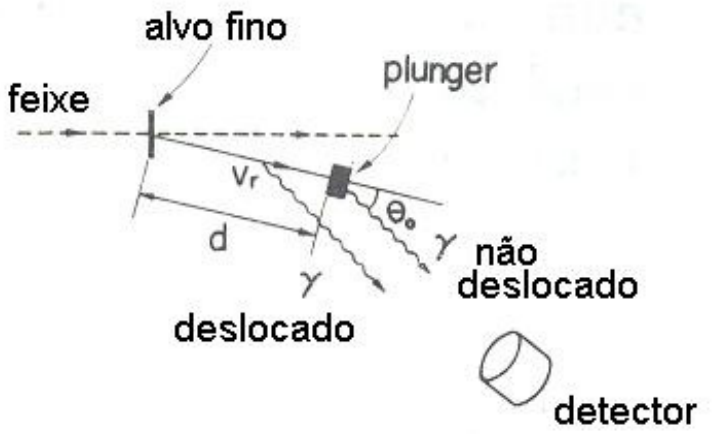

(a)

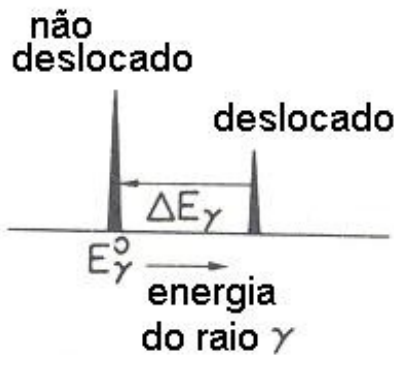

(b)

Figura 1.4: Princípio de funcionamento da técnica de medida de vidas médias utilizando um Plunger. Observa-se um exemplo de montagem experimental em (a) e o espectro de raios $\gamma$ em (b) (MORINAGA, 1976). 


\subsubsection{Método utilizando Feixe Pulsado (Pulsed Beam Method)}

A técnica utilizando feixe de partículas pulsado (Pulsed Beam Method) permite medidas de vidas médias na faixa de $10 \mathrm{~ns}$ até $100 \mathrm{~ms}$, dependendo das características do feixe pulsado disponível. Esta técnica consiste em utilizar um pulso de feixe para produzir núcleos residuais excitados através de uma reação nuclear e em seguida interromper o feixe por um tempo de 5 a 10 vezes maior que a vida média que se deseja medir. O tempo de cada decaimento é medido eletronicamente, sendo o pulso de feixe o início da contagem de tempo e o raio $\gamma$ emitido no intervalo entre dois pulsos consecutivos o fim da contagem de tempo. A cada pulso de feixe um decaimento pode ser medido, de modo que a vida média pode ser extraída diretamente do espectro de tempo resultante. Um exemplo de espectro de tempo obtido com essa técnica pode ser visto na Figura 1.5.

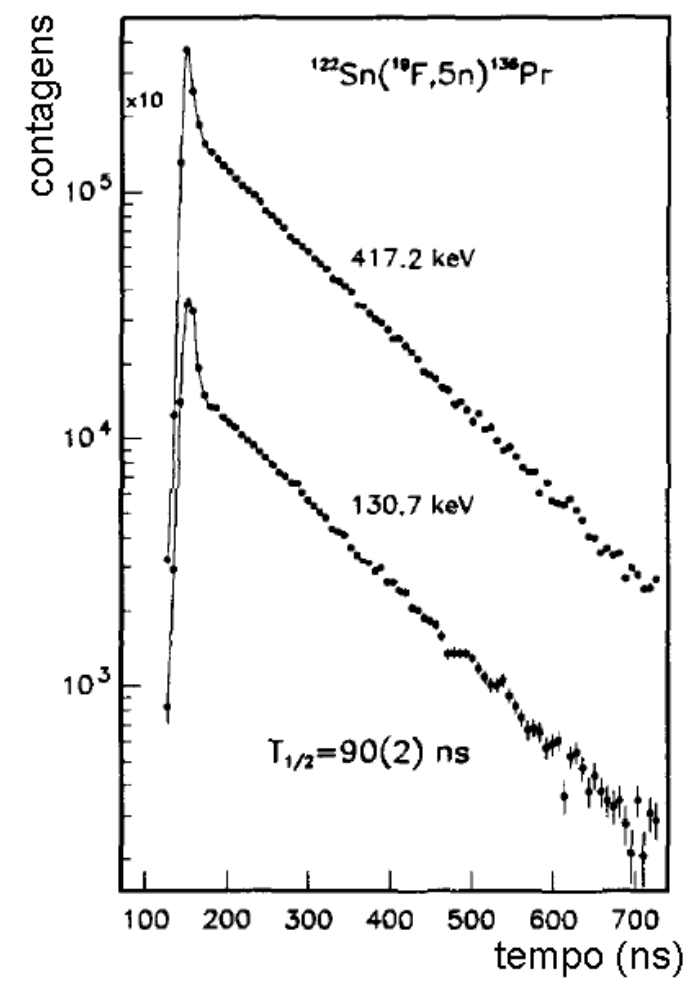

Figura 1.5: Exemplo de espectros de tempo obtidos através da técnica de medida de vidas médias utilizando feixe pulsado para o estudo do ${ }^{136} \mathrm{Pr}$. O ajuste do decaimento exponencial desses dados permite a medida da meia vida do estado isomérico (BAZZACCO, 1993). 
Esta técnica pode cobrir uma grande faixa de valores de vidas médias, pois as características do feixe pulsado podem ser ajustadas de forma a otimizar o experimento para determinados valores de vidas médias. O valor máximo que pode ser medido depende da diferença em tempo entre dois pulsos de feixe consecutivos, ou seja, depende da freqüência do feixe. Assim para medidas de vidas médias longas usa-se freqüências baixas e para medidas de vidas médias curtas usam-se freqüências altas de feixe. Por outro lado, o valor de vida média mínimo que pode ser medido depende de dois fatores: da resolução, ou largura, do pulso de feixe e do tempo de resposta da eletrônica de aquisição, pois esta precisa ser capaz de medir diferenças em tempo pequenas. A resolução temporal dos pulsos de feixe é de tipicamente 1 ns. A Figura 1.6 ilustra um perfil de feixe pulsado.

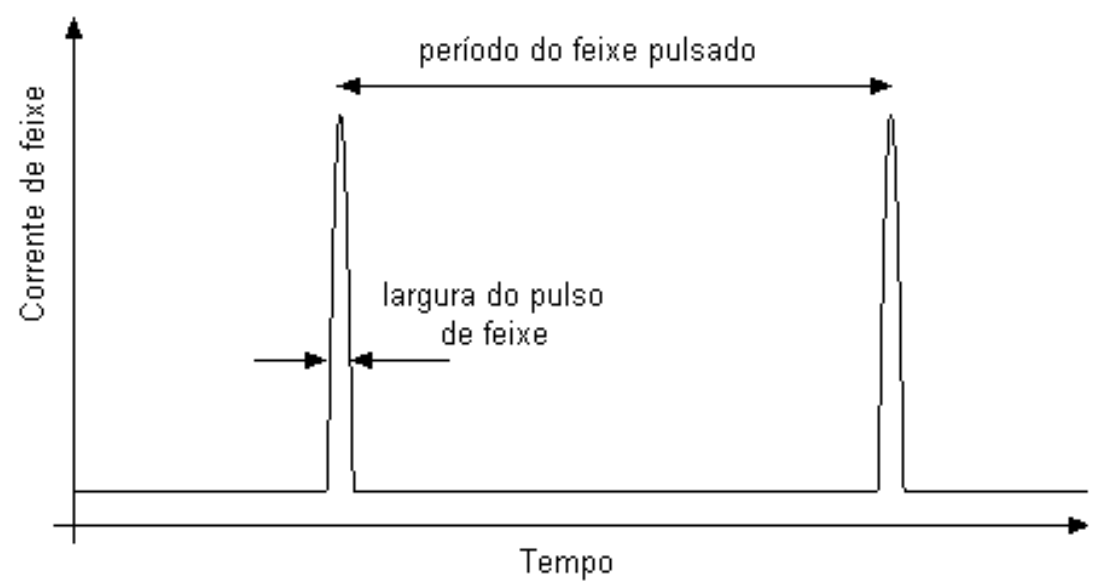

Figura 1.6: Perfil típico de um feixe pulsado, cujas principais características são: a largura do pulso de feixe e a diferença em tempo, período, entre dois pulsos consecutivos.

\subsubsection{Método através da medida da atividade de uma amostra.}

Para a medida de meias vidas na faixa de alguns segundos até anos, pode-se utilizar técnicas da medida da atividade de uma amostra. Nesta técnica, os núcleos residuais são produzidos, por exemplo através de um feixe de íons ou através de reações com nêutrons, durante certo intervalo de tempo. Após a irradiação, a atividade desta amostra é medida em intervalos regulares de tempo. Com isso, é possível construir um gráfico da intensidade dos 
raios $\gamma$ em função do tempo. A vida média do estado excitado pode ser então determinada diretamente do ajuste da curva de decaimento exponencial.

\subsection{SISTEMA PARA MEDIDAS DE ESTADOS NUCLEARES ISOMÉRICOS (SISMEI)}

Este trabalho apresenta uma técnica alternativa para a medida de vidas médias de estados nucleares na faixa de $10 \mathrm{~ns}$ a $10 \mu \mathrm{s}$, sem a utilização de feixe pulsado. Este técnica baseia-se principalmente na coincidência atrasada entre partículas carregadas (prótons e alfas) evaporadas pelo núcleo composto, formado na reação de fusão-evaporação, e os raios $\gamma$ emitidos pelo núcleo residual. Para a implementação desta técnica foi desenvolvido o equipamento para a medida de vidas médias de estados isoméricos denominado SISMEI: SIStema para MEdidas de estados nucleares Isoméricos (TOUFEN, 2008).

O SISMEI foi desenvolvido a partir do espectrômetro de partículas carregadas SACI, Sistema Ancilar de Cintiladores, composto por 11 cintiladores plásticos $\Delta \mathrm{E}-\mathrm{E}$ (ALCÁNTARA-NÚÑEZ, 1999; 2003), visto na Figura 1.7. Neste sistema, o núcleo residual formado na reação nuclear, após a evaporação de partículas $\left(\sim 10^{-19} \mathrm{~s}\right)$, recua em vácuo, por uma distância suficiente para permitir a blindagem dos detectores de raios gama da intensa radiação proveniente do alvo, até atingir um anteparo (stopper). Com isso, os decaimentos de estados isoméricos com vida-média da ordem do tempo de vôo do núcleo, ou superior, podem ser observados por detectores de raios gama nas proximidades do anteparo, em coincidência atrasada com as partículas carregadas observadas nos detectores do SACI. 


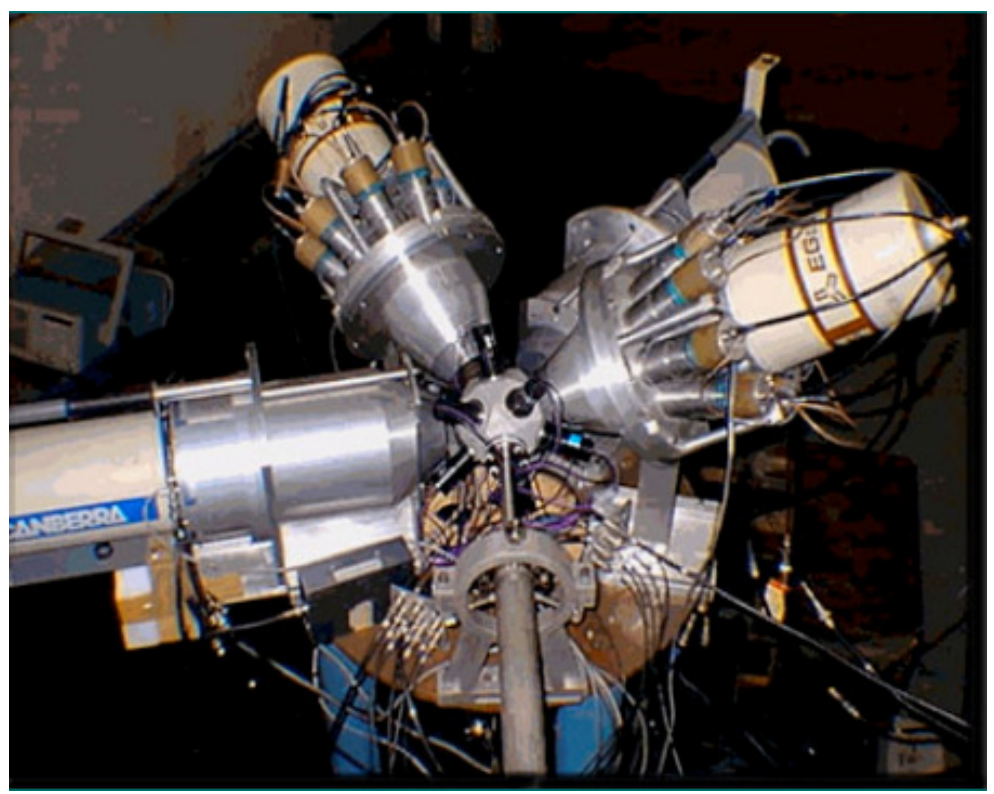

Figura 1.7: Espectrômetro de raios $\gamma$ SACI-PERERE montado na canalização $30^{\mathrm{a}}$ do acelerador Pelletron.

Na Figura 1.8, à esquerda, está representado um desenho esquemático do sistema SISMEI e, à direita, uma vista superior do sistema SISMEI, montado na canalização 30A do acelerador Pelletron. O SISMEI utiliza dois detectores de raios $\gamma$ diferentes: um detector de GeHP e um de NaI(Tl) (KNOLL, 1989). O detector de GeHP é utilizado devido a sua boa resolução em energia( $\sim 2 \mathrm{keV}$ em $1,3 \mathrm{MeV})$, essencial para distinguir picos de raios $\gamma$ com energias próximas. Já o detector de $\mathrm{NaI}(\mathrm{Tl})$ tem uma resolução em tempo superior ( $\sim \mathrm{ns})$, o que é importante para se realizar medidas de vidas médias mais curtas. A resolução temporal dos detectores de GeHP é da ordem de dezenas de ns. 

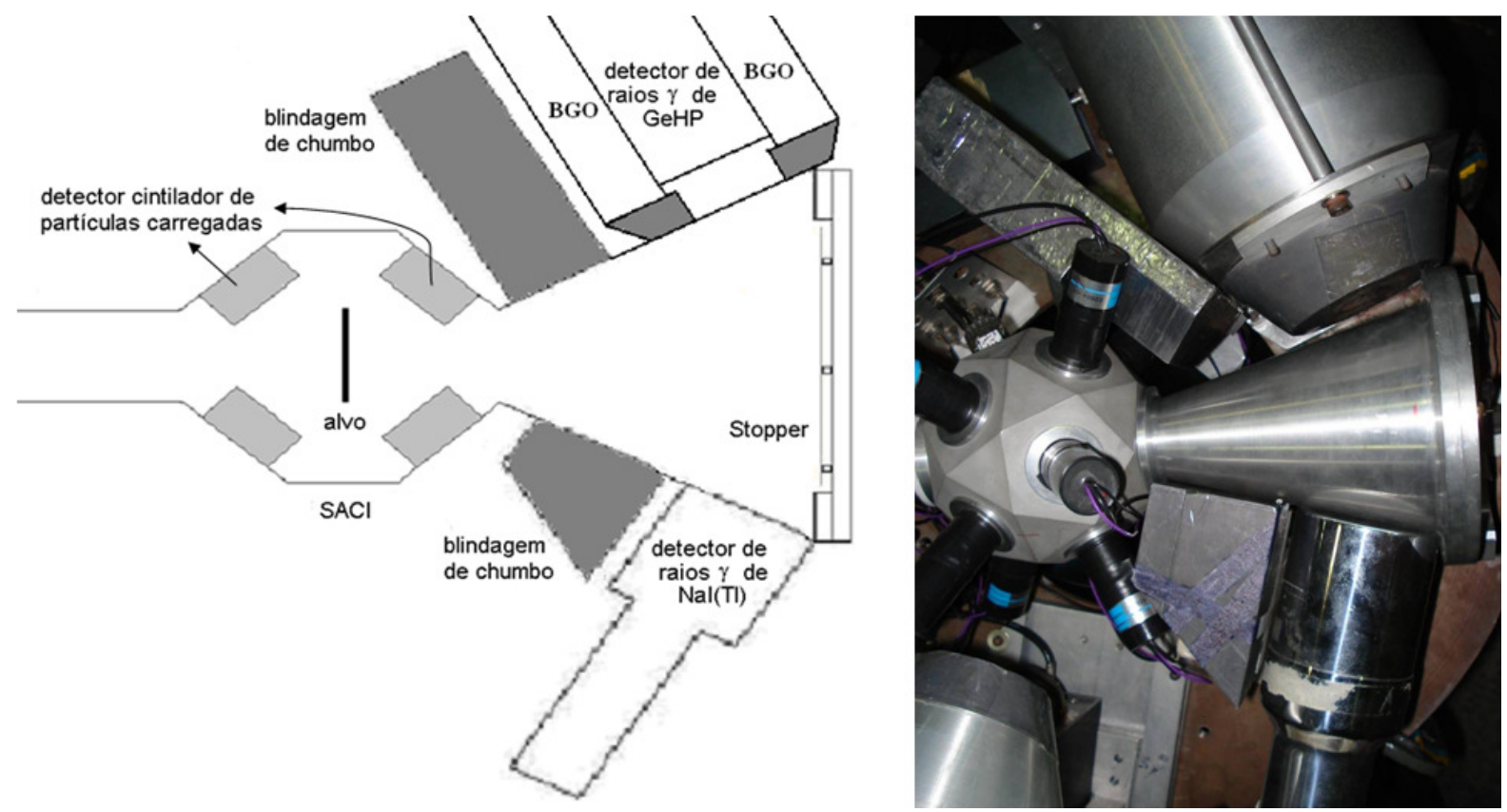

Figura 1.8: Sistema de Medidas de Estados Isoméricos (SISMEI) à direita e diagrama esquemático do SISMEI, à esquerda.

No SISMEI, o sinal do início da contagem de tempo (start) será dado pelos detectores de partículas carregadas do SACI e o sinal do fim da contagem de tempo (stop) será fornecido pelos detectores de raios $\gamma$ de $\mathrm{NaI}(\mathrm{Tl})$ e/ou GeHP, posicionados na extremidade final do cone.

No capítulo 2, é feita uma descrição detalhada dos aspectos mecânicos do SIMEI, bem como a descrição da eletrônica completa de aquisição de dados utilizada no SISMEI.

No capítulo 3 são apresentadas as experiências realizadas para os testes do SISMEI, assim como os resultados obtidos para cada um dos experimentos: ${ }^{46} \mathrm{Ti}\left({ }^{11} \mathrm{~B}, \mathrm{p} 2 \mathrm{n}\right){ }^{54} \mathrm{Fe}$, $\mathrm{E}_{\text {feixe }}=30$ e $33 \mathrm{MeV}$.

No capítulo 4 é feita a interpretação das propriedades do estado isomérico $10^{+}$do ${ }^{54} \mathrm{Fe}$, utilizado nos testes do SISMEI, através do Modelo de Camadas de Larga Escala (LSSM) (CAURIER, 2005) e o código Antoine (CAURIER, 1999).

No capítulo 5 são apresentadas as conclusões e perspectivas referentes a este trabalho. 


\section{MATERIAIS E MÉTODOS}

O desenvolvimento do SISMEI envolveu o projeto de peças mecânicas, algumas para alto vácuo, para serem adicionadas ao espectrômetro de raios $\gamma$ SACI-PERERE. Além disso, foi desenvolvida a eletrônica modular capaz de integrar a funcionalidade do SACI (Sistema Ancilar de CIntiladores) com a medida de diferenças de tempo entre partículas carregadas ou raios $\gamma$, emitidos na região do alvo, e raios $\gamma$, emitidos na região do stopper, de até $2 \mu \mathrm{s}$.

\subsection{ASPECTOS MECÂNICOS DO SISMEI}

Do ponto de vista mecânico, o SISMEI é composto por uma peça cônica de duralumínio (1), cuja extremidade menor fica acoplada ao SACI(6), um detector cintilador de raios $\gamma$ de $\mathrm{NaI}(\mathrm{Tl})$ (Iodeto de Sódio dopado com Tálio)(2), um detector semicondutor de raios $\gamma$ de GeHP (Germânio hiperpuro) com supressor Compton de BGO (Germanato de Bismuto: $\left.\mathrm{Bi}_{4} \mathrm{Ge}_{3} \mathrm{O}_{12}\right)(3)$, duas peças de chumbo com $5 \mathrm{~cm}$ e $7 \mathrm{~cm}$ de espessura (4 e 5), que blindam respectivamente os detectores de GeHP e $\mathrm{NaI}(\mathrm{Tl})$ da intensa radiação proveniente do alvo e um parador de feixe (stopper) de chumbo, fixado em uma base de alumínio que se encontra na extremidade maior da peça cônica. A Figura 2.1 mostra o SISMEI com suas partes constituintes. 


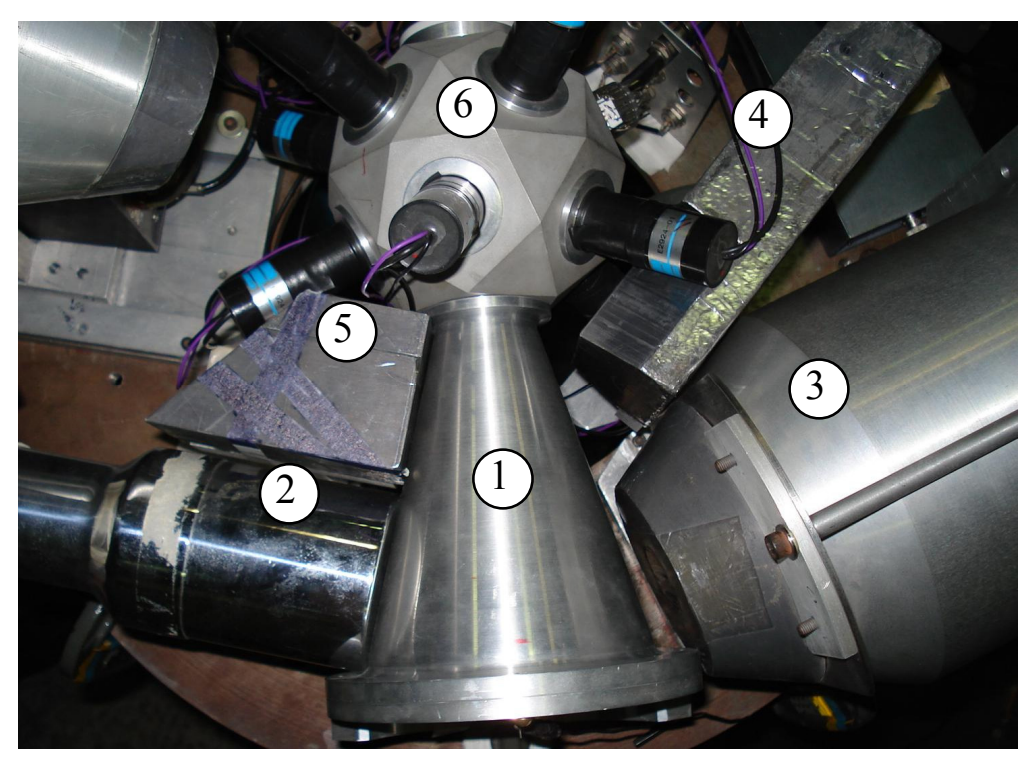

Figura 2.1: SISMEI visto por cima. Pode se observar: uma peça cônica (1), cuja extremidade menor fica acoplada ao SACI, um detector cintilador de raios $\gamma$ de NaI(Tl) (2), um detector semicondutor de raios $\gamma$ de GeHP com supressor Compton (3), duas peças de chumbo com $5 \mathrm{~cm}$ e $7 \mathrm{~cm}$ de espessura que blindam os detectores de GeHP e NaI(Tl), respectivamente (4) e (5) e o Sistema Ancilar de Cintiladores (SACI) (6). O alvo é posicionado no centro do SACI.

O cone que constitui o SISMEI foi projetado de modo que todos os núcleos produzidos pela reação nuclear no alvo, com abertura angular de até $15^{\circ}$ em relação à direção do feixe, possam recuar em vácuo até o parador, que se encontra a uma distância de 20,9(1) cm do alvo, no final do cone. Esta última distância, e conseqüentemente o comprimento do cone, foi projetada de modo a ser a distância mínima possível que permitisse o posicionamento dos detectores de raios gama e suas respectivas blindagens de chumbo.

A espessura da blindagem do detector de $\mathrm{NaI}(\mathrm{Tl})$ foi projetada de modo que no máximo $0,16 \%$ dos raios $\gamma$ de $2,5 \mathrm{MeV}$, provenientes do alvo atinjam o detector. Esta energia foi escolhida por ser a energia na qual se tem a menor eficiência do chumbo, como mostra o gráfico da Figura 2.2. A porcentagem de raios $\gamma$ que atravessam a blindagem foi calculada utilizando-se a Equação 2.1 (CHUNG, 2001) e os seguintes valores: $\frac{\mu_{e n}}{\rho}=0,023 \mathrm{~cm}^{2} / \mathrm{g}, l=7$ cm e $\rho=11,35 \mathrm{~g} / \mathrm{cm} 3$ (YAO, 2006). 


$$
T=e^{-\frac{\mu_{e n}}{\rho} * \rho * l}
$$

Onde: T é a transmissão de raios $\gamma$ através da blindagem para uma determinada energia, $\frac{\mu_{e n}}{\rho}$ é o coeficiente de absorção de massa do chumbo, obtido no gráfico da Figura 2.2, $\rho$ é a densidade do chumbo em $\mathrm{g} / \mathrm{cm}^{3}$ e $l$ é a espessura da blindagem de chumbo em $\mathrm{cm}$.

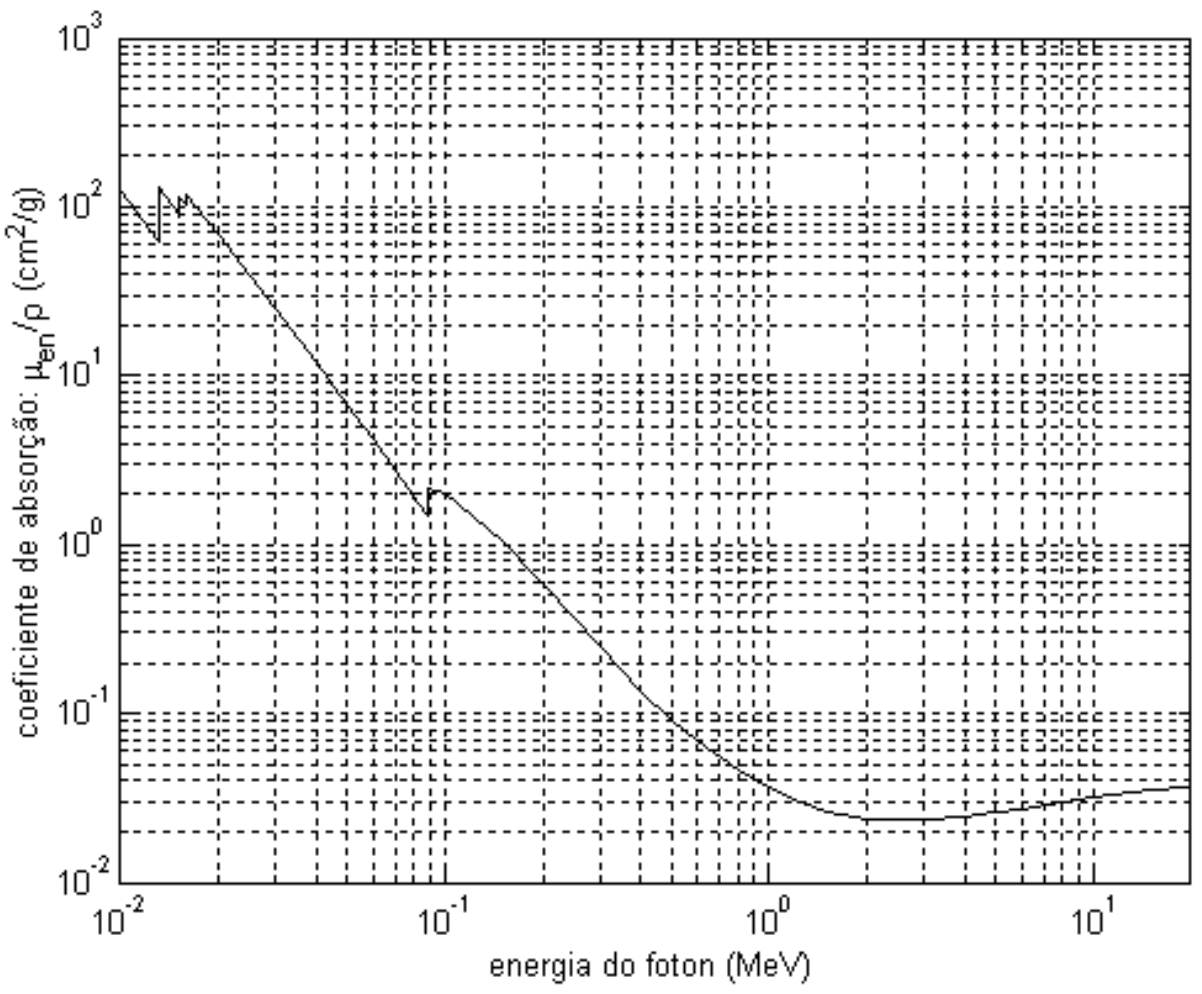

Figura 2.2: Curva de absorção do chumbo em função da energia do fóton. (HUBBELL, 2004)

Para o detector de raios $\gamma$ de GeHP, a espessura da blindagem de chumbo foi reduzida para $5 \mathrm{~cm}$, uma vez que esse detector é montado no interior de um Supressor Compton de BGO, cujo cristal tem espessura mínima de $3 \mathrm{~cm}$.

O parador do feixe (stopper), posicionado no final do cone de alumínio, precisa possuir espessura suficiente para frear os diversos tipos de feixe produzidos no acelerador Pelletron: ${ }^{6,7} \mathrm{Li},{ }^{10,11} \mathrm{~B},{ }^{12,13} \mathrm{C},{ }^{16,17,18} \mathrm{O},{ }^{19} \mathrm{~F},{ }^{28,29,30} \mathrm{Si},{ }^{35} \mathrm{Cl}$ entre outros (LAFN, 2008). Para isso, 
foi necessária a escolha adequada do material. Materiais de número atômico alto são uma escolha natural, pois esses materiais não permitem reações de fusão com os feixes de íons produzidos no acelerador Pelletron, além de possuírem alto poder de freamento em função da sua espessura e densidade. Os materiais disponíveis para a confecção do parador com essa característica eram chumbo e tântalo, e entre eles escolheu-se chumbo. A escolha do chumbo como parador de feixe foi feita devido, principalmente, à ausência de estados de baixa energia neste núcleo. O estado excitado de mais baixa energia para os três isótopos naturais do chumbo $\left({ }^{206} \mathrm{~Pb}(24 \%),{ }^{207} \mathrm{~Pb}(22 \%)\right.$ e $\left.{ }^{208} \mathrm{~Pb}(54 \%)\right)$ está presente no ${ }^{207} \mathrm{~Pb}\left(\mathrm{~J}^{\pi}=5 / 2^{-}\right)$e possui $\mathrm{E}=569,7 \mathrm{keV}$ (MARTIN, 1993), enquanto o tântalo possui um estado de $\mathrm{E}=136,3 \mathrm{keV}$ (WU, 2005). Diferentemente de outros possíveis núcleos, o chumbo possui baixa seção de choque para excitações colombianas devido à sua forma muito esférica. Isso impede um aumento do fundo aleatório, que poderia ser formado pela à emissão de raios $\gamma$ de estados populados por excitação colombiana, observado pelos detectores de raios $\gamma$ do SISMEI.

O parador do feixe é composto por dois discos concêntricos: um de alumínio de $96 \mathrm{~mm}$ de diâmetro e um disco de chumbo de $30 \mathrm{~mm}$ de diâmetro. O disco de alumino é utilizado como base para o disco chumbo, já que este é maleável demais para ser parafusado diretamente nos suportes cerâmicos, que fixam o parador à flange traseira do cone de alumínio. Para a fixação do disco de chumbo ao alumínio, foi feito um rebaixo circular de $30 \mathrm{~mm}$ de diâmetro e $0,4 \mathrm{~mm}$ de profundidade no disco de alumínio. O disco de chumbo, que inicialmente possuía $26 \mathrm{~mm}$ de diâmetro, foi então prensado e colado neste rebaixo utilizando um adesivo epóxi e uma pressão de aproximadamente 5,4 MPa de modo que o chumbo se amoldasse ao diâmetro do rebaixo. A espessura final do disco de chumbo é de no mínimo $0,7 \mathrm{~mm}$.

A corrente de feixe que atinge o parador de chumbo é coletada diretamente através de um fio condutor que está ligado a este parador e a um passador elétrico com isolamento 
cerâmico, localizado na flange traseira do cone de alumínio, que conecta o interior ao exterior da câmara de vácuo. O parador montado em sua flange é visto na Figura 2.3.

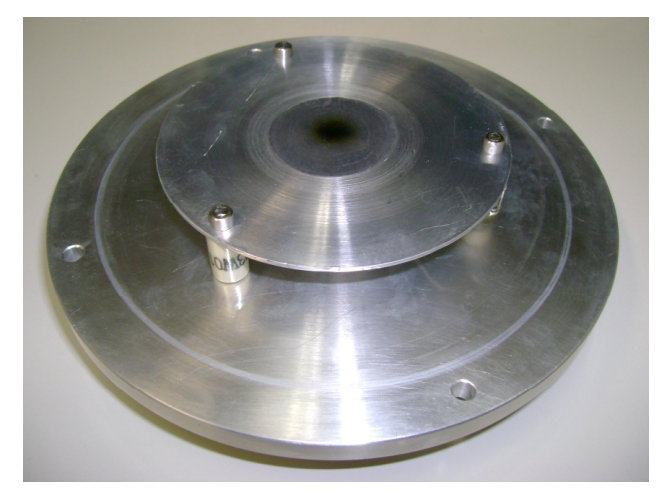

Figura 2.3: Parador de feixe do SISMEI montado em sua flange. Observa-se que o parador é composto por um disco de chumbo colado em um disco maior de alumínio.

Outros detalhes mecânicos do SISMEI, como a vedação para vácuo por exemplo, podem ser observados na Figura 2.4. Esta figura apresenta um corte horizontal, em escala, do cone do SISMEI acoplado ao SACI.

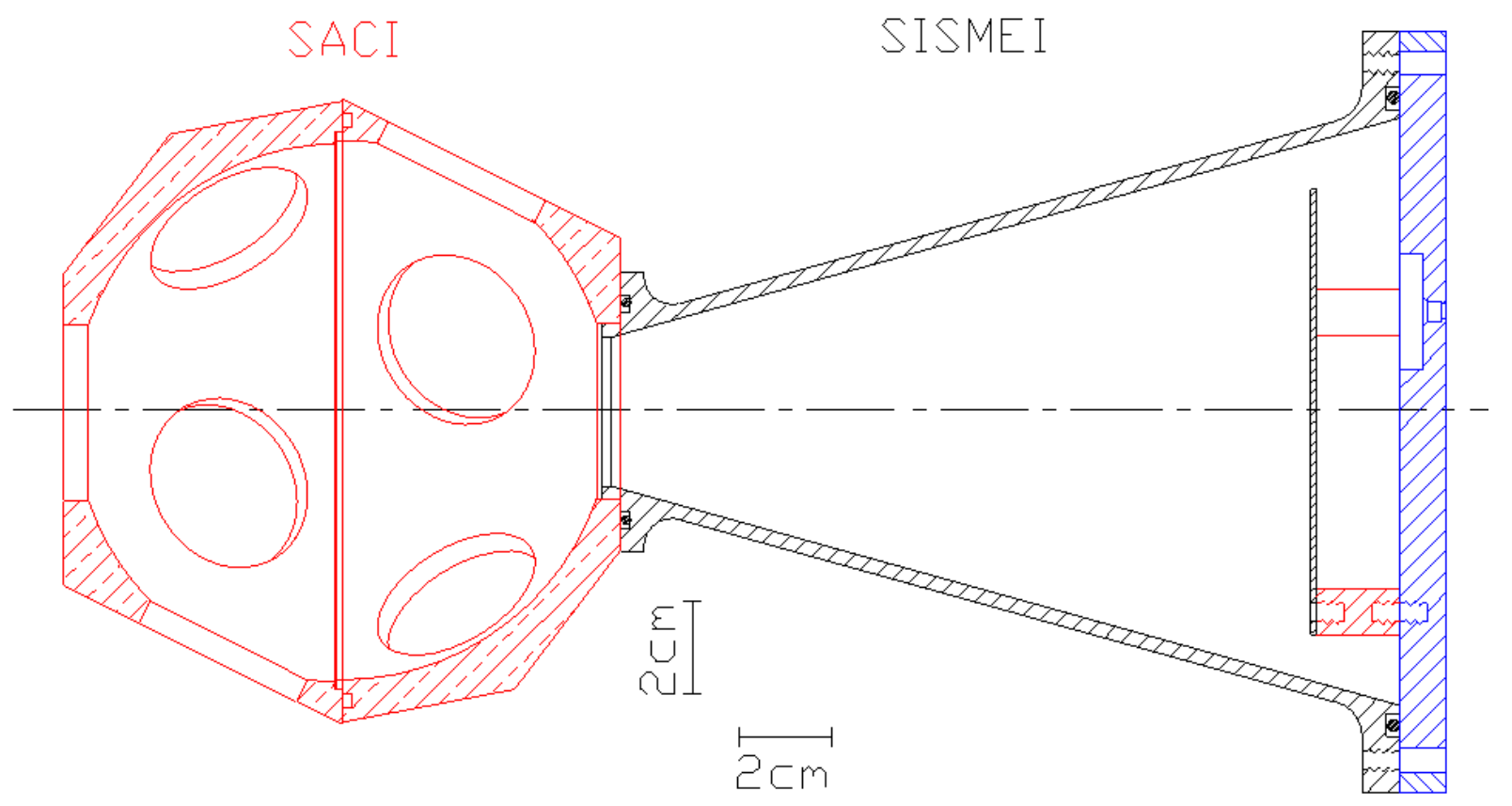

Figura 2.4: Corte horizontal, em escala, do cone de alumínio do SISMEI acoplado ao SACI.

Com o intuito de permitir uma maior taxa de contagens nos detectores cintiladores $\Delta \mathrm{E}-\mathrm{E}$ do $\mathrm{SACI}$, desenvolveu-se bases ativas para as fotomultiplicadoras destes detectores 
(TRIUMPHO, 2007). Com as bases passivas, utilizadas anteriormente no SACI, o ganho em energia dos detectores $\Delta \mathrm{E}-\mathrm{E}$ muda conforme a taxa de contagens, tornando mais difícil a distinção entre as partículas carregadas detectadas: prótons e alfas. Essa alteração no ganho é notada de forma mais contundente no espectro de energia dos detectores plásticos $\Delta \mathrm{E}$ do SACI. Esse comportamento indesejado aumenta à medida que a taxa de partículas incidentes nos detectores aumenta, o que torna o sistema pouco confiável para taxas altas. Tal problema foi solucionado com a implementação de bases ativas. Mais detalhes sobre o desenvolvimento das bases ativas podem ser encontrados no apêndice A. Outro desenvolvimento importante para o SISMEI foi a construção de um módulo de BUSY mais eficiente, com a finalidade de reduzir o tempo morto da eletrônica de aquisição. Mais detalhes sobre o desenvolvimento do módulo de BUSY podem ser vistos no apêndice B.

\subsection{A ELETRÔNICA MODULAR DO SISMEI}

O SISMEI utiliza a coincidência atrasada gama-partícula $(\gamma-p)$ ou gama-gama $(\gamma-\gamma)$ para medir a vida média de estados isoméricos. Para isso, faz-se necessário o uso de uma eletrônica específica, modificada a partir da eletrônica utilizada nas medidas com o espectrômetro de raios $\gamma$ SACI-PERERE. As informações principais que esta eletrônica adquire são descritas a seguir:

- Energia do raio $\gamma$ do detector de GeHP, posicionado no SISMEI;

- Energia do raio $\gamma$ do detector de NaI(Tl), posicionado no SISMEI;

- Energia do raio $\gamma$ do detector de GeHP, posicionado próximo ao SACI;

- Diferença em tempo entre a detecção de partículas carregadas no SACI e a detecção de um raio $\gamma$ nos detectores posicionados no SISMEI; 
- Diferença em tempo entre a detecção de um raio $\gamma$ no detector de GeHP posicionado próximo ao SACI e a detecção de um raio $\gamma$ nos detectores posicionados no SISMEI.

A eletrônica de aquisição do SISMEI é complexa. Um evento válido requer que um raio $\gamma$ seja detectado em um dos detectores de raios $\gamma$ posicionados próximos ao SISMEI. Como estes detectores necessitam de um tempo de conversão dos seus pulsos bem maior do que o tempo de conversão dos detectores cintiladores de partículas carregadas do SACI, não é possível esperar a confirmação de um evento válido para iniciar a conversão da informação vinda destes detectores de partículas. Isso obriga o sistema eletrônico a abortar a conversão do pulso dos detectores de partículas, caso um evento válido não se confirme. Sem esse controle o tempo morto do sistema aumentaria muito.

Outro fator que aumenta a complexidade da eletrônica reside na dificuldade de se exigir uma coincidência atrasada com um intervalo longo $(2 \mu \mathrm{s})$. Essa peculiaridade da eletrônica do SISMEI requer que muitos sinais lógicos, que carregam informações ligadas aos tempos de detecção das partículas carregadas e de raios $\gamma$, sejam atrasados em até $2 \mu$ s. Isto resulta em um aumento considerável na quantidade de módulos necessários para a implementação da eletrônica de aquisição.

Como se trata de uma eletrônica relativamente extensa optou-se por dividi-la em 10 tipos de circuitos menores com funções específicas. O diagrama de blocos da eletrônica do SISMEI é observado na Figura 2.5, já o diagrama completo da eletrônica, com os 10 tipos de circuitos destacados, é visto na Figura 2.18, no fim deste capítulo. 


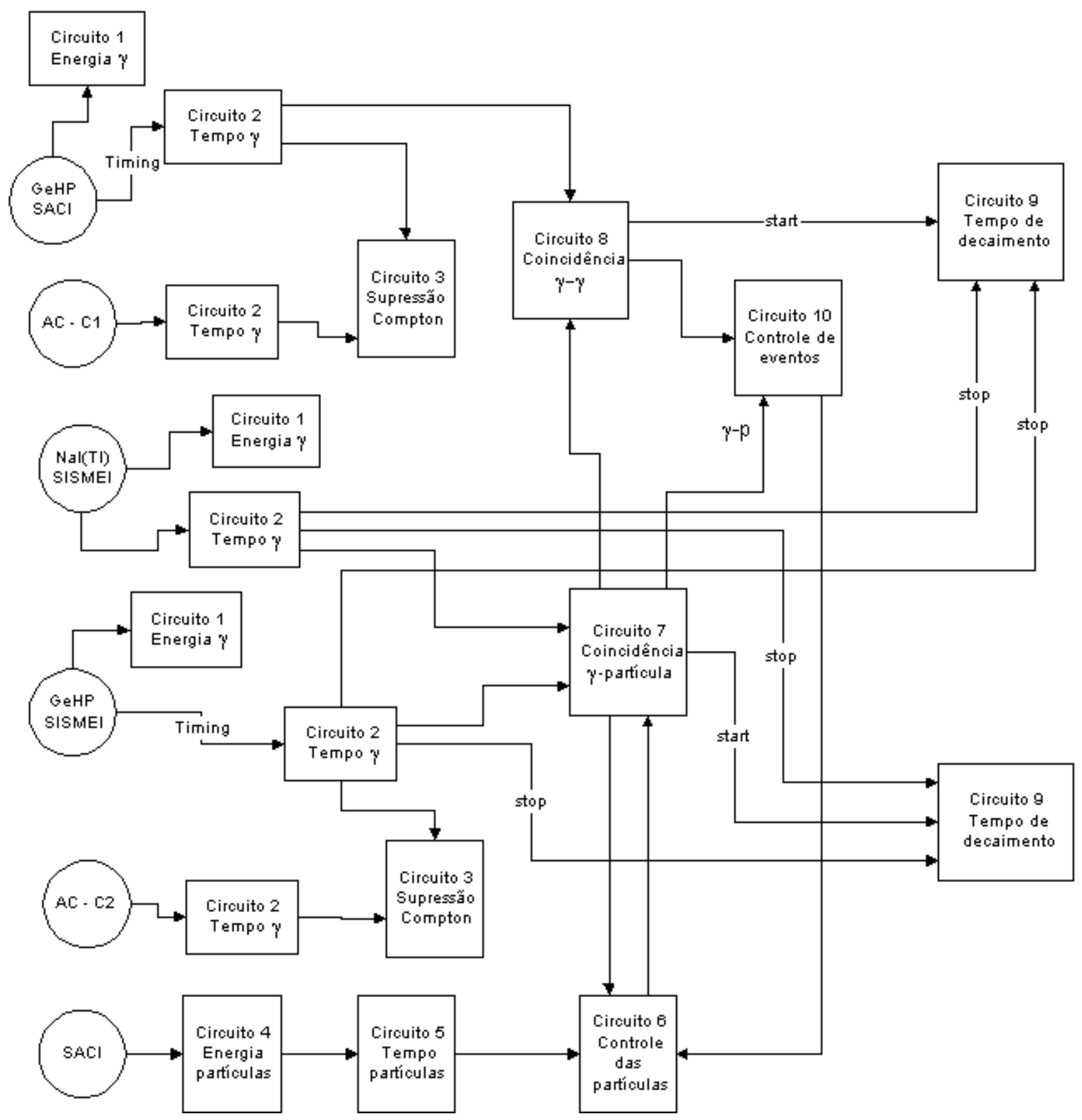

Figura 2.5: Diagrama em blocos funcionais da eletrônica modular do SISMEI.

\subsubsection{Circuito 1: Circuito de energia dos detectores de raios $\gamma$}

O circuito de energia dos detectores de raios $\gamma$ é responsável por converter os pulsos de saída dos detectores de raios $\gamma$ em uma informação digital, ou seja, este circuito é responsável por adquirir as energias dos raios $\gamma$ detectados. Um exemplo deste circuito pode ser visto na Figura 2.6. 


\section{circuito 1}

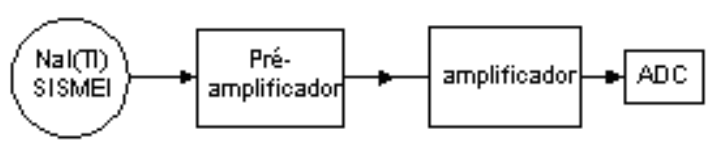

Figura 2.6: Exemplo de circuito de energia de um dos detectores de raios $\gamma$. O detector é representado como um círculo.

O sinal proveniente do detector é composto por pulsos que carregam a informação da energia do raio $\gamma$. O papel do pré-amplificador é integrar e amplificar o pulso, tornando-o mais imune a ruídos. O pré-amplificador também pode inverter a polaridade do pulso.

A função do amplificador é de filtrar e melhorar as características elétricas do pulso proveniente do pré-amplificador, de modo que na sua saída o amplificador fornece um pulso de forma gaussiana cuja altura é proporcional à energia do raio $\gamma$. Por fim o $\mathrm{ADC}^{[1]}$ é um módulo capaz de converter a altura do pulso analógico, proveniente do amplificador, em um número digital de 12 bits.

No caso dos detectores de raios $\gamma$ de GeHP o circuito é similar, porém o préamplificador é montado internamente ao detector o que torna seus sinais de saída mais imunes a ruídos externos. Além disso, este pré-amplificador trabalha com um transistor FET (Transistor de Efeito de Campo) resfriado à temperatura de nitrogênio líquido $\left(\approx-196{ }^{\circ} \mathrm{C}\right)$ para reduzir drasticamente o ruído eletrônico inserido pelo pré-amplificador. Essa redução é necessária para preservar a excelente resolução em energia dos detectores de GeHP.

\subsubsection{Circuito 2: Circuito de tempo dos detectores de raios $\gamma$}

O circuito de tempo dos detectores de raios $\gamma$ é responsável por fornecer um sinal lógico indicando que um raio $\gamma$ foi detectado. Posteriormente, este sinal é utilizado em outras

\footnotetext{
${ }^{1}$ Módulo ADC, Analogical to Digital Converter: módulo CAMAC que tem a função de gerar um número digital proporcional à altura do sinal de tensão da sua entrada.
} 
partes da eletrônica como marca de tempo do raio $\gamma$. Um exemplo deste circuito pode ser visto na Figura 2.7.

\section{circuito 2}

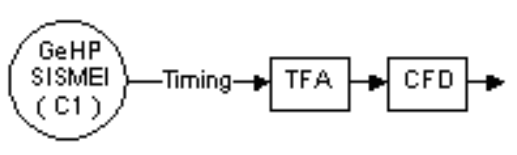

Figura 2.7: Exemplo de circuito de tempo de um dos detectores de raios $\gamma$.

Neste circuito, o pulso proveniente do detector é tratado em um módulo $\mathrm{TFA}^{[2]}$ sendo filtrado e amplificado de forma rápida para que a informação do tempo de chegada do raio $\gamma$ não se perca. Em seguida, o pulso é enviado para um módulo $\mathrm{CFD}^{[3]}$, que produz um sinal lógico, cuja borda inicial está ligada ao instante de chegada do pulso. A marca de tempo (sinal lógico) produzida pelo CFD tem a vantagem de ser independente da altura do pulso de entrada, uma característica essencial para que essa marca de tempo seja igual tanto para os raios $\gamma$ muito energéticos (de grande amplitude), quanto para os raios $\gamma$ pouco energéticos (de baixa amplitude).

\subsubsection{Circuito 3: Circuito de Supressão Compton}

Os circuitos de Supressão Compton têm a finalidade de informar quando um raio $\gamma$ detectado em um dos detectores de GeHP está em coincidência temporal com um fóton detectado no seu respectivo Supressor Compton (AC - anti-Compton). Essa informação será

\footnotetext{
${ }^{2}$ Módulo TFA, Timing and Filter Amplifier: Modulo que filtra e amplifica sinais de forma rápida.

${ }^{3}$ Módulo CFD, Constant Fraction Discriminator: Módulo que converte um pulso analógico em um pulso lógico cujo tempo independe da amplitude do pulso de entrada. Este módulo possui um controle de threshold para que o usuário possa evitar que sinais de baixa amplitude, provenientes de ruídos eletrônicos, sejam convertidos em falsos pulsos lógicos.
} 
usada durante a redução dos dados para eliminar os raios $\gamma$ que realizaram um espalhamento Compton em um dos detectores de GeHP.

Cada um dos detectores de GeHP utiliza um circuito eletrônico diferente, mas com a mesma finalidade. Os circuitos de Supressão Compton dos detectores de GeHP do SACI e do SISMEI são vistos na Figura 2.8 .

\section{circuito 3}
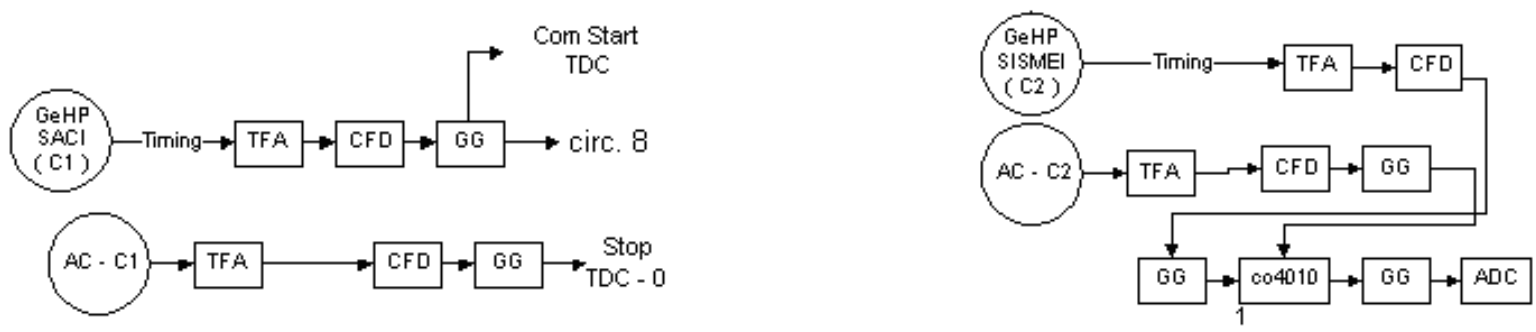

Figura 2.8: Circuitos de Supressão Compton dos detectores de raios $\gamma$ de GeHP.

No circuito do detector de GeHP do SACI, à esquerda da Figura 2.8, as informações de tempo provenientes dos circuitos de tempo dos detectores de GeHP e AC são enviadas para os módulos $\mathrm{GG}^{[4]}$, usados para atrasar os pulsos. Quando os sinais de tempo são originalmente síncronos, o pulso proveniente do GG do AC será gerado 250 ns atrasado em relação ao pulso proveniente do GG do detector de GeHP. O pulso proveniente do detector de GeHP é enviado para a entrada "Common Start" do Módulo $\mathrm{TDC}^{[5]}$ e o pulso proveniente do Supressor Compton é enviado para a entrada "STOP-0" do mesmo Módulo TDC. O módulo TDC converter a diferença em tempo entre os pulsos das entradas "Common Start" e "STOP-0" em um número digital. Estes dois módulos GG também adicionam um atraso de

\footnotetext{
${ }^{4}$ Módulo GG, Gate Generator: Módulo que gera um sinal lógico com atraso e largura ajustáveis a partir de um sinal lógico na entrada.

${ }^{5}$ Módulo TDC, Time to Digital Converter: Módulo CAMAC que converte a diferença em tempo de até 500ns entre as entradas lógicas start e o stop em um número digital de 11 bits. Possui uma entrada de start comum (Common START) e oito entradas de STOP (0-7). Possui ainda uma entrada de Clear que interrompe a conversão atual e prepara o módulo para uma nova conversão (ELECTRONICS, 2008).
} 
aproximadamente $1,5 \mu \mathrm{s}$ nos dois pulsos. Este atraso é necessário para o funcionamento do circuito 8 .

$\mathrm{O}$ circuito do detector de GeHP do SISMEI, à direita da Figura 2.8, é igual ao anterior até os dois módulos GG, que desta vez estão configurados para que os pulsos sejam síncronos mas com larguras de aproximadamente 100 ns. Os pulsos de saída destes módulos GG são direcionados ao módulo lógico co4010 ${ }^{[6]}$, que está configurado para realizar a função lógica AND entre as duas entradas. Quando os circuitos de tempo do detector de GeHP e do AC fornecerem pulsos, em coincidência temporal, para o módulo co4010, este deve fornecer um pulso lógico para um módulo GG. Este módulo por sua vez irá produzir um sinal lógico para um ADC. O resultado é que, quanto houver uma coincidência temporal entre o detector de GeHP e o AC, num intervalo de no máximo 200 ns, o ADC registrará uma contagem em um canal fixo, que poderá ser utilizada durante a redução de dados para eliminar esses eventos coincidentes indesejáveis.

\subsubsection{Circuito 4: Circuito de energia (E- $\Delta E)$ dos detectores de partículas do SACI}

O circuito de energia dos detectores de partículas do SACI converte os sinais de energia, tanto $\mathrm{E}$ quanto $\triangle \mathrm{E}$, de cada partícula detectada pelos detectores cintiladores do $\mathrm{SACI}$ em informação digital. Este circuito é o equivalente ao Circuito 1, só que para partículas carregadas detectadas. Um esquema deste circuito é visto na Figura 2.9.

\footnotetext{
${ }^{6}$ Módulo Lógico co4010: Módulo com entradas e saídas lógicas que permite configurar a saída como uma função lógica qualquer (AND, OR e NOT) das entradas.
} 


\section{circuito 4}
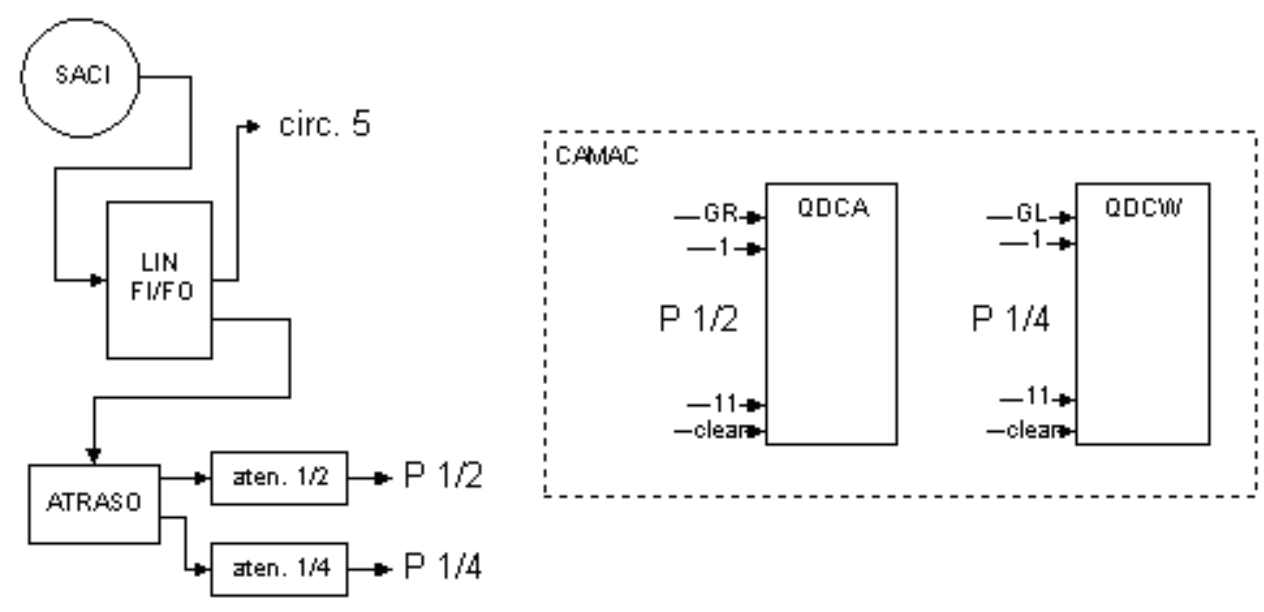

Figura 2.9: Circuito de energia dos detectores de partículas do SACI

O SACI, quando acoplado ao SISMEI, possui 10 detectores cintiladores do tipo E- $\Delta \mathrm{E}$.

Cada um destes detectores possui uma única saída de sinal e, através dela as informações de $\Delta \mathrm{E}$ e de $\mathrm{E}$ são transmitidas em um único pulso, mas separadas temporalmente. Os detectores $\Delta \mathrm{E}$ e $\mathrm{E}$ apresentam tempos de resposta muito distintos, sendo o detector cintilador $\Delta \mathrm{E}$ muito mais rápido $(2,4 \mathrm{~ns})$ que o detector $\mathrm{E}(264 \mathrm{~ns})$. Com isso, o início do pulso de saída do conjunto $\mathrm{E}-\Delta \mathrm{E}$ é formado principalmente pela informação do detector cintilador $\Delta \mathrm{E}$, enquanto o restante do tempo de duração do pulso carrega apenas a informação do detector cintilador E. Em ALCÁNTARA-NÚÑEZ (1999) pode-se encontrar uma descrição detalhada do funcionamento dos detectores de partículas do SACI.

Neste circuito, cada um dos 10 detectores está ligado a um módulo LIN FI/FO ${ }^{[7]}$ que duplica o sinal analógico, proveniente do detector, permitindo que um mesmo pulso seja enviado tanto para o atraso quanto para o Circuito 5. O atraso representado na Figura 2.9 como um bloco, trata-se que um conjunto de 10 cabos coaxiais de $50 \Omega$ de impedância e $9 \mathrm{~m}$ de comprimento que atrasam os pulsos provenientes dos 10 detectores em 45 ns sem deformá-

\footnotetext{
${ }^{7}$ Módulo LIN FI/FO, Linear Fan-in/Fan-out: Módulo que soma, ou combina, as diversas entradas analógicas e fornece o resultado para todas as suas saídas (analógicas), sem atenuar nem deformar os sinais de entrada.
} 
los significativamente. Este atraso é necessário para permitir aos circuitos lógicos processarem o tempo das partículas antes dos pulsos alcançarem os módulos CAMAC $\mathrm{QDCA}^{[8]}$ e QDCW ${ }^{[9]}$.

Os módulos CAMAC QDCA e QDCW são similares ao módulo ADC, mas com uma importante diferença: eles convertem a carga do pulso de corrente de entrada em informação digital e não a altura do pulso como os ADCs. Os QDCs não têm controle de ganho, por isso são utilizados atenuadores (de $1 / 2$ ou de $1 / 4$ ) para evitar perdas de informação devido a um estouro de escala. O módulo QDCA é utilizado para converter a informação da energia perdida pelas partículas carregadas no detector $\triangle \mathrm{E}$ e o QDCW para a informação da energia perdida pelas partículas carregadas no detector E. No entanto, a não ser pela atenuação, o sinal de entrada dos dois módulos é o mesmo. O que vai diferenciar a parte do pulso que será convertida são os sinais de GL (gate lento, no caso de E) e GR (gate rápido, no caso de $\Delta \mathrm{E}$ ) que são enviados pelo circuito 5 .

\subsubsection{Circuito 5: Circuito de tempo dos detectores de partículas do SACI}

O circuito de tempo dos detectores de partículas tem a função de fornecer um sinal lógico, indicando que pelo menos uma partícula foi detectada em pelo menos um dos detectores cintiladores do SACI. Além disso, é esse circuito que comanda os módulos QDC vistos no circuito 4. O esquema deste circuito pode ser observado na Figura 2.10.

\footnotetext{
${ }^{8}$ Módulo QDCA, Charge Analog-to-Digital Converter: Módulo CAMAC que converte a carga do sinal de entrada em um número digital. Além das entradas padrão, possui uma entrada de gate que delimita o intervalo de tempo em que o sinal será integrado e uma entrada clear que interrompe a conversão e limpa o módulo para que este possa receber um novo sinal para converter.

${ }^{9}$ Módulo QDCW, Charge ADC with Wide Gates: Módulo CAMAC análogo ao QDCA, mas que permite Gates largos: até $10 \mu \mathrm{s}$, enquanto o QDCA permite Gates de até 200ns.
} 


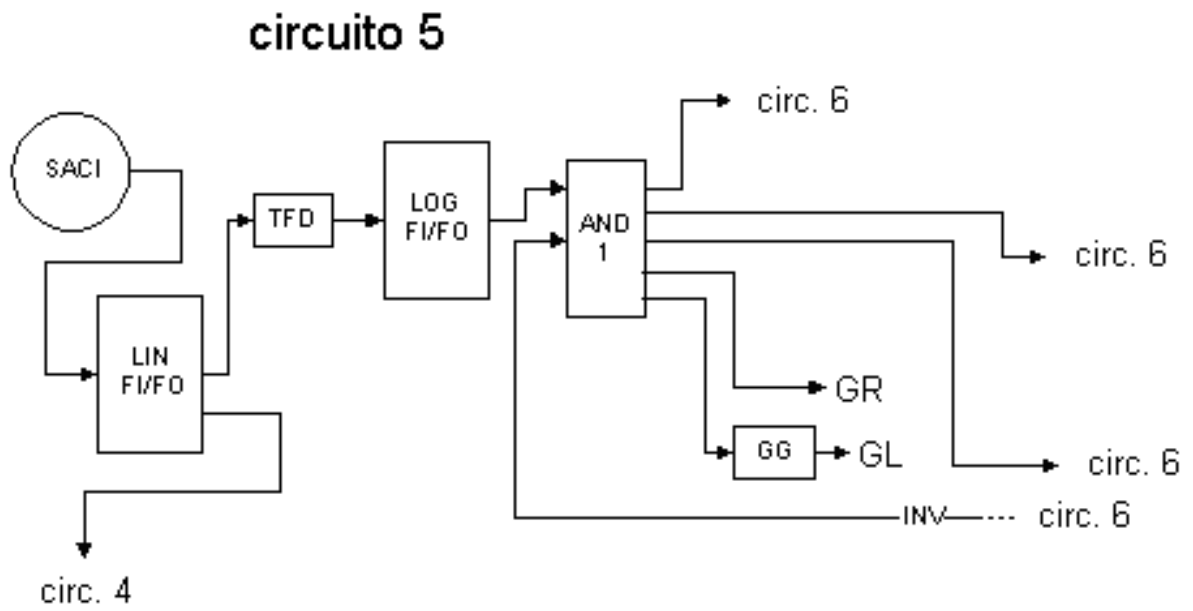

Figura 2.10: Circuito de tempo dos detectores de partículas do SACI

Os pulsos provenientes do módulo LIN FI/FO, discutido no circuito 4, são enviados para 10 módulos $\mathrm{TFD}^{[10]}$. Este tipo de módulo produz um sinal lógico que carrega a informação do instante de tempo em que a partícula foi detectada, é um módulo idêntico ao CFD.

Os 10 sinais lógicos provindos dos 10 módulos TFD são agrupados em um único módulo LOG FI/FO ${ }^{[11]}$ que, fornecerá então, como saída, a informação do instante de tempo da primeira partícula detectada por qualquer um dos 10 detectores, ou seja, a partir deste ponto todos os detectores do SACI são considerados como um único detector. Convém ressaltar que, como a evaporação de partículas pelo núcleo composto é muito rápida, da ordem de $10^{-19} \mathrm{~s}(\mathrm{KONDEV}, 2008)$, e o tempo de vôo destas partículas ( $\left.\mathrm{t}_{\text {vôo }}<1 \mathrm{~ns}\right)$ é pequeno, se comparado com o tempo de resposta da eletrônica, então mesmo que mais de uma partícula seja detectada, em mais de um detector do SACI, todas estas partículas podem ser consideradas simultâneas.

\footnotetext{
${ }^{10}$ Módulo TFD, Timing Discriminator: Módulo que converte um pulso analógico em um pulso lógico. Este módulo possui um controle de threshold para que o usuário possa evitar que sinal de ruído seja convertido em pulsos lógicos falsos. É um módulo idêntico ao CFD.

11 Módulo LOG FI/FO, Logic Fan-in/Fan-out: Módulo que combina, com uma operação lógica "OR”, às diversas entradas lógicas e fornece o resultado para todas as suas saídas (lógicas).
} 
A informação do instante de chegada das partículas é então enviada ao módulo $\mathrm{AND}^{[12]} 1$, que além desta entrada, possui outra entrada invertida do circuito 6. Esta entrada invertida é utilizada como veto, ou seja, caso esta entrada esteja ativa, este sinal bloqueia a informação de tempo da partícula. Este veto é utilizado para impedir que a informação de duas ou mais partículas, provenientes de núcleos residuais diferentes se sobreponham, causando a deterioração de ambos os eventos. Assim, sempre que o sistema já estiver adquirindo um evento, a entrada invertida do modulo AND 1 fica ativa e veta qualquer outro novo evento. Com isso, na saída do módulo AND tem-se a informação do instante de tempo chegada das partículas. A partir deste módulo, essa informação é enviada para outros pontos da eletrônica, além disso, uma das saídas, um pulso de 30 ns de largura, é usada diretamente como sinal de GR (gate rápido) que é utilizado no o módulo CAMAC QDCA (circuito 4) e controla o intervalo do pulso de energia dos detectores de partículas que será integrado para formar a informação do $\Delta \mathrm{E}$.

Para gerar o sinal de GL (gate lento) a informação do tempo das partículas precisa passar por um módulo GG. Este módulo irá gerar um pulso lógico com largura de 380 ns e com atraso de $80 \mathrm{~ns}$, em relação ao pulso de entrada. Este pulso, com largura e atrasos adequados, será enviado ao módulo CAMAC QDCW (circuito 4) para controlar o intervalo do pulso de energia dos detectores de partículas que será integrado para formar a informação de E.

\footnotetext{
${ }^{12}$ Módulo AND, Coincidence: Módulo que combina, com uma operação lógica "AND”, as 4 entradas lógicas e cujo o resultado é apresentado igualmente em todas as suas saídas (lógicas). Este módulo também pode ser configurado para a operação lógica "OR". Neste trabalho quando um módulo for nomeado AND, este estará configurado para a operação "AND”.
} 


\subsubsection{Circuito 6: Circuito de controle das partículas}

A aquisição dos dados, provenientes dos detectores de partículas do SACI, só deve ser considerada quando houver um evento válido. Um evento no SISMEI será válido e poderá ser adquirido quando um dos dois detectores de raios $\gamma$ posicionados no SISMEI forem acionados. Além disso, para um evento ser considerado válido é preciso que uma partícula carregada seja detectada no SACI ou o detector de GeHP posicionado próximo ao SACI seja acionado. Controlar a eletrônica para adquirir apenas os eventos válidos é a tarefa do circuito 6, visto na Figura 2.11.

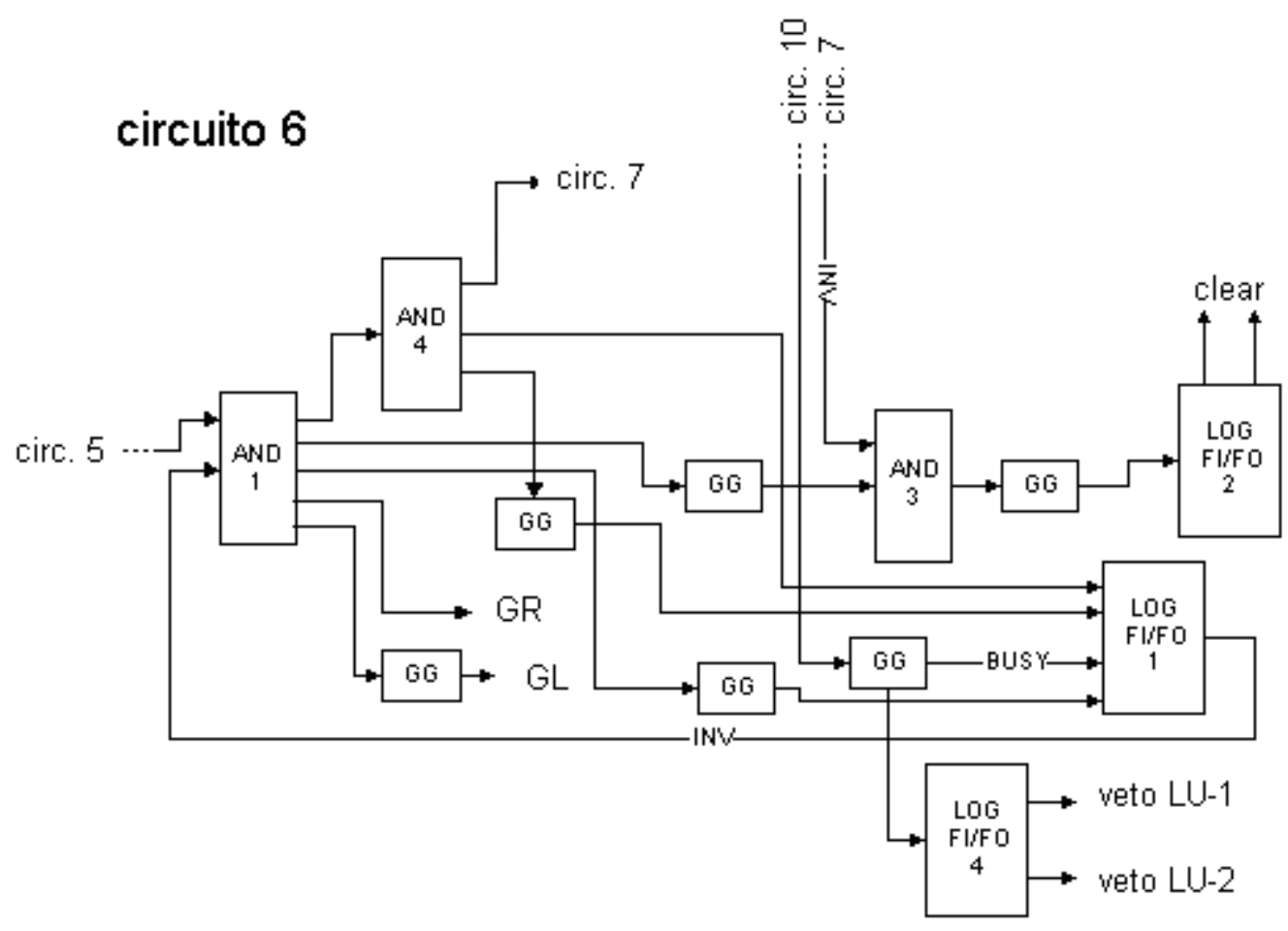

Figura 2.11: Circuito de controle das partículas.

O circuito 6 utiliza três saídas do módulo AND 1 (circuito 5). Uma dessas saídas é conectada diretamente em um GG com atraso e largura de pulso mínimos. O sinal gerado é enviado para o módulo LOG FI/FO 1. Este saída é usado para inibir a entrada de um novo sinal de partícula, como já discutido no circuito 5. 
A saída superior do módulo AND 1 é enviada para o módulo OR 4 que aqui é utilizado apenas para duplicar a informação lógica. Um desses sinais é enviado para o circuito 7, levando a informação de tempo de partícula. O outro sinal é usado em um módulo GG, configurado com atraso mínimo e pulso de largura 30 ns. Este pulso é conectado ao módulo LOG FI/FO 1 e inibe a entrada da informação de uma nova partícula por mais tempo, permitindo que a informação de um evento válido, ou não, seja processada no circuito 10 .

A informação de que foi adquirido um evento válido, vinda do circuito 10, é enviada a um módulo GG, configurado para atraso mínimo, mas com largura de pulso de $400 \mu$ s. Este pulso é chamado de sinal de $B U S Y$, pois é ele que define o tempo em que todo o sistema ficará esperando, enquanto todas as informações do evento são convertidas nos módulos ADC, QDC e TDC. Este sinal de $B U S Y$ é enviado para o módulo LOG FI/FO 1, e para o LOG FI/FO 4. Este último irá enviar um sinal de veto para as LU ${ }^{[13]}-1$ (circuito 8) e LU-2 (circuito 7). Estes sinais de veto irão bloquear qualquer tipo de evento, incluindo raios $\gamma$, enquanto o sinal de BUSY estiver ativo.

O módulo AND 3 tem a função de controlar as entradas de clear dos módulos QDCA e QDCW. Uma de suas entradas vem do módulo AND 1, passando por um GG com largura de pulso mínima, mas com atraso suficiente para que o circuito 7 tenha tempo de enviar um sinal lógico, indicando se um evento válido foi adquirido. Como o sinal que vem do circuito 7 é invertido, ele funciona como um veto, ou seja, se um evento válido foi adquirido, o módulo AND 3 é vetado e portanto os sinais de clear não são enviados para os módulos QDCA e QDCW. O módulo LOG FI/FO 2 tem a função apenas de duplicar o sinal lógico na sua entrada.

\footnotetext{
${ }^{13}$ Módulo LU, Logic Unit: Um módulo com entradas e saídas lógicas que pode executar as seguintes operações lógicas de acordo com o que foi configurado: OR, AND multiplicidade 2 (ou seja, sempre que pelo menos 2 entradas forem coincidentes a saída é ativada), AND multiplicidade 3 e AND multiplicidade 4.
} 


\subsubsection{Circuito 7: Circuito de coincidência atrasada $\gamma$-partícula}

A função do circuito de coincidência atrasada $\gamma$-partícula é centralizar as informações de tempo dos detectores de raios $\gamma$ do SISMEI e dos detectores de partículas do SACI e com isso gerar um sinal quanto houver uma coincidência atrasada entre um raio $\gamma$ no SISMEI e uma partícula no SACI. O diagrama deste circuito é visto na Figura 2.12.

\section{circuito 7}

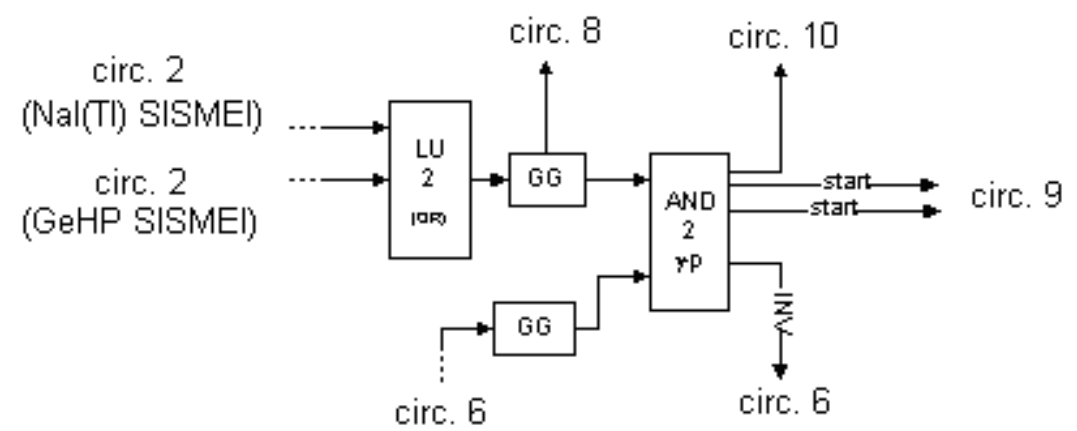

Figura 2.12: Circuito de coincidência atrasada $\gamma$-partícula

Os sinais de tempo dos raios $\gamma$ dos circuitos 2 dos detectores $\mathrm{NaI}(\mathrm{Tl})$ e GeHP (ambos do SISMEI) são as entradas do módulo LU-2, que está configurada com lógica OR. Com isso, haverá um sinal lógico na saída deste módulo quando um raio $\gamma$ foi detectado no SISMEI. Essa informação é enviada para um GG, configurado com atraso mínimo e largura de pulso de $2 \mu$ s. A largura desse pulso é muito importante, pois define o intervalo de tempo total do espectro de tempo que será adquirido, ou seja, nos experimentos realizados o intervalo de tempo que pode ser medido é de até $2 \mu$ s. O sinal de saída deste GG é enviado para o circuito 8 e para o módulo AND 2.

O módulo AND 2 também recebe o sinal de um GG, cuja entrada é o pulso de tempo das partículas, vinda do circuito 6. Este GG está configurado com largura de pulso mínima e atraso de 1,5 $\boldsymbol{\mu s}$. Com isso, o módulo AND 2 irá indicar uma coincidência atrasada entre um raio $\gamma$ detectado no SISMEI e uma partícula, desde que o raio $\gamma$ não esteja mais do que $0,5 \mu \mathrm{s}$ 
adiantado ou 1,5 $\mu$ s atrasado em relação à partícula. Um diagrama dos pulsos de entrada (raio $\gamma$ e partícula) e saída do módulo AND 2 para a condição em que raio $\gamma$ e partícula são detectados simultaneamente é visto na Figura 2.13.

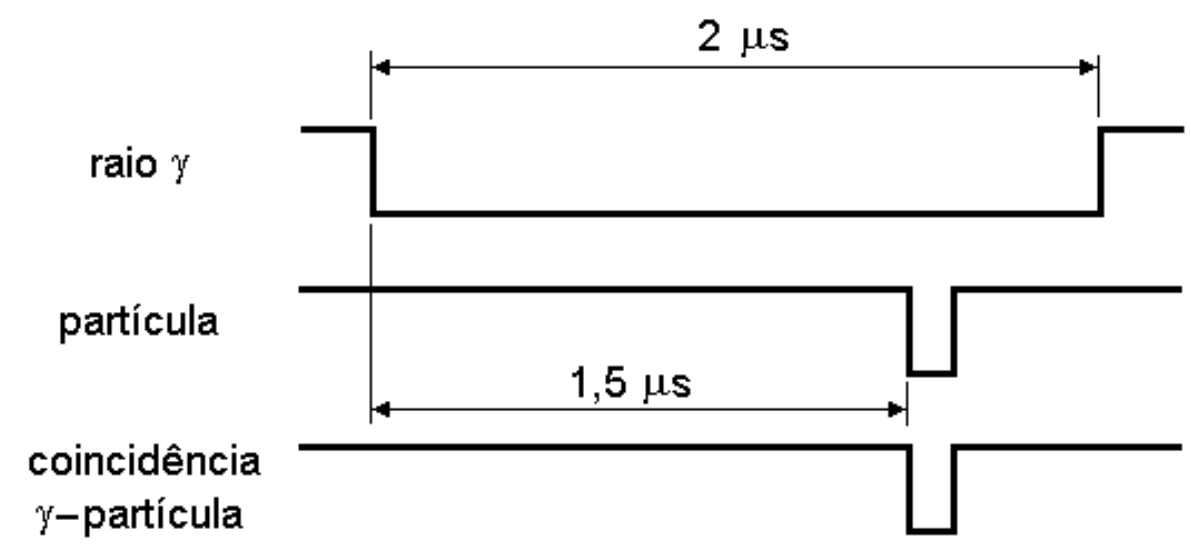

Figura 2.13: Diagrama dos pulsos lógicos de entrada (raio $\gamma$ e partícula) e saída do módulo AND 2 (coincidência $\gamma$-partícula) para a condição em que raio $\gamma$ e partícula são detectados simultaneamente.

Com essas configurações dos dois módulos GG, espera-se que o pico de coincidência instantânea (prompt) esteja na posição de $0,5 \mu$ s do espectro de tempo, o que permite que se meçam decaimentos ocorridos com até $1,5 \mu$ s de atraso.Isso possibilita a medida de estados isoméricos com vidas médias de até alguns microsegundos.

A informação de coincidência $\gamma$-partícula é então enviada para os circuitos 9 e 10. Essa mesma informação, só que invertida, é enviada também para o circuito 6.

\subsubsection{Circuito 8: Circuito de coincidência atrasada $\gamma-\gamma$}

O circuito de coincidência atrasada $\gamma-\gamma$ é similar ao circuito 7 , porém ao invés do sinal de tempo dos detectores de partículas do SACI é utilizado o sinal de tempo do detector de raios $\gamma$ de GeHP, posicionado no SACI. Este circuito é visto na Figura 2.14. 


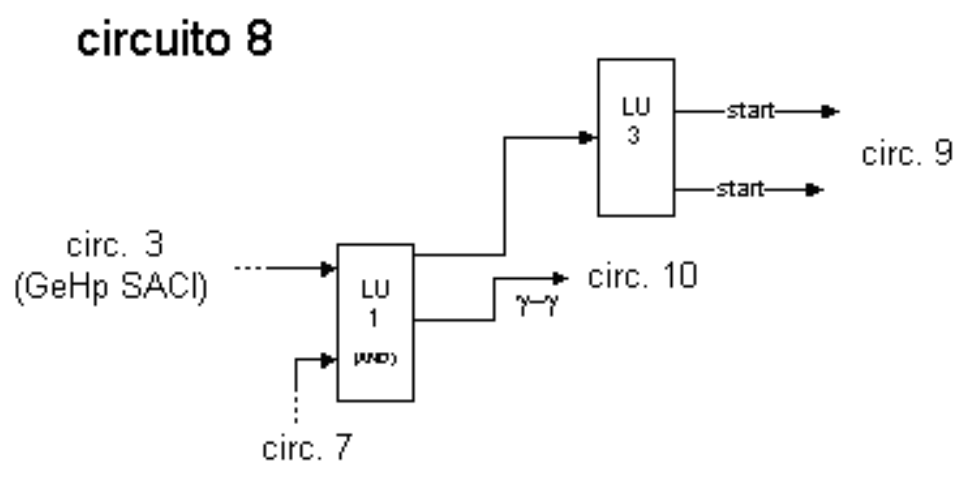

Figura 2.14: Circuito de coincidência atrasada $\gamma-\gamma$

A informação de tempo do detector de raios $\gamma$ do SACI (circuito 3) é enviada ao módulo LU-1, configurado como AND multiplicidade 2, juntamente com a informação de tempo de um dos dois detectores de raios $\gamma$ do SISMEI. Assim, a saída do módulo LU-1 corresponde à informação de coincidência atrasada $\gamma-\gamma$. Convém mencionar que os atrasos explicados no circuito 7 já foram implementados no circuito 3 e no próprio circuito 7.

A informação de coincidência atrasada $\gamma-\gamma$ é então enviada para o circuito 10 e para um módulo LU-3. Este módulo tem a função apenas de duplicar o sinal lógico. Essas duas saídas são enviadas para o circuito 9 .

\subsubsection{Circuito 9: Circuito de medida de tempo de decaimento}

O objetivo do circuito de medida de tempo de decaimento é adquirir a informação da diferença em tempo entre a partícula ou raio $\gamma$, adquiridos no detector próximo ao SACI, e o raio $\gamma$ adquirido em um dos detectores do SISMEI. O diagrama do circuito 9 é visto na Figura 2.15 . 


\section{circuito 9}

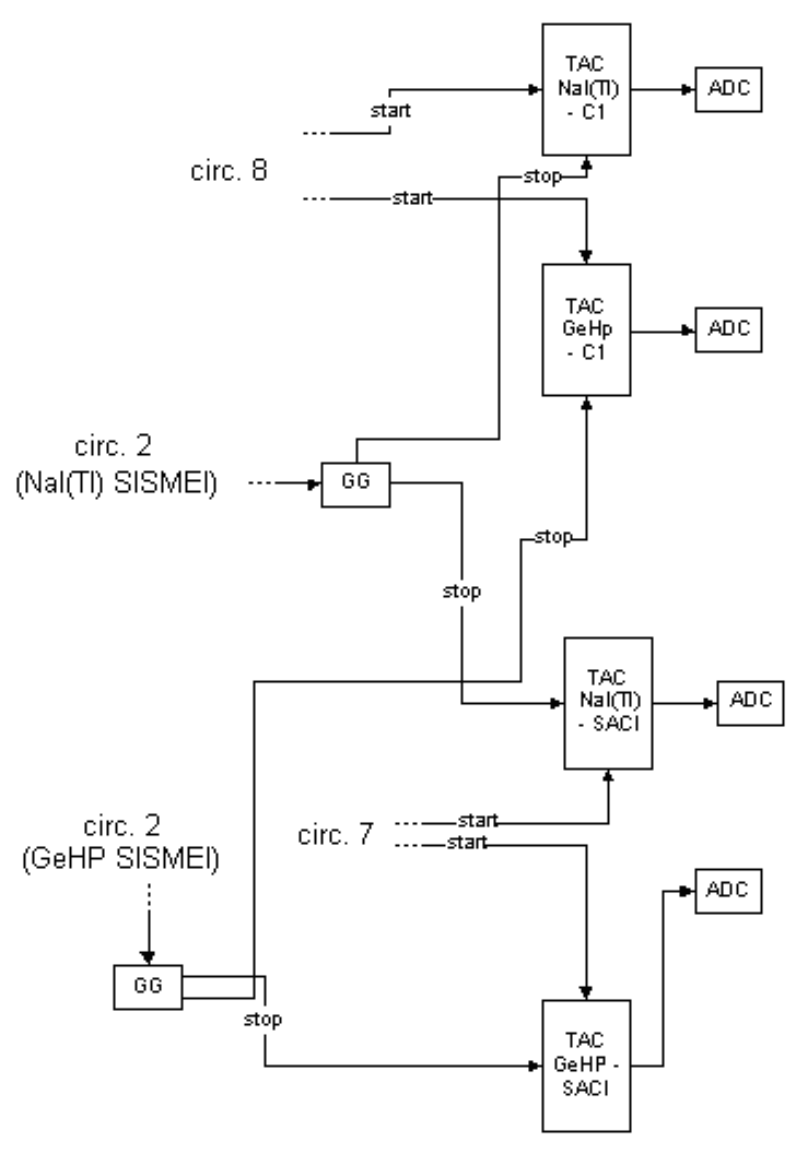

Figura 2.15: Circuito de medida de tempo de decaimento.

Para cumprir seu objetivo este circuito utiliza 4 módulos $\mathrm{TAC}^{[14]}$ para medir a diferença em tempo entre os seguintes eventos:

- Partícula detectada nos detectores do SACI e raio $\gamma$ detectado no detector de GeHP localizado no SISMEI;

- Partícula detectada nos detectores do SACI e raio $\gamma$ detectado no detector de $\mathrm{NaI}(\mathrm{Tl})$ localizado no SISMEI;

\footnotetext{
${ }^{14}$ Módulo TAC, Time to Pulse Height Converter: Módulo que converte a diferença em tempo entre as entradas lógicas start e o stop em amplitude de um pulso analógico de saída. Estes módulos são mais versáteis que os TDC pois possibilitam um maior ajuste da escala de tempo. No entanto precisam de um módulo CAMAC ADC para converter a amplitude do pulso de saída em informação digital.
} 
- Raio $\gamma$ detectado no detector de GeHP localizado no SACI e raio $\gamma$ detectado no detector de GeHP localizado no SISMEI;

- Raio $\gamma$ detectado no detector de GeHP localizado no SACI e raio $\gamma$ detectado no detector de $\mathrm{NaI}(\mathrm{Tl})$ localizado no SISMEI;

Os sinais do inicio da contagem de tempo (START) destes 4 módulos TAC são os sinais de coincidência atrasada $\gamma$-partícula e $\gamma-\gamma$, obtidos diretamente dos circuitos 7 e 8 . Estes sinais estão relacionados temporalmente com o tempo das partículas (vide diagrama da Figura 2.13) ou com o tempo do raio $\gamma$ do detector de GeHP do SACI. Os sinais correspondentes ao final das contagens de tempo (STOP) são obtidos dos circuitos 2 dos detectores de raios $\gamma$ do SISMEI. Estes sinais entram em módulos GG, configurados para largura de pulso mínima e atraso de $2 \mu \mathrm{s}$. Como os sinais de START estão atrasados 1,5 $\mu \mathrm{s}$, o resultado é que, quando uma partícula, por exemplo, é detectada simultaneamente a um raio $\gamma$ no SISMEI o sinal de STOP estará 500 ns atrasado em relação ao de START. Os sinais de START e STOP de entrada dos módulos TAC são representados no diagrama da Figura 2.16 para a condição em que a partícula, por exemplo, foi detectada simultaneamente ao raio $\gamma$ do SISMEI.

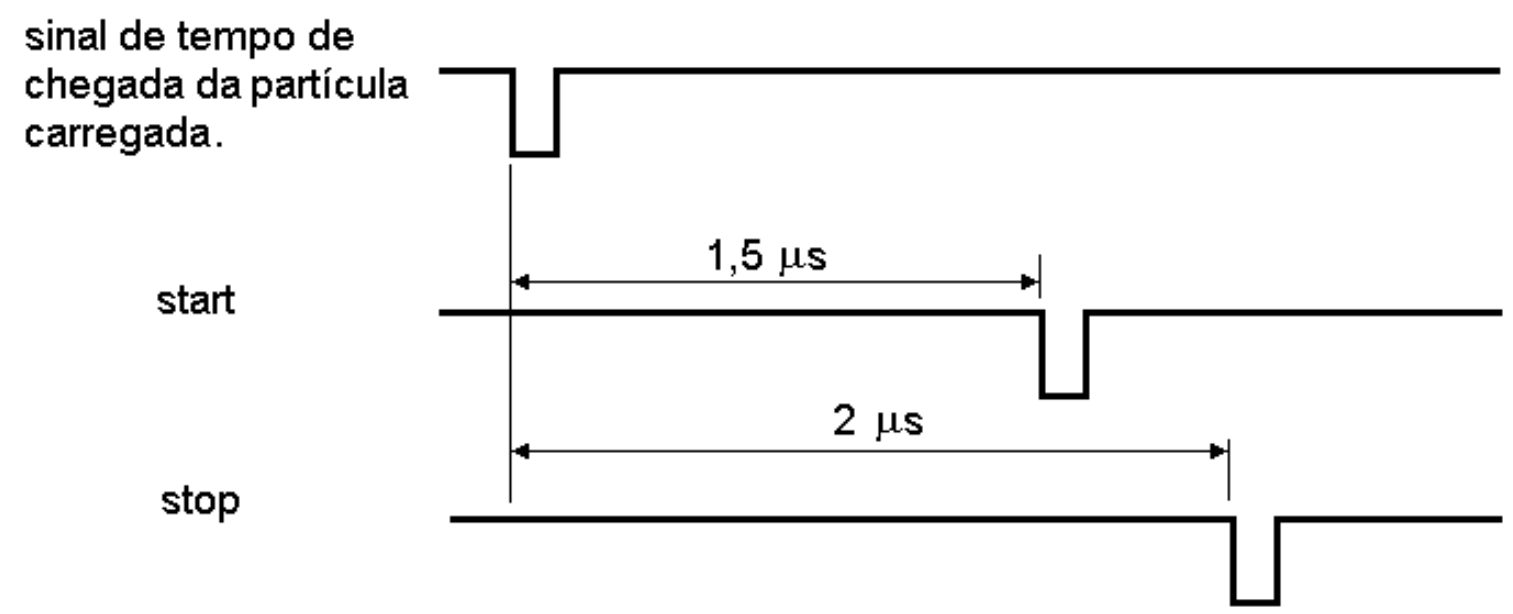

Figura 2.16: Sinais de START e STOP dos módulos TAC para a condição em que a partícula, por exemplo, foi detectada simultaneamente ao raio $\gamma$ do SISMEI. 
Por fim, cada módulo TAC está ligado a um ADC para que a diferença em tempo entre os sinais de $S T A R T$ e $S T O P$ seja convertida em informação digital.

\subsubsection{Circuito 10: Circuito de controle de eventos}

O objetivo do circuito de controle de eventos é produzir um sinal lógico que leva a informação que um evento válido está sendo adquirido. O diagrama deste circuito é visto na Figura 2.17.

\section{circuito 10}
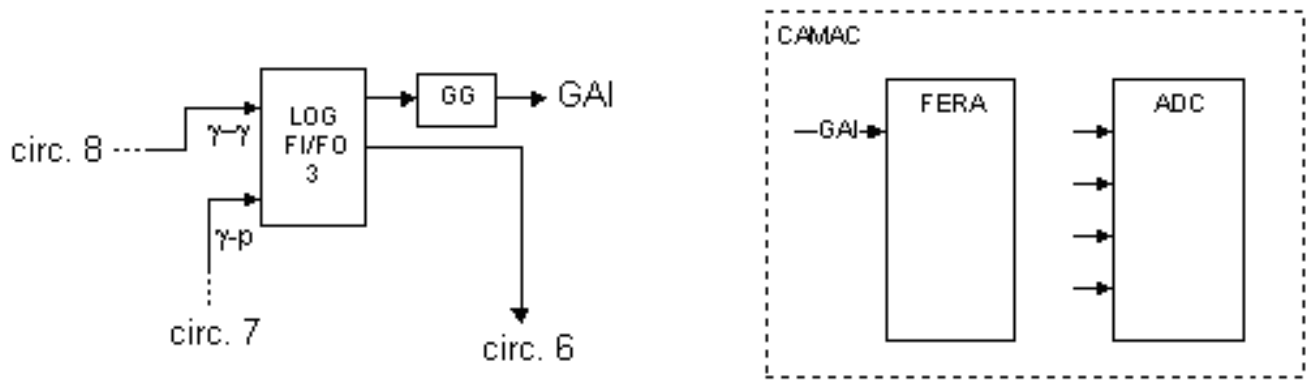

Figura 2.17: Circuito de controle de eventos.

Neste circuito o módulo LOG FI/FO 3 tem como entradas as informações de coincidência atrasada $\gamma$-partícula e $\gamma-\gamma$, vindas dos circuitos 7 e 8 . Como este módulo executa uma operação lógica OR, o resultado é que nas suas saídas têm-se a informação de que alguma das duas coincidências atrasadas ocorreu e isso significa que se trata de um evento válido. O sinal com a informação de evento válido é enviado para o circuito 6 , onde irá gerar o sinal de BUSY. Esse sinal também é enviado para um módulo GG onde o pulso é atrasado e alargado de modo que este tenha um tempo de duração longo $(\approx 400 \mathrm{~ns})$ suficiente para englobar todos os pulsos analógicos de entrada dos ADC. Este pulso é então enviado para a entrada GAI do Módulo CAMAC FERA ${ }^{[15]}$ indicando a chegada de um evento válido. É

\footnotetext{
${ }^{15}$ Módulo CAMAC FERA, FERA Driver: Módulo CAMAC específico para o controle das funções dos módulos de ADC, como master gate (entrada GAI), clear entre outros.
} 
nesse intervalo de tempo que todos os ADCs convertem os pulsos analógicos em informação digital.

\subsubsection{Eletrônica modular completa do SISMEI}

O diagrama da Figura 2.18 apresenta o diagrama completo da eletrônica modular do SISMEI, incluindo os módulos CAMAC e as interconexões internas de cada circuito. Neste diagrama os tipos de circuitos estão destacados por cores. 

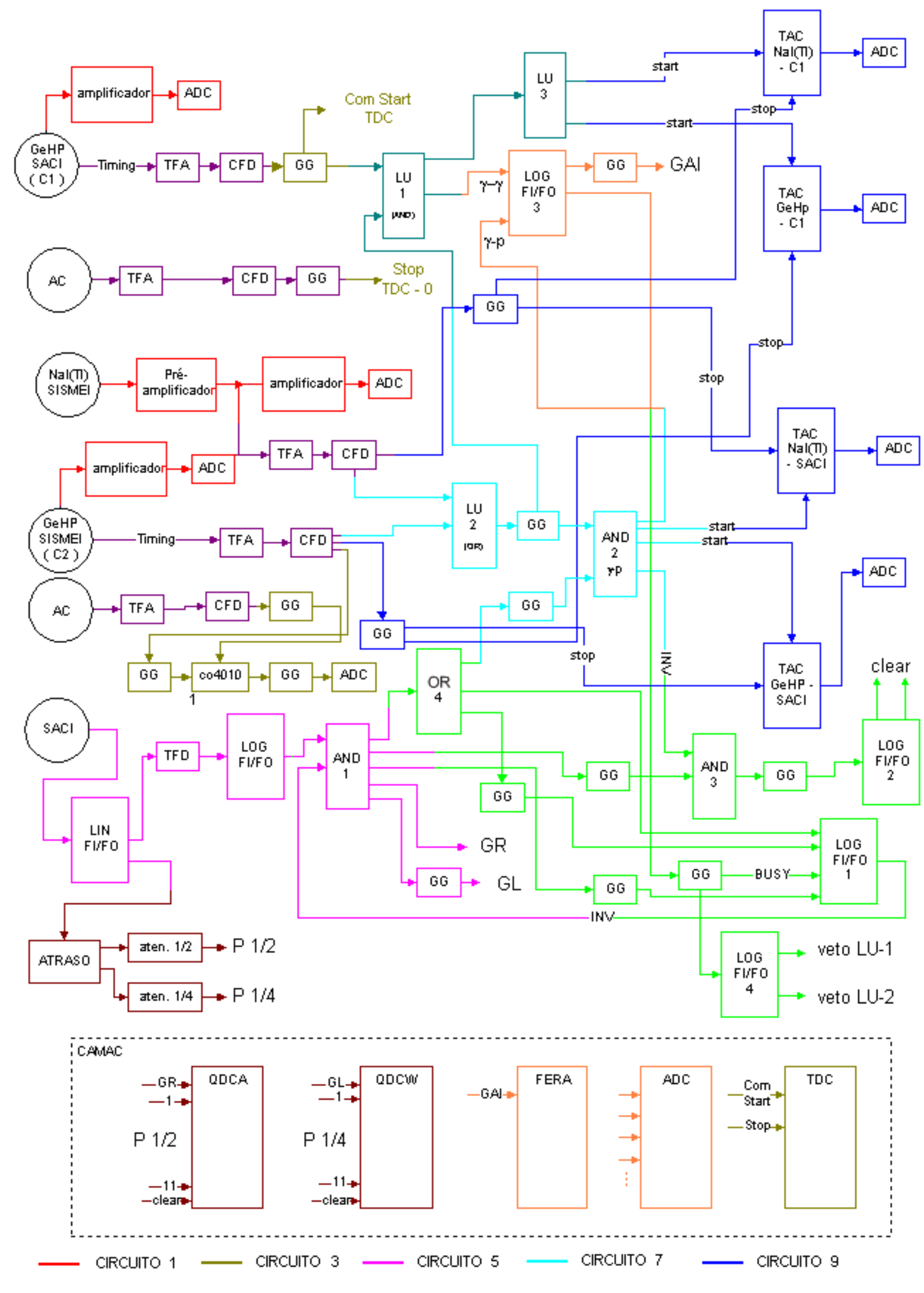

CIRCUITO $2-$ CIRCUITO $4-$ CIRCUITO $6-$ CIRCUITO $8-$ CIRCUITO 10

Figura 2.18: Diagrama completo da eletrônica modular do SISMEI. 


\subsection{CONTROLE E AQUISIÇÃO DE DADOS}

O sistema SPM-linux (RIBAS, 2002) do laboratório Pelletron é responsável por controlar a aquisição dos dados através do CAMAC e armazenar os eventos em disco. O sistema SPM-linux obtém as informações para controlar o CAMAC de um arquivo de instruções no qual constam as posições dos módulos que fornecerão as informações de interesse (ADCs, QDCs, etc.), a ordem de aquisição destas informações e quais as condições para sua aquisição. Os eventos são armazenados em modo fila para que os dados possam ser analisados após a experiência. O sistema de aquisição de dados permite também o acompanhamento do experimento através dos espectros de energia e tempo dos detectores, histogramados durante a aquisição de dados. 


\section{EXPERIÊNCIAS REALIZADAS E RESULTADOS OBTIDOS}

Para o teste do SISMEI foram realizadas duas experiências utilizando a canalização 30A do acelerador de Pelletron (8UD tipo tandem), pertencente ao Laboratório Aberto de Física Nuclear (LAFN) do Instituto de Física da Universidade de São Paulo. Os eventos foram armazenados em intervalos de aproximadamente 2 horas (runs) para facilitar a sua análise. Os dados foram analisados utilizando o software DAMM (MILNER, 1987).

\subsection{A EXPERIÊNCIA ${ }^{46} \mathrm{Ti}\left({ }^{11} \mathrm{~B}, 1 \mathrm{p} 2 \mathrm{n}\right){ }^{54} \mathrm{Fe}, \mathrm{E}_{\mathrm{F}}=30 \mathrm{MeV}$}

O primeiro teste do SISMEI foi realizado através da reação de fusão evaporação ${ }^{11} \mathrm{~B}+{ }^{46} \mathrm{Ti}, \mathrm{E}_{\mathrm{F}}=30 \mathrm{MeV}$, utilizando um alvo de ${ }^{46} \mathrm{Ti}$ enriquecido com $1,1(1) \mathrm{mg} / \mathrm{cm}^{2}$ de espessura. As seções de choque previstas pelo programa PACE (GAVRON, 1980) para esta reação podem ser observadas na Figura 3.1.

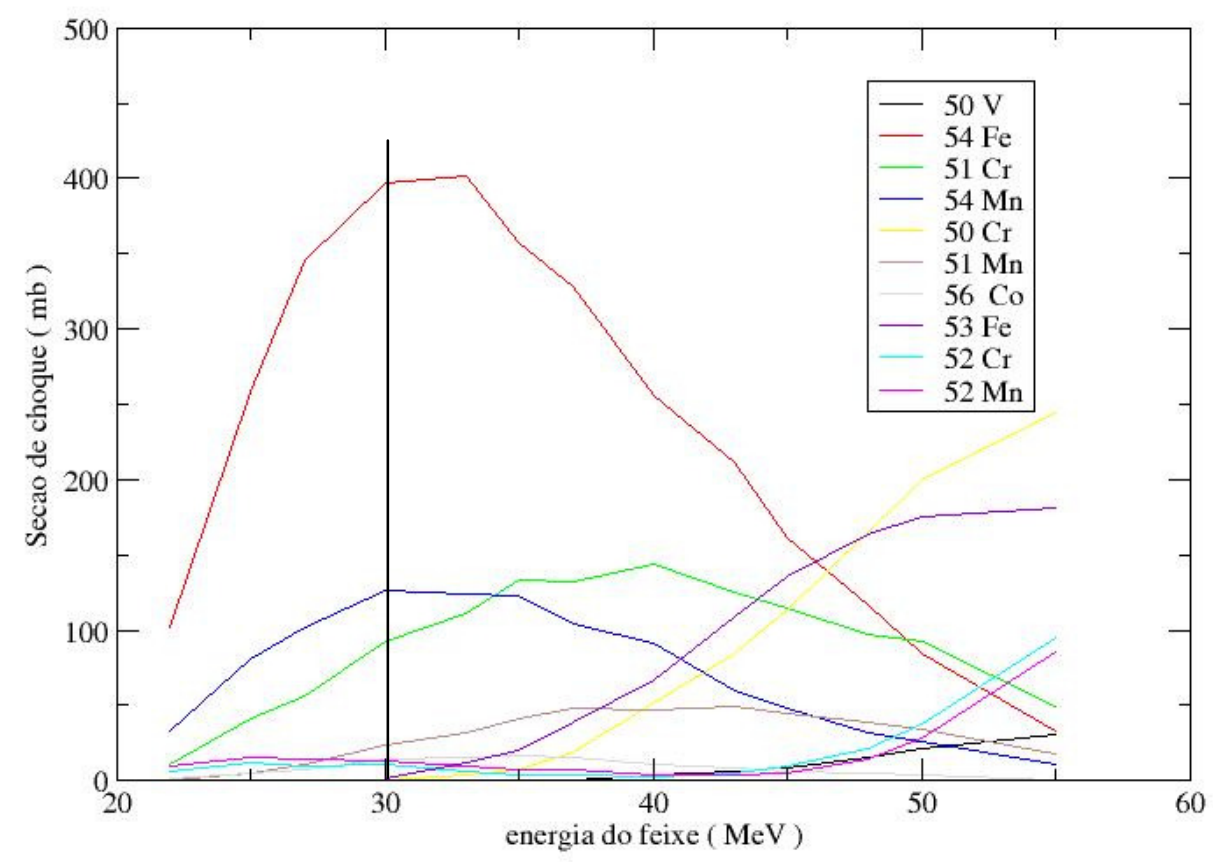

Figura 3.1: Seções de choque previstas para a experiência ${ }^{11} \mathrm{~B}+{ }^{46} \mathrm{Ti}$, utilizada para testar o SISMEI. A energia utilizada na experiência está marcada com uma barra vertical. 
Observa-se, pela Figura 3.1, que o canal ${ }^{54} \mathrm{Fe}$ é previsto como sendo o mais intenso desta reação $(\sigma \approx 400 \mathrm{mb})$. Este núcleo possui o estado isomérico $10^{+}\left(\mathrm{E}_{\mathrm{L}}=6526 \mathrm{keV}\right)$, com meia vida de $T_{1 / 2}=364(7)$ ns (DAFNI, 1978), valor apropriado para o teste do sistema. Além disso, o estado $10^{+}$decai através de uma cascata de 6 raios $\gamma$ com diferentes energias, o que facilita a sua detecção e análise dos dados. O esquema de nível conhecido do ${ }^{54} \mathrm{Fe}$ é mostrado na Figura 3.2, o estado isomérico $10^{+}$é evidenciado na parte inferior à direita.

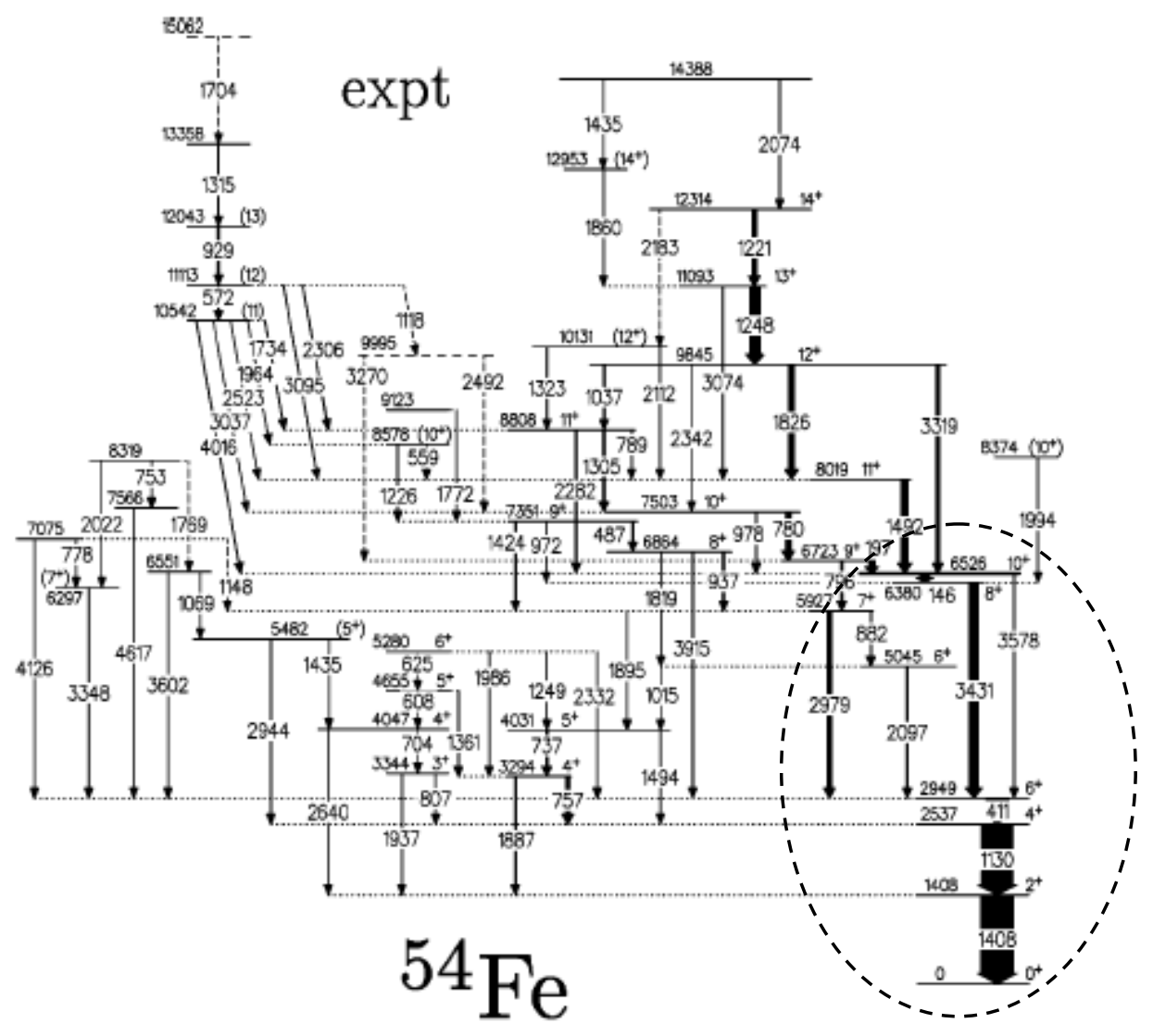

Figura 3.2: Esquema de níveis conhecido do ${ }^{54} \mathrm{Fe}$ (RUDOLPH, 1999), o estado isomérico $10^{+}\left(\mathrm{E}_{\mathrm{L}}=6526 \mathrm{keV}\right.$, $\left.\mathrm{T}_{1 / 2}=364(7) \mathrm{ns}\right)$ se encontra destacado à direita.

Nesta experiência utilizou-se uma eletrônica um pouco diferente do que a descrita no capítulo 2, pois não havia o detector de GeHP posicionado no SACI, com isso o circuito 8 não foi necessário assim como algumas partes dos circuitos 1,9 e 10 . Neste experimento, o supressor Compton do detector de GeHP, posicionado no SISMEI, estava desligado, por isso o circuito 3 também não foi utilizado. A Figura 3.3 mostra o diagrama em blocos funcionais da eletrônica utilizada nesta experiência. Outro fato importante é que durante esta experiência 
não foram coletadas as informações de tempo dos raios gama dos dois detectores, com a exceção de quando os dois estavam em coincidência $\gamma$ - $\gamma$. Com isso, a análise em tempo dos dados adquiridos no modo simples (single) não pôde ser realizada.

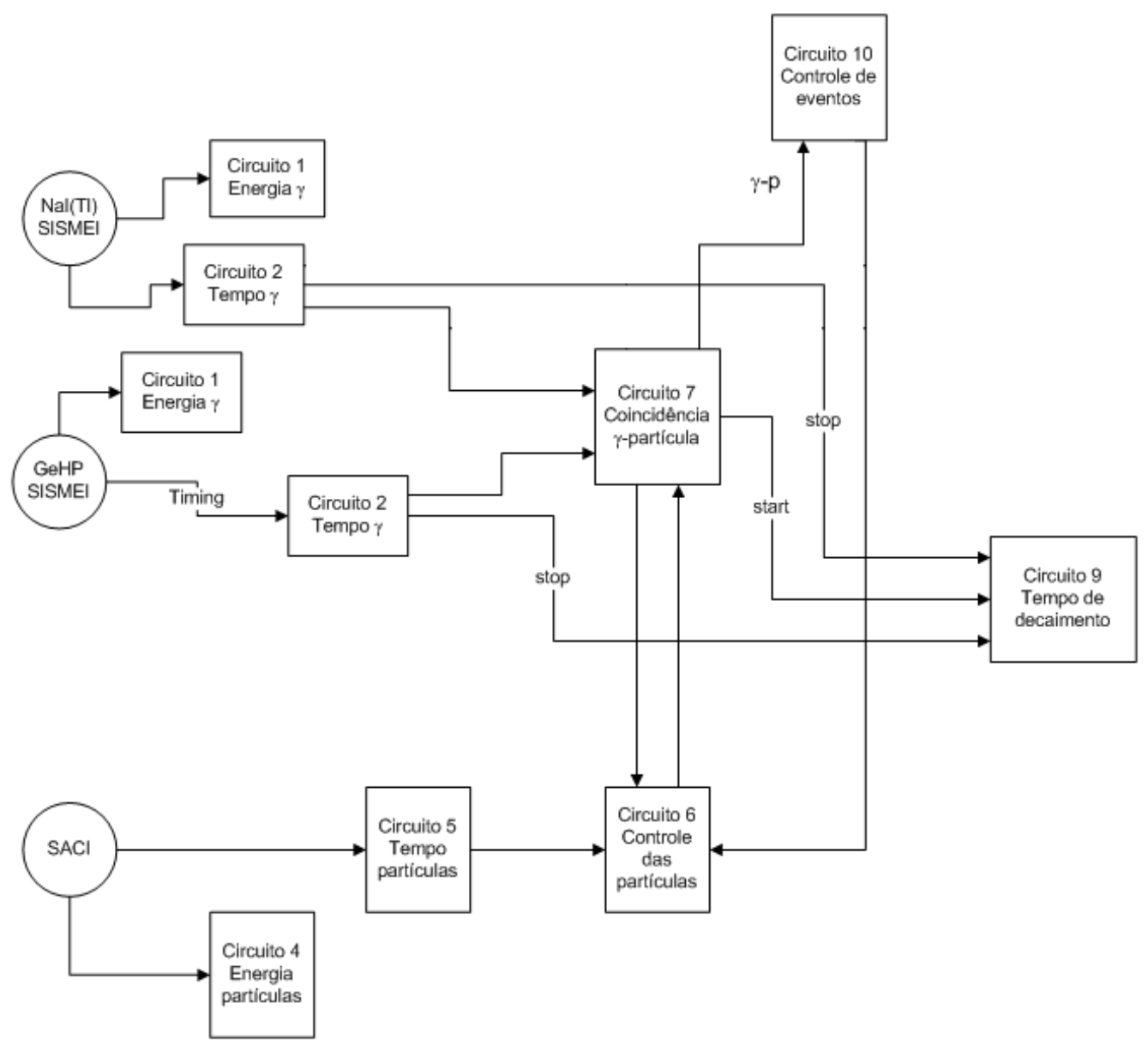

Figura 3.3: Diagrama em blocos funcionais da eletrônica modular utilizada na primeira experiência de teste do SISMEI

\subsubsection{Redução e Análise dos Dados}

O primeiro passo para a redução dos dados consistiu em comparar os espectros de energia e tempo de cada run, para verificar se seria necessário calibrar os eventos em energia e em tempo antes de somar todos os eventos coletados na experiência. Esta verificação demonstrou que não era necessária uma recalibração dos eventos, pois em todos os runs os picos de raios $\gamma$ estavam centrados nos mesmos canais e os picos dos espectros de tempo também estavam centrados nos mesmos canais. Este fato já era esperado, pois a experiência 
foi curta o suficiente para não sofrer com alterações significativas na eletrônica, uma vez que o tempo efetivo de tomada de dados foi de aproximadamente 10 horas.

O passo seguinte foi encontrar as curvas de calibração em tempo e energia para os dois detectores de raios $\gamma$. Para a calibração em tempo, utilizou-se um espectro adquirido ao final da experiência com picos de tempo adquiridos através de uma fonte de ${ }^{152} \mathrm{Eu}$ e um módulo GG calibrado com um osciloscópio para vários atrasos distintos, cobrindo uma faixa de $300 \mathrm{a}$ 1000 ns. Para a calibração do espectro de raios $\gamma$ em energia, realizou-se uma calibração interna através das principais transições do ${ }^{54} \mathrm{Fe}\left(\mathrm{E}_{\gamma}=146,2(2) \mathrm{keV}, 411,4(5) \mathrm{keV}\right.$, $1129,9(3) \mathrm{keV}, 1408,1(2) \mathrm{keV}$ e $3432,0(18) \mathrm{keV}$ ) para os dois detectores de raios gama. Os gráficos de calibração em energia e tempo para o detector de raios $\gamma$ de GeHP são vistos na Figura 3.4.
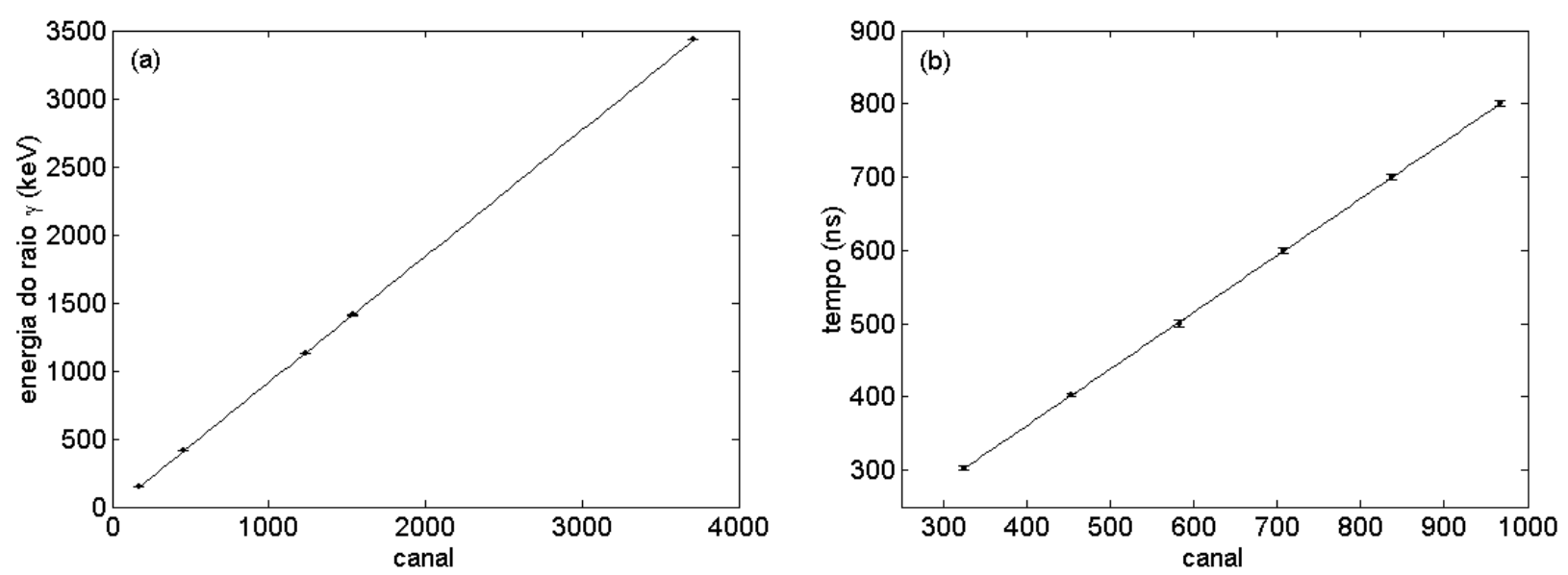

Figura 3.4: Curvas de calibração em energia (a) utilizando as principais transições do ${ }^{54} \mathrm{Fe}\left(\mathrm{E}_{\gamma}=146,2(2) \mathrm{keV}\right.$, $411,4(5) \mathrm{keV}, 1129,9(3) \mathrm{keV}, 1408,1(2) \mathrm{keV}$ e 3432,0(18) keV) e em tempo (b) utilizando um módulo GG calibrado com um osciloscópio para vários atrasos distintos.

O histograma referente à diferença em tempo entre a coleta da partícula carregada nos detectores do SACI e o instante de chegada do raio $\gamma$ no detector de GeHP é visto na Figura 3.5(a). Na Figura 3.5(b) é apresentado o espectro de raios $\gamma$ adquirido pelo detector de GeHP. Neste espectro estão evidenciados os picos correspondentes aos raios $\gamma$ de 146, 411, 1130, 
1408 e $3432 \mathrm{keV}$ pertencentes à cascata de raios $\gamma$ que depopulam os estados abaixo do estado isomérico $10^{+}$do ${ }^{54} \mathrm{Fe}$ (vide Figura 3.2).
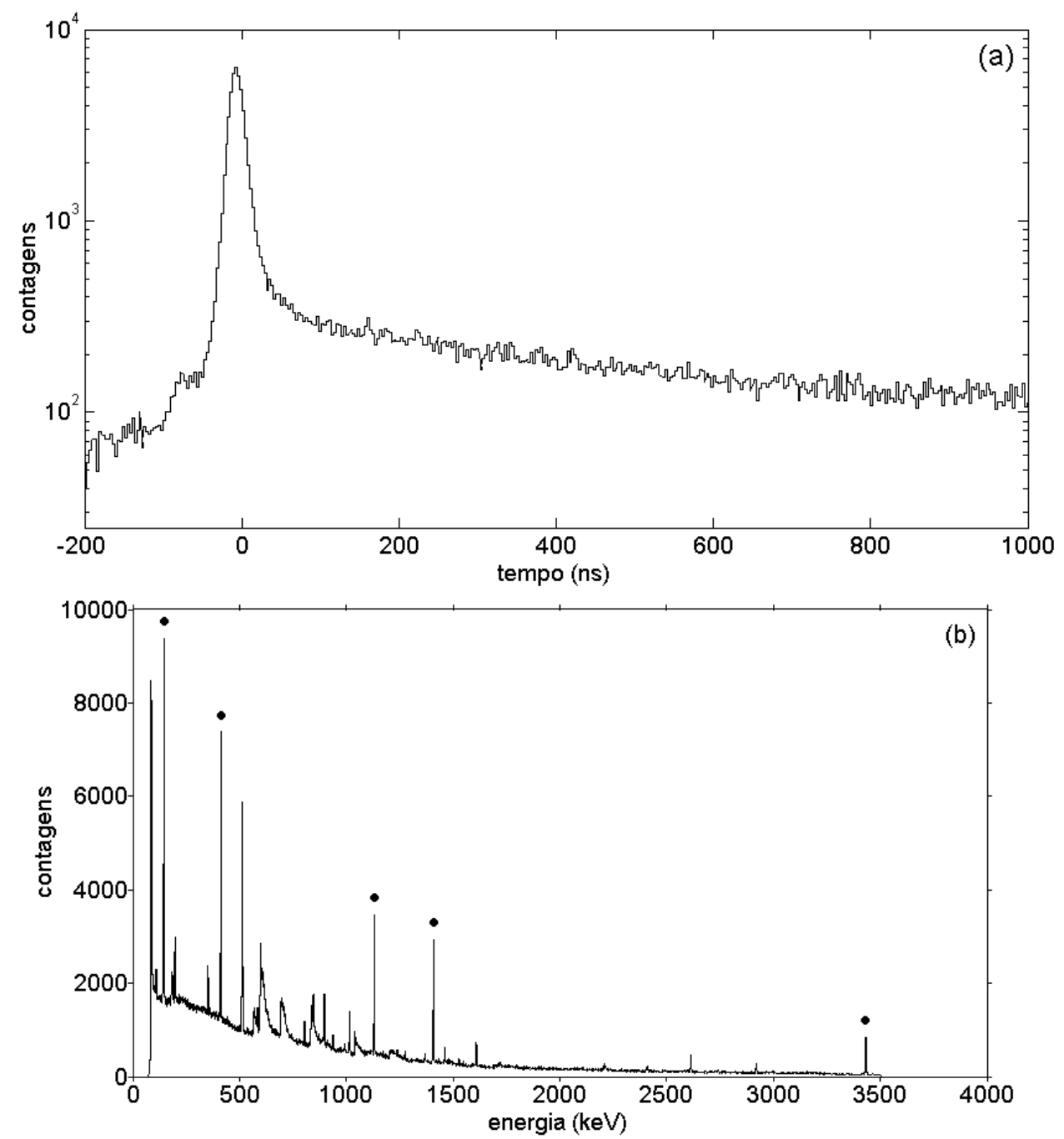

Figura 3.5: Histograma referente a diferença em tempo entre a coleta da partícula carregada nos detectores do SACI e o instante de chegada do raio $\gamma$ no detector de GeHP (a). E espectro de raios $\gamma$ adquirido pelo detector de GeHP (b). O picos marcados com um ponto indicam transições pertencentes ao ${ }^{54} \mathrm{Fe}$ que depopulam o estado isomérico $10^{+}$, vide Figura 3.2.

Na figura 3.4(a) observa-se um pico de contagens em torno de 120 ns, este pico contém os raios $\gamma$ em coincidência $\gamma$-p instantânea (prompt). Neste espectro pode-se observar também que os dados apresentam uma forma de decaimento exponencial a partir de $150 \mathrm{~ns}$, essa região do espectro contém os raios $\gamma$ em coincidência $\gamma$-p atrasada (delay). 
A etapa seguinte da redução dos dados foi construir histogramas biparamétricos (matrizes) $\gamma$-tempo apenas para os eventos com coincidência $\gamma$ - $\gamma$ para os dois detectores de raios $\gamma$. A matriz $\gamma$-tempo do detector de GeHP é vista na Figura 3.6. Nesta matriz a energia do raio $\gamma$ é representada no eixo $\mathrm{x}$, o tempo de detecção do raio $\gamma$ no eixo y e o número de contagens é representado pelo tom de cinza de cada ponto.

Nas matrizes $\gamma$-tempo dos dois detectores é possível identificar claramente as transições que estão abaixo do estado isomérico $10^{+}$, por apresentarem uma vida média longa e conseqüentemente estarem associadas à região de tempos após o pico de prompt. Pode-se observar que estas transições formam linhas verticais na matriz $\gamma$-tempo.

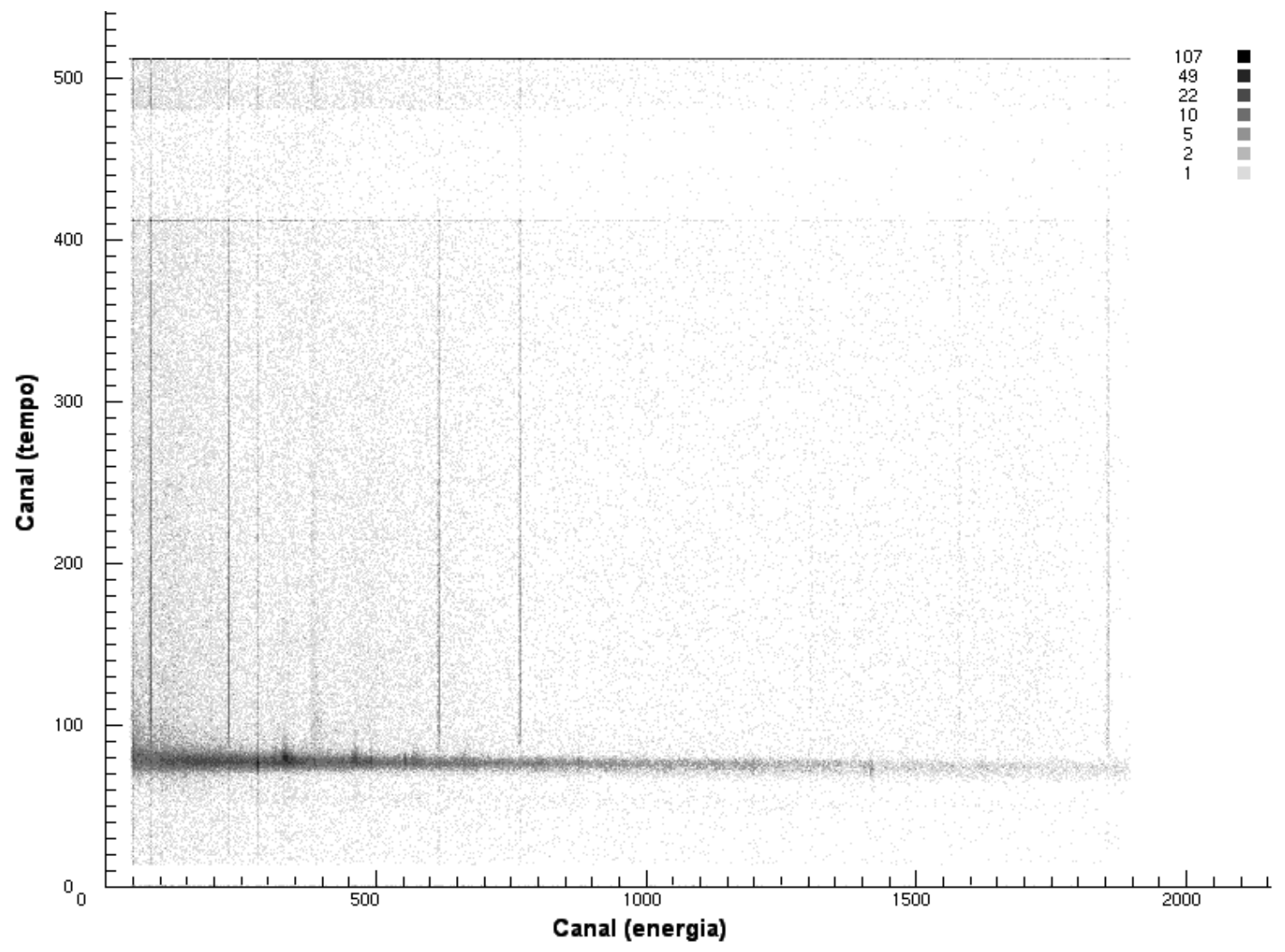

Figura 3.6:Matriz $\gamma$-tempo do detector de GeHP obtida em coinidência $\gamma$ - $\gamma$ com o detector de NaI(Tl). Nesta matriz os raios gama que depopulam os estados abaixo do estado isomérico $10^{+}$, vide Figura 3.2, podem ser facilmente identificados como linhas verticais. 
A partir das matrizes $\gamma$-tempo selecionou-se os raios $\gamma$ em coincidência $\gamma$-p instantânea (prompt) e em coincidência $\gamma$-p atrasada (delay). Os espectros resultantes, já calibrados em energia, são vistos na Figura 3.7.

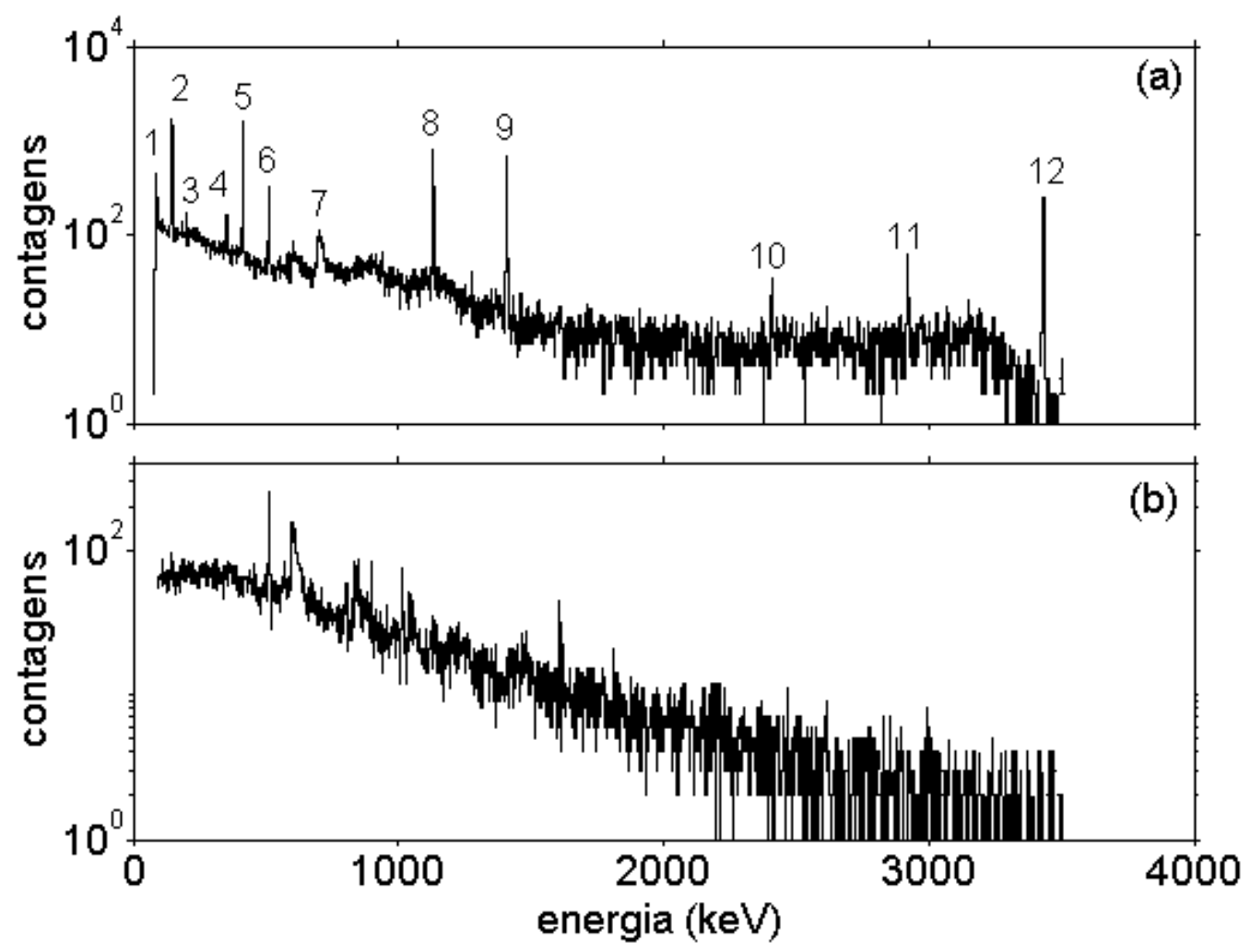

Figura 3.7: Espectros de raios $\gamma$ do detector GeHP em coincidência $\gamma$-p atrasada, delay, (a) e em coincidência $\gamma$-p instantânea, prompt, (b). Nota-se que as transições abaixo do estado isomérico $10^{+}$são observadas apenas no espectro delay, mostrando assim que o sistema é capaz de identificar transições ligadas a estados isoméricos. Os picos identificados no espectro delay foram numerados e estão descritos na Tabela 3.1.

No espectro em coincidência $\gamma$-p atrasada, (a) da Figura 3.7, é possível observar as transições que estão abaixo do estado isomérico $10^{+}$do núcleo ${ }^{54} \mathrm{Fe}$, cujo esquema de níveis conhecido é visto na Figura 3.2. Nota-se que estas transições não são vistas no espectro em coincidência $\gamma$-p instantânea, (b) da Figura 3.7, demonstrando assim que o sistema SISMEI possibilita a identificação de transições ligadas a estados isoméricos. Isso ocorre, pois no intervalo de tempo do pico de prompt o núcleo residual encontra-se em vôo, próximo ao alvo, e, portanto a grande maioria dos raios $\gamma$ emitidos é atenuada pela blindagem de chumbo. 
Através de uma análise cuidadosa do espectro de raios $\gamma$ em coincidência $\gamma$-p atrasada, a origem dos picos observados foi identificada. O número dos picos no espectro (a) da Figura 3.7, energia, área, largura a meia altura (FWHM) e origem destes picos são apresentado na Tabela 3.1, as incertezas apresentadas para as áreas estão relacionadas com a raiz quadrada do número de contagens e com a subtração do fundo. O pico de raios $\gamma$ originário do ${ }^{21} \mathrm{Ne}$ pode ser visto no espectro em coincidência $\gamma-p$ atrasada uma vez que tal núcleo pode ser produzido por processos de decaimento $\beta^{-}$, com vidas médias da ordem de segundos, de outros núcleos produzidos na reação do feixe de ${ }^{11} \mathrm{~B}$ com contaminantes no alvo.

\begin{tabular}{|c|c|c|c|c|}
\hline $\begin{array}{l}\text { Número } \\
\text { do pico }\end{array}$ & $\begin{array}{c}\text { energia } \\
\text { (keV) }\end{array}$ & área & $\begin{array}{c}\text { FWHM } \\
\text { (keV) }\end{array}$ & Origem \\
\hline 1 & $86,4(6)$ & $1097(30)$ & 2,5 & Raio $\mathrm{X}(\mathrm{k} \alpha)$ proveniente do chumbo \\
\hline 2 & $146,3(6)$ & $3451(60)$ & 1,9 & ${ }^{54} \mathrm{Fe}$ \\
\hline 3 & $197,9(6)$ & $111(15)$ & 1,3 & ${ }^{19} \mathrm{~F}$ \\
\hline 4 & $351,2(7)$ & $157(17)$ & 1,8 & ${ }^{21} \mathrm{Ne}$ \\
\hline 5 & $412,2(7)$ & $2555(52)$ & 1,7 & ${ }^{54} \mathrm{Fe}$ \\
\hline 6 & $511,8(7)$ & $617(26)$ & 2,1 & $\mathrm{~B}^{+}$(Produção de Pares) \\
\hline 7 & $704,5(9)$ & $659(27)$ & 9,6 & Reação (n,n') no interior do detector \\
\hline 8 & $1130,2(11)$ & $1485(39)$ & 1,8 & ${ }^{54} \mathrm{Fe}$ \\
\hline 9 & $1407,9(13)$ & $1371(38)$ & 2,2 & ${ }^{54} \mathrm{Fe}$ \\
\hline 10 & $2407,8(24)$ & $83(9)$ & 2,8 & $\begin{array}{c}2^{\circ} \text { escape do pico de raios } \gamma \text { de } 3434 \\
\mathrm{keV} .\end{array}$ \\
\hline 11 & $2919,6(31)$ & $165(13)$ & 3,1 & $\begin{array}{c}1^{\circ} \text { escape do pico de raios } \gamma \text { de } 3434 \\
\mathrm{keV} .\end{array}$ \\
\hline 12 & $3434,2(39)$ & $666(27)$ & 3,7 & ${ }^{54} \mathrm{Fe}$ \\
\hline
\end{tabular}

Tabela 3.1: Principais transições identificadas no espectro em coincidência $\gamma$-p atrasada do detector de GeHP, visto na Figura 3.7.

A fim de medir a meia vida relacionada a uma determinada transição, retorna-se à matriz $\gamma$-tempo da Figura 3.6 e seleciona-se uma determinada faixa de energias (gate) que englobe apenas a transição desejada e projeta-se o resultado no eixo dos tempos. Com isso, 
obtém-se o espectro de tempo relacionado à transição escolhida. Como o estado isomérico decai populando outros estados de meias vida curta, o espectro de tempo desses estados apresenta a mesma forma que o espectro de tempo do estado isomérico. Assim, pode-se somar os espectros de todas essas transições para se medir com melhor precisão a meia vida do estado isomérico. O espectro de tempo somando-se a contribuição das transições de 146, 411, 1130, 1408 e $3434 \mathrm{keV}$ é visto na Figura 3.8. Neste espectro, os canais em tempo foram agrupados de 32 em 32 canais para aumentar a estatística de cada canal.

No espectro de tempo da Figura 3.8 observa-se o pico de prompt, onde se encontram as transições consideradas instantâneas para essa escala de tempo. Antes do pico de prompt, encontra-se um espectro relacionado apenas ao fundo estatístico, enquanto que após o pico de prompt observa-se o espectro de decaimento das transições escolhidas. As linhas tracejadas representam a região escolhida para estimar o fundo estatístico enquanto as linhas pontilhadas representam a região escolhida para a medida da meia vida do estado isomérico.

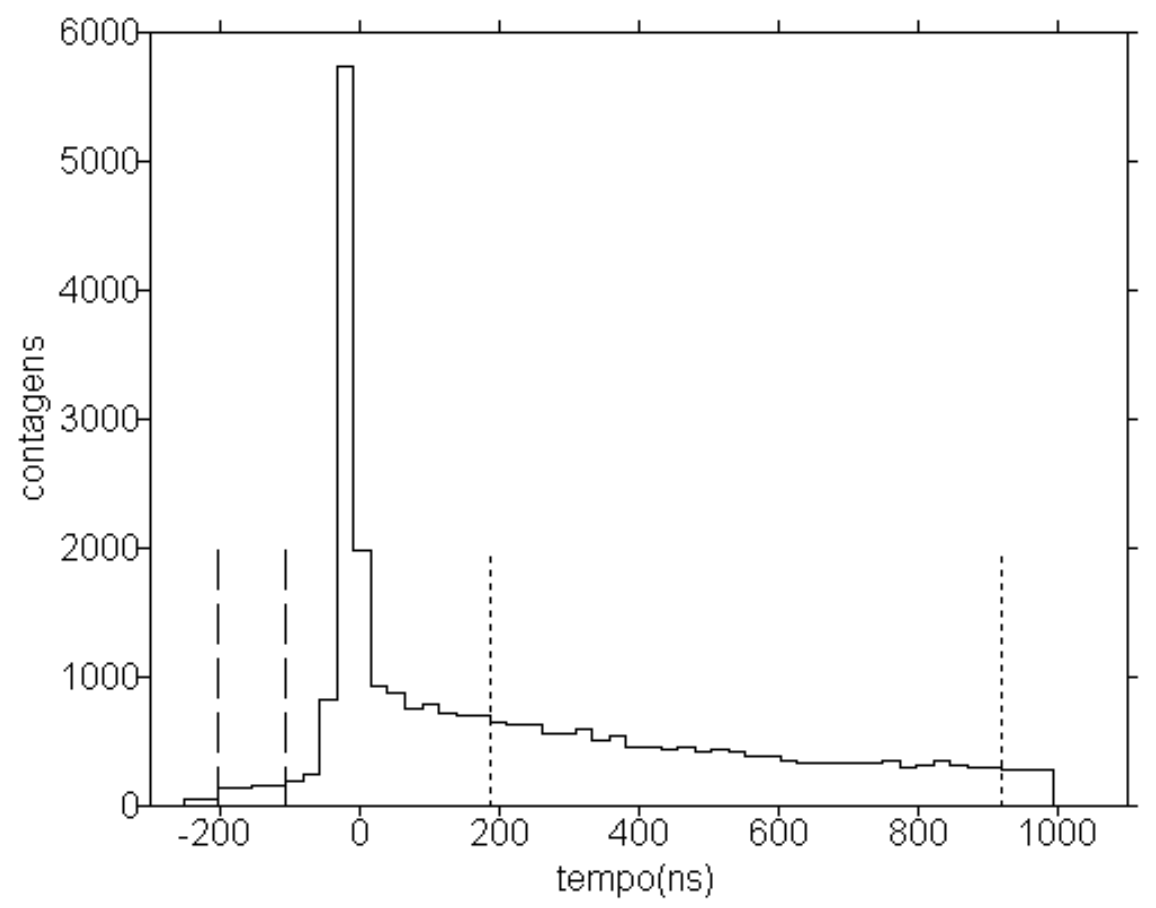

Figura 3.8: Espectro de tempo em coincidência com as transições do ${ }^{54} \mathrm{Fe}$ com energias de 146, 411, 1130,1408 e $3434 \mathrm{keV}$. As linhas tracejadas representam a região escolhida para estimar o fundo estatístico enquanto as linhas pontilhadas representam a região escolhida para a medida da meia vida. 
O número médio de contagens do fundo aleatório, neste caso foi de $\mathrm{N}_{\mathrm{f}}=144(13)$, sendo que a incerteza foi estimada a partir da dificuldade em se escolher o intervalo de tempo para obtenção do fundo. Este fundo aleatório representa tempos de eventos que não estão correlacionados.

Tendo o valor do fundo fixado, a meia vida do estado $10^{+}$foi obtida através de um ajuste pelo método dos mínimos quadrados (HELENE, 1991), da Equação 3.1. A meia vida ajustada para o estado $10^{+}$do ${ }^{54} \mathrm{Fe}$ foi de $375(16) \mathrm{ns}$, sendo o $\chi^{2}$ reduzido do ajuste igual a 1,02 . A Figura 3.9 mostra o resultado deste ajuste.

$$
\mathrm{N}=\mathrm{N}_{\mathrm{o}} e^{-\frac{\ln 2}{\mathrm{~T}_{1 / 2}} \mathrm{t}}+N_{f}
$$

Onde: $\mathrm{N}$ é o número de contagens em função do tempo, $\mathrm{N}_{\mathrm{f}}$ é o número médio de contagens do fundo, t é o tempo, $\mathrm{N}_{\mathrm{o}}$ é um parâmetro ajustável que representa o número de contagens para $t=0$ e $\left(\ln 2 / T_{1 / 2}\right)$ é o parâmetro do ajuste que está relacionado com a meia vida do estado isomérico.

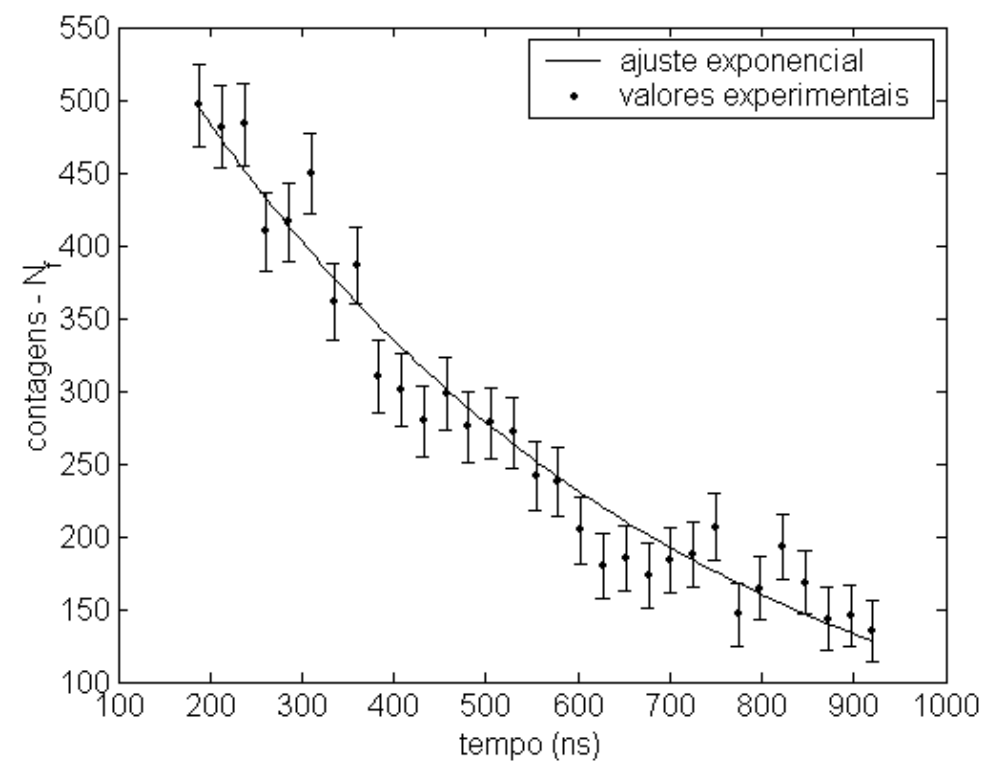

Figura 3.9: Ajuste exponencial para a determinação da meia vida do estado isomérico $10^{+}$do núcleo ${ }^{54} \mathrm{Fe}$. 


\subsubsection{Discussão dos Resultados}

Através desta experiência o SISMEI mostrou-se capaz de separar transições rápidas, com vida média menor ou igual a alguns nanosegundos, de transições lentas, com vidas médias maiores do que 10 ns. Utilizando o SISMEI foi possível medir a meia vida do estado isomérico $10^{+}$do ${ }^{54} \mathrm{Fe}$, sendo que a meia vida encontrada, $\mathrm{T}_{1 / 2}=375(16) \mathrm{ns}$, é compatível com a meia vida conhecida da literatura, $\mathrm{T}_{1 / 2}=364(7) \mathrm{ns}$, (DAFNI, 1978). Tais resultados demonstram que o SISMEI pode ser utilizado para a procura de estados isoméricos de núcleos produzidos através de reações de fusão evaporação na faixa de 10 ns à $1 \mu \mathrm{s}$.

\subsection{A EXPERIÊNCIA ${ }^{46} \mathrm{Ti}\left({ }^{11} \mathrm{~B}, 1 \mathrm{p} 2 \mathrm{n}\right){ }^{54} \mathrm{Fe}, \mathrm{E}_{\mathrm{F}}=33 \mathrm{MeV}$}

Neste experimento o SISMEI estava completo, ou seja, um segundo detector de GeHP foi posicionado no SACI para possibilitar coincidências $\gamma-\gamma_{\text {atrasado }}$ e foram utilizados supressores Compton nos detectores de GeHP, afim de reduzir o fundo dos espectros de raios $\gamma$ devido ao espalhamento Compton nos cristais dos detectores de GeHP. Um diagrama do SISMEI mostrando a posição do segundo detector de raios $\gamma$ de GeHP é visto na Figura 3.10.

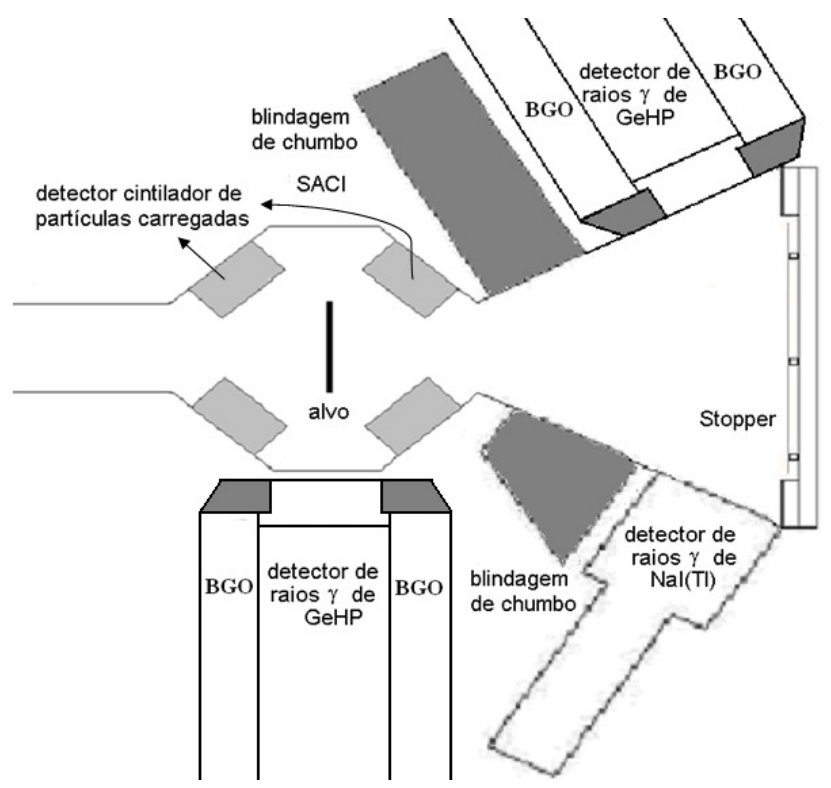

Figura 3.10: Figura esquemática do SISMEI completo, com um detector de raios $\gamma$ de GeHP posicionado no SACI, além dos dois detectores de raios $\gamma$ posicionando no fim do cone do SISMEI. 
O segundo detector de GeHP possui a mesma função que os detectores de partículas do SACI, sendo que ambos atuam em paralelo. No caso deste segundo detector de GeHP, o que se mede é a diferença em tempo entre um raio $\gamma$ detectado no detector de GeHP posicionado no SACI e o raio $\gamma$ detectado em um dos detectores de raios $\gamma$ posicionados no SISMEI, assim pode-se construir matrizes $\gamma-\gamma_{\text {atrasado }}$ além das matrizes partícula- $\gamma_{\text {atrasado }}$. Se por um lado a eficiência do detector de GeHP é muito baixa quando comparada aos 10 detectores de partículas do SACI, por outro lado é possível detectar a energia do raio $\gamma$ que inicia a contagem de tempo e com isso identificar quais transições populam um determinado estado isomérico. Essa montagem pode, portanto, ser utilizada para confirmar se um determinado estado isomérico pertence ao núcleo em estudo, além disso, ela também permite a medida de estado isoméricos em núcleos residuais que não são populados pela emissão de partículas carregadas.

\subsubsection{Redução e Analise dos Dados}

A redução dos dados desta experiência é semelhante ao experimento anterior. O espectro em delay obtido através da coincidência partícula- $\gamma_{\text {atrasado }}$ é visto na Figura 3.11. Neste espectro de raios $\gamma$ podem ser vistos os picos correspondentes aos raios $\gamma$ de 146, 411, 1130, 1408, 3432 e $3578 \mathrm{keV}$. Este último pico não havia sido observado no experimento anterior. Nesta experiência os dados de energia e tempo também foram ser adquiridos em modo simples (singles), e não apenas em coincidência $\gamma-\gamma$ como na experiência anterior. 


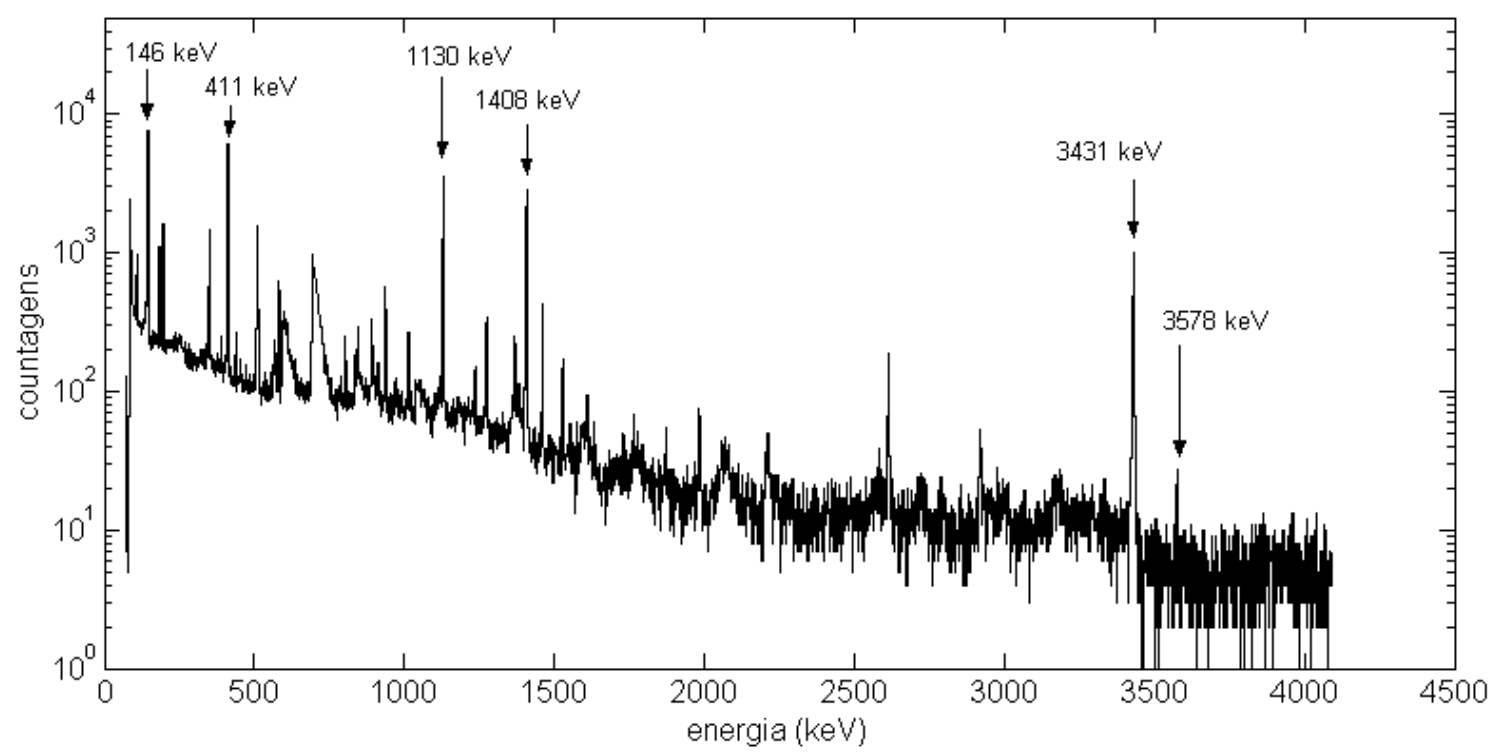

Figura 3.11: Espectro de raios $\gamma$ em coincidência $\gamma$-p atrasada, delay. Neste espectro pode ser observadas todas as transições abaixo do estado isomérico $10^{+}$do ${ }^{54} \mathrm{Fe}$.

O espectro de tempo em coincidência com as transições de 146, 411, 1130, 1408 e $3431 \mathrm{keV}$ é visto na Figura 3.12.

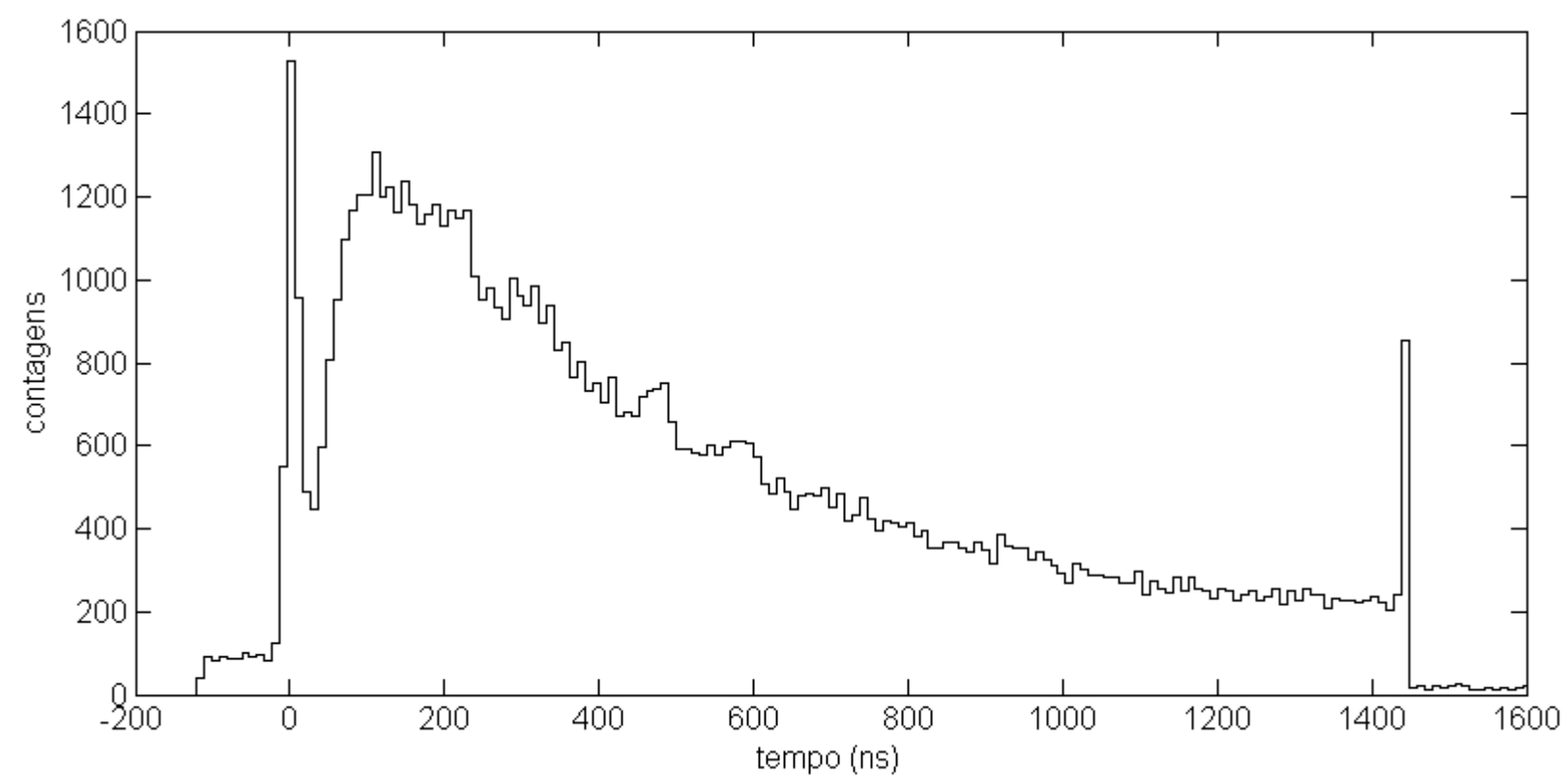

Figura 3.12: Espectro de tempo em coincidência com as transições de $146 \mathrm{keV}, 411 \mathrm{keV}, 1130 \mathrm{keV}, 1408 \mathrm{keV}$ e $3431 \mathrm{keV}$ do ${ }^{54} \mathrm{Fe}$.

Neste experimento também foi analisado o espectro de tempo em coincidência com a transição de $197 \mathrm{keV}\left(5 / 2^{+} \rightarrow 1 / 2^{+}\right)$do ${ }^{19} \mathrm{~F}$, sendo que o estado isomérico $5 / 2^{+}$possui uma meia vida de: $\mathrm{T}_{1 / 2}=89,3(10)$ ns (TILLEY, 1995). Este núcleo é produzido pela reação do feixe 
com contaminantes presentes no alvo. Este espectro é visto na Figura 3.13 e a meia vida medida para este estado foi de $T_{1 / 2}=100(36)$ ns. A calibração em tempo utilizada para esta medida foi obtida através do espectro de tempo das transições do ${ }^{54} \mathrm{Fe}$, visto na Figura 3.12.

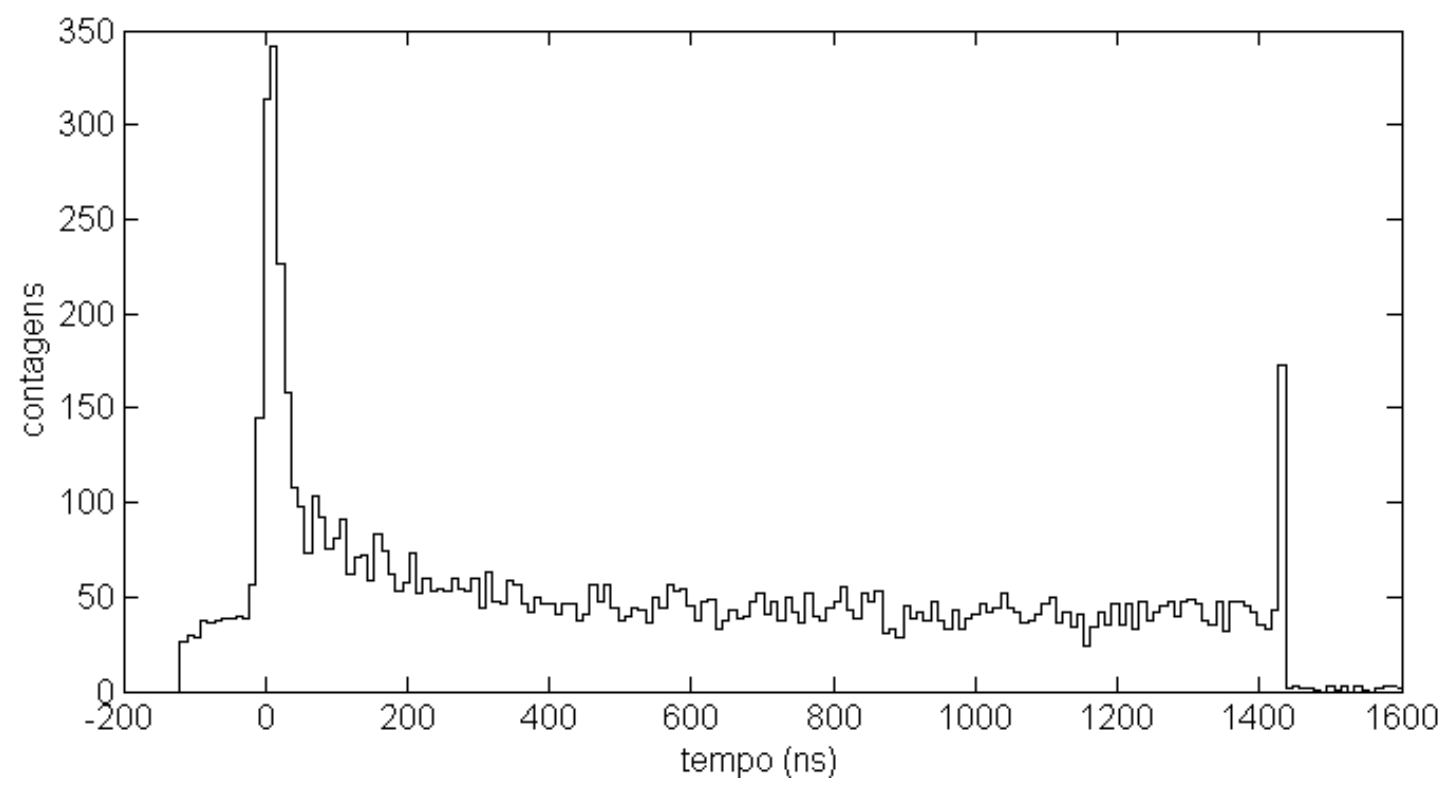

Figura 3.13: Espectro de tempo em coincidência com a transição de $197 \mathrm{keV}$ proveniente do estado $5 / 2^{+}$ $\left(\mathrm{T}_{1 / 2}=89,3(10) \mathrm{ns}\right)$ do ${ }^{19} \mathrm{~F}$.

Para verificar as potencialidades do SISMEI, analisou-se o espectro de tempo em coincidência com a transição de $351 \mathrm{keV}$ do estado $5 / 2^{+}$do ${ }^{21} \mathrm{Ne}$, visto na Figura 3.14. Nesta figura pode-se observar um espectro praticamente plano indicando uma meia vida longa. $\mathrm{O}$ ${ }^{21} \mathrm{Ne}$ é produzido neste experimento por processos de decaimento $\beta^{-}$de núcleos produzidos pela reação do feixe de ${ }^{11} \mathrm{~B}$ com contaminantes presentes no alvo. Estes processos, em geral, possuem meia vida da ordem de segundos, como é o caso do ${ }^{21} \mathrm{Ne}$ que pode ser produzido pelo decaimento do núcleo de ${ }^{21} \mathrm{~F}$ com $\mathrm{T}_{1 / 2}=4,158(20) \mathrm{s}$ (FIRESTONE, 2004). Assim, o espectro da Figura 3.14 está relacionado com a meia vida do decaimento $\beta^{-}$e não com a meia vida do estado $5 / 2^{+}$do ${ }^{21} \mathrm{Ne}$. Essa meia vida longa faz com que o espectro de tempo delay tenha um número de contagens aproximadamente constante, representando uma meia vida muito maior do que o intervalo de tempo deste histograma $(\approx 1,5 \mu \mathrm{s})$. 


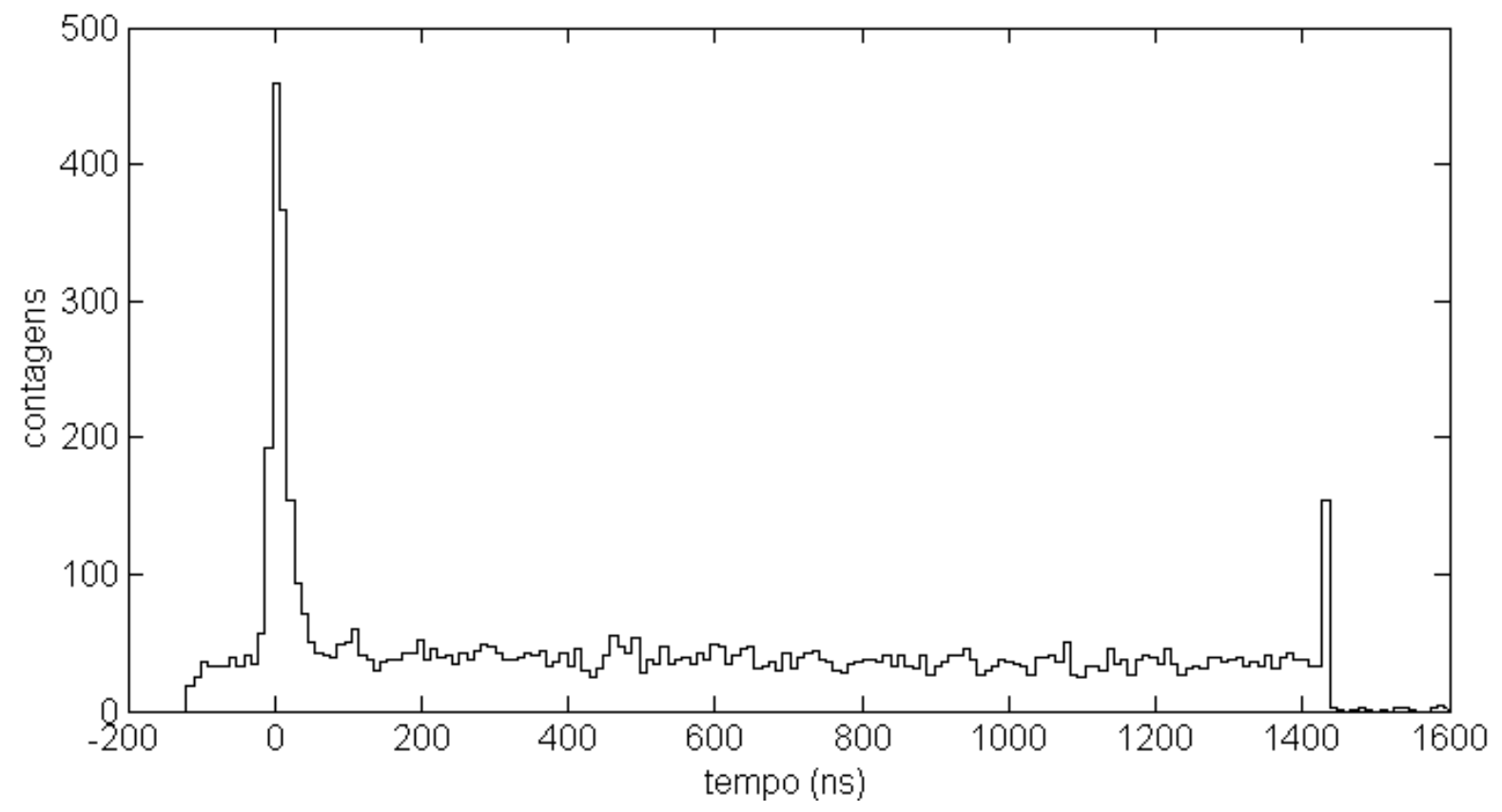

Figura 3.14: Espectro de tempo em coincidência com a transição de $351 \mathrm{keV}$ do ${ }^{21} \mathrm{Ne}$. Esta transição apresenta meia vida longa, já que o ${ }^{21} \mathrm{Ne}$ é produzido por processos de decaimento $\beta$, que possuem meia vida da ordem de segundos.

O segundo detector de GeHP, posicionado no SACI, possibilitou a construção de uma matriz $\gamma-\gamma_{\text {atrasado. }}$ Embora esta matriz possua poucas contagens, pôde-se construir o espectro de raios $\gamma$ instantâneos em coincidência atrasada com as transições de 146, 411, 1130, 1408 e $3431 \mathrm{keV}$, vista na Figura 3.15. Neste espectro é possível identificar as transições de 197, 780 e $1492 \mathrm{keV}$, pertencentes ao ${ }^{54} \mathrm{Fe}$, que populam o estado isomérico $10^{+}$do ${ }^{54} \mathrm{Fe}$. 


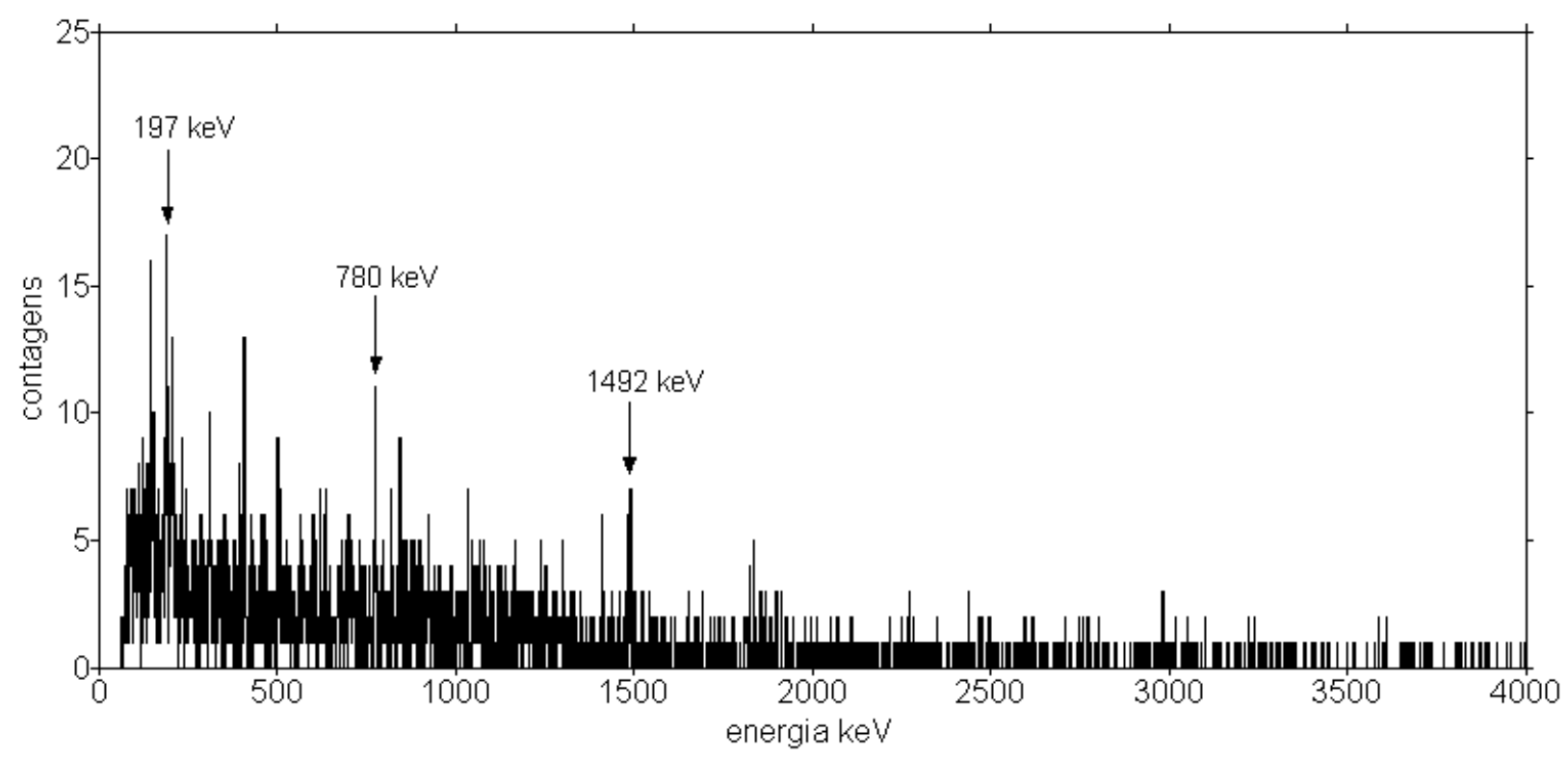

Figura 3.15: Espectro do detector de raios $\gamma$ de GeHP posicionado no SACI em coincidência $\gamma-\gamma$ atrasada com as transições: $146,411,1130,1408$ e $3431 \mathrm{keV}$, provenientes do estado isomérico $10^{+}$do ${ }^{54} \mathrm{Fe}$. Neste espectro é possível identificar, três transições que populam o estado isomérico $10^{+}$(vide Figura 3.2).

\subsubsection{Discussão dos Resultados}

Com esta segunda experiência foi possível testar o SISMEI completo. Desta vez foi possível observar a transição de $3578 \mathrm{keV}$, que depopula o estado isomérico $10^{+}$do ${ }^{54} \mathrm{Fe}$. A observação desse raio $\gamma$ demonstra a sensibilidade do sistema, já que a intensidade relativa desta transição é de apenas 2,0(2) \% (JUNDE, 2006) em relação à transição de 146 keV.

Com o espectro de tempo em coincidência com a transição de $197 \mathrm{keV}$ do ${ }^{19} \mathrm{~F}\left(5 / 2^{+} \rightarrow\right.$ $1 / 2^{+}$) foi possível calcular a meia vida do estado $5 / 2^{+}$, sendo o resultado $\left(\mathrm{T}_{1 / 2}=100(36) \mathrm{ns}\right)$ compatível com o valor conhecido $\left(\mathrm{T}_{1 / 2}=89,3(10) \mathrm{ns}\right)$. A grande incerteza nesse valor reflete simplesmente o pouco número de contagens desta transição, já que o experimento não foi direcionado para a produção do ${ }^{19} \mathrm{~F}$. Isso mostra a capacidade do SISMEI para medir vidas médias mais curtas. Já o espectro de tempo em coincidência com a transição de $351 \mathrm{keV}$ do estado $5 / 2^{+}$do ${ }^{21} \mathrm{Ne}$, visto na Figura 3.14 , mostra que o SISMEI é capaz de identificar transições que carregam meias vidas longas $\left(\mathrm{T}_{1 / 2}>10 \mu \mathrm{s}\right)$. 
Utilizando o segundo detector de raios $\gamma$ de GeHP, foi possível medir o espectro prompt que está em coincidência atrasada com as transições provenientes do estado isomérico $10^{+} \mathrm{e}, \mathrm{com}$ isso, identificar algumas das transições que populam este estado isomérico. Esse tipo de técnica tem grande importância pois permite identificar a qual núcleo um estado isomérico novo pertence. O baixo número de contagens do espectro da Figura 3.15 reflete a eficiência do detector de GeHP posicionado no SACI ( $\sim 0,2 \%$ para $1,3 \mathrm{MeV})$ em comparação com os 10 detectores de partículas carregadas do SACI ( $20 \%$ para prótons e $\sim 5 \%$ para alfas).

Com este outro detector de GeHP, posicionado próximo ao SACI, pode-se utilizar o SISMEI para medir a vida média de estados pertencentes a núcleos residuais que sejam produzidos sem a evaporação de partículas carregadas. Para a utilização desta técnica, são necessários casos com grande seção de choque ou mesmo longo tempo de aquisição de dados, devido a menor eficiência do detector de GeHP em relação aos 10 detectores de partículas do SACI. 


\section{INTERPRETAÇÃO TEÓRICA DO ${ }^{54}$ FE ATRAVÉS DO LSSM}

\subsection{O MODELO DE CAMADAS DE LARGA ESCALA (LSSM)}

O modelo de camadas nuclear surgiu a partir de evidências experimentais que indicavam certas propriedades especiais nos núcleos com números particulares de núcleons: 2, 8, 20, 50, 82 e 126. Estes números, conhecidos como números mágicos, referem-se ao número de núcleons necessários para fechar uma camada nuclear.

Uma evidência experimental desses números mágicos pode ser obtida graficando-se a energia do primeiro estado excitado dos núcleos estáveis, normalizados por um fator $\mathrm{A}^{1 / 3}$, em função do número de prótons $(\mathrm{Z})$ ou do número de nêutrons $(\mathrm{N})$. Os núcleos com números mágicos apresentam os valores mais altos dessa energia, indicando que a configuração interna destes núcleos é muito estável, pois é necessária mais energia para retirar um núcleon da camada fechada e posicioná-lo na camada acima. Estes gráficos são mostrados na Figura 4.1, os dados para a construção destes foram retirados de ENSDF (2008).
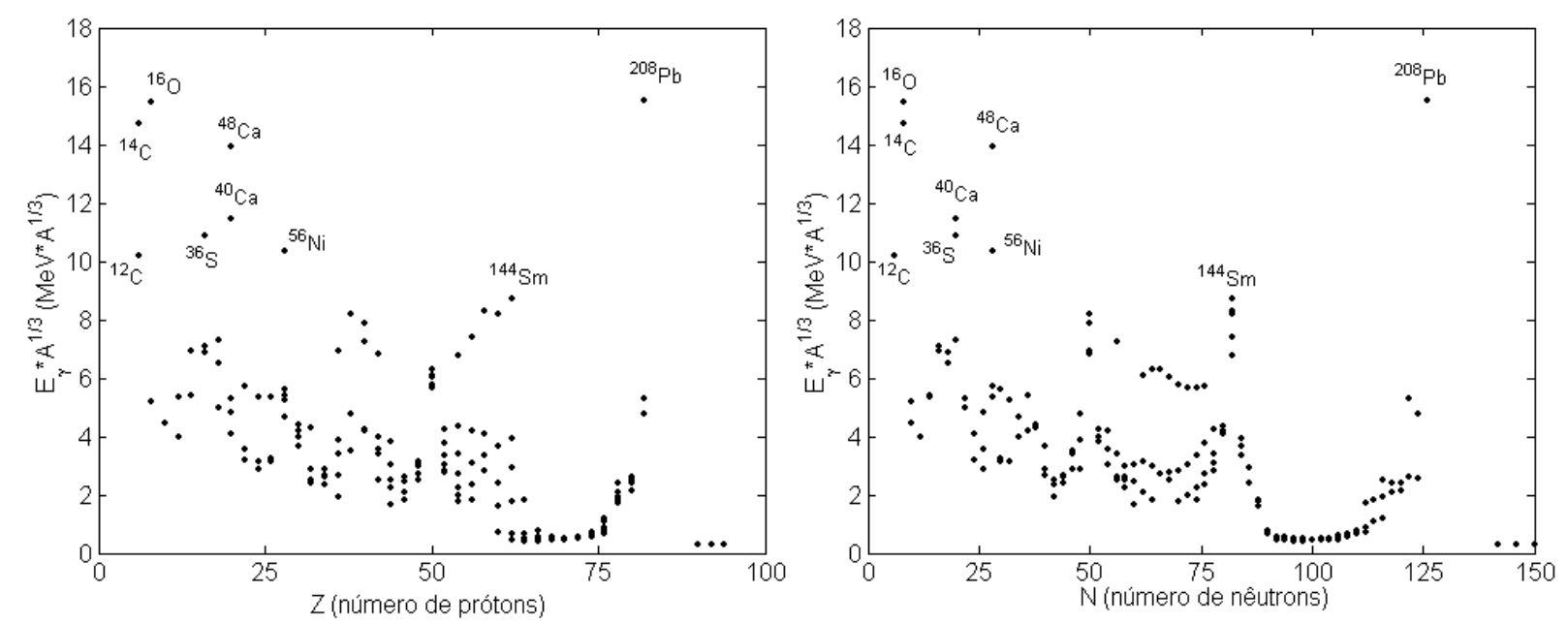

Figura 4.1: Energia do primeiro estado excitado normalizada por $\mathrm{A}^{1 / 3}$ para os núcleos conhecidos com meia vida maior que $10^{15} \mathrm{~s}$ em função do número de prótons $(\mathrm{Z})$ e do número de nêutrons $(\mathrm{N})$. Os núcleos com números mágicos de núcleons apresentam os valores mais altos, isso indica que a configuração interna destes núcleos é muito estável. 
Os primeiros modelos de camadas procuravam explicar o comportamento de núcleos com apenas um núcleon acima de uma camada fechada, como o ${ }^{17} \mathrm{O}$ que possui apenas um nêutron a mais que o duplamente mágico ${ }^{16} \mathrm{O}$. Com isso, o modelo é similar ao modelo atômico, porém o núcleo atômico é substituído por um caroço inerte de 16 núcleons e a força de interação é a nuclear forte. Tais modelos são conhecidos como modelos de partícula independente.

No modelo de partícula independente assume-se que a interação entre um núcleon e os demais núcleons de um determinado núcleo pode ser aproximada pela interação de um núcleon com um potencial central. Com isso, o mesmo formalismo utilizado pela mecânica quântica para explicar a estrutura atômica pode ser aplicado na tentativa de explicar a estrutura nuclear (COOK, 2006).

Uma escolha simples para o potencial nuclear em um modelo de camadas nuclear é o potencial do oscilador harmônico esférico. Porém, como nesse potencial os níveis de energia são degenerados, devido a não influência do momento angular orbital, o potencial do oscilador harmônico pode ser modificado para incluir uma dependência com o momento angular ou ser substituído por outros tipos de potencial, como o de Woods-Saxon. Qualquer que seja a escolha, para que o modelo seja capaz de reproduzir os números mágicos observados experimentalmente é preciso adicionar um forte termo de interação spin orbita na hamiltoniana de partícula única (BRUSSAARD, 1977).

A Figura 4.2 mostra os níveis de energia de partícula única para o oscilador harmônico esférico (S.H.O.), o oscilador harmônico esférico modificado com um termo de momento angular $\left(1^{2}\right)$ e o oscilador harmônico esférico modificado com um termo de momento angular $\left(1^{2}\right)$ acrescido de termo de interação spin órbita (l.s). 


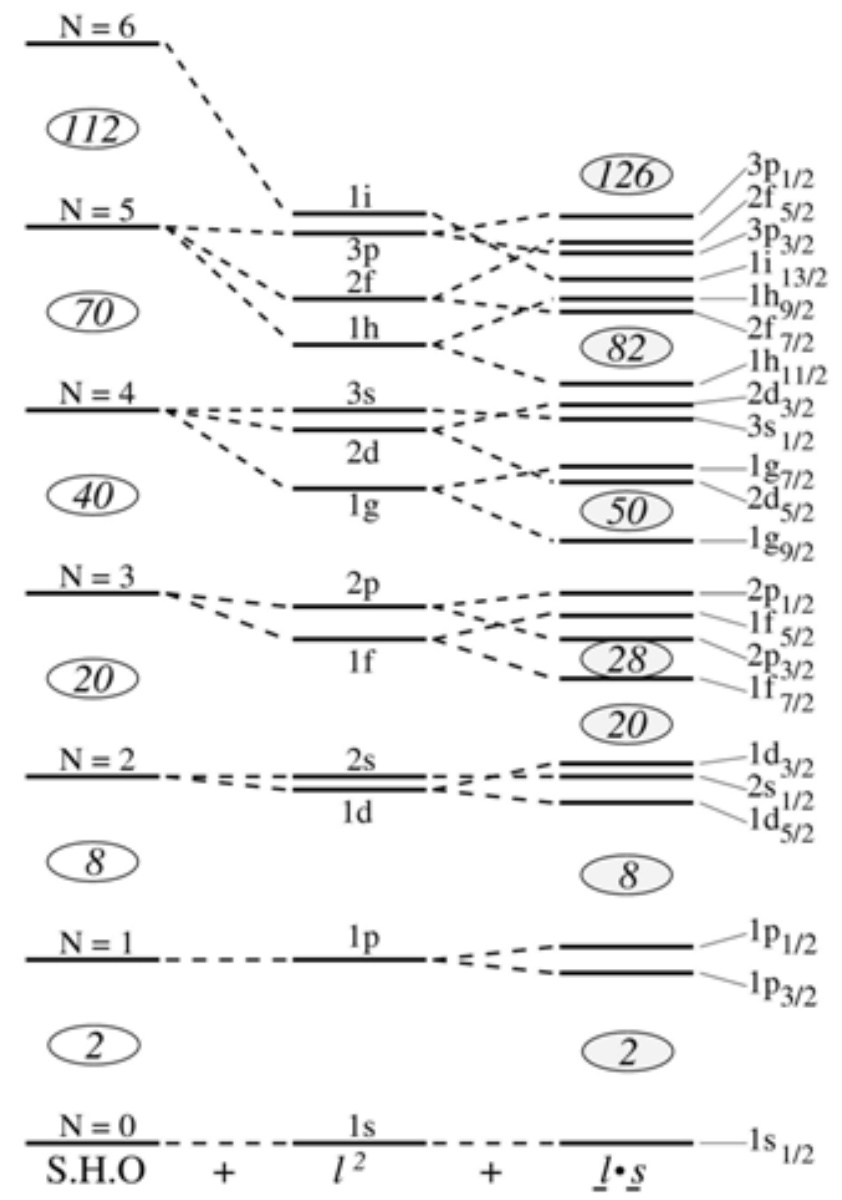

Figura 4.2: níveis de energia de partícula única para o oscilador harmônico esférico (S.H.O.), oscilador harmônico esférico modificado com um termo de momento angular $\left(1^{2}\right)$ e oscilador harmônico esférico modificado com um termo de momento angular, acrescido de tempo de interação spin órbita(l.s), retirado de CASTEN (2005).

Pela Figura 4.2, observa-se que os números mágicos são muito bem descritos pelo modelo. O número 28 também está destacado por ser muitas vezes considerado como um número semi-mágico. A Figura 4.3 é similar à Figura 4.2, no entanto mostra os níveis de energia de partícula única quando se utiliza o potencial de Woods-Saxon ao invés do oscilador harmônico modificado com o termo $1^{2}$. A diferença entre os resultados é pequena, porém perceptível. A diferença de energia entre os níveis $2 \mathrm{p}_{1 / 2}$ e $1 g_{9 / 2}$, por exemplo, é consideravelmente menor quando se utiliza o potencial de Woods-Saxon. 


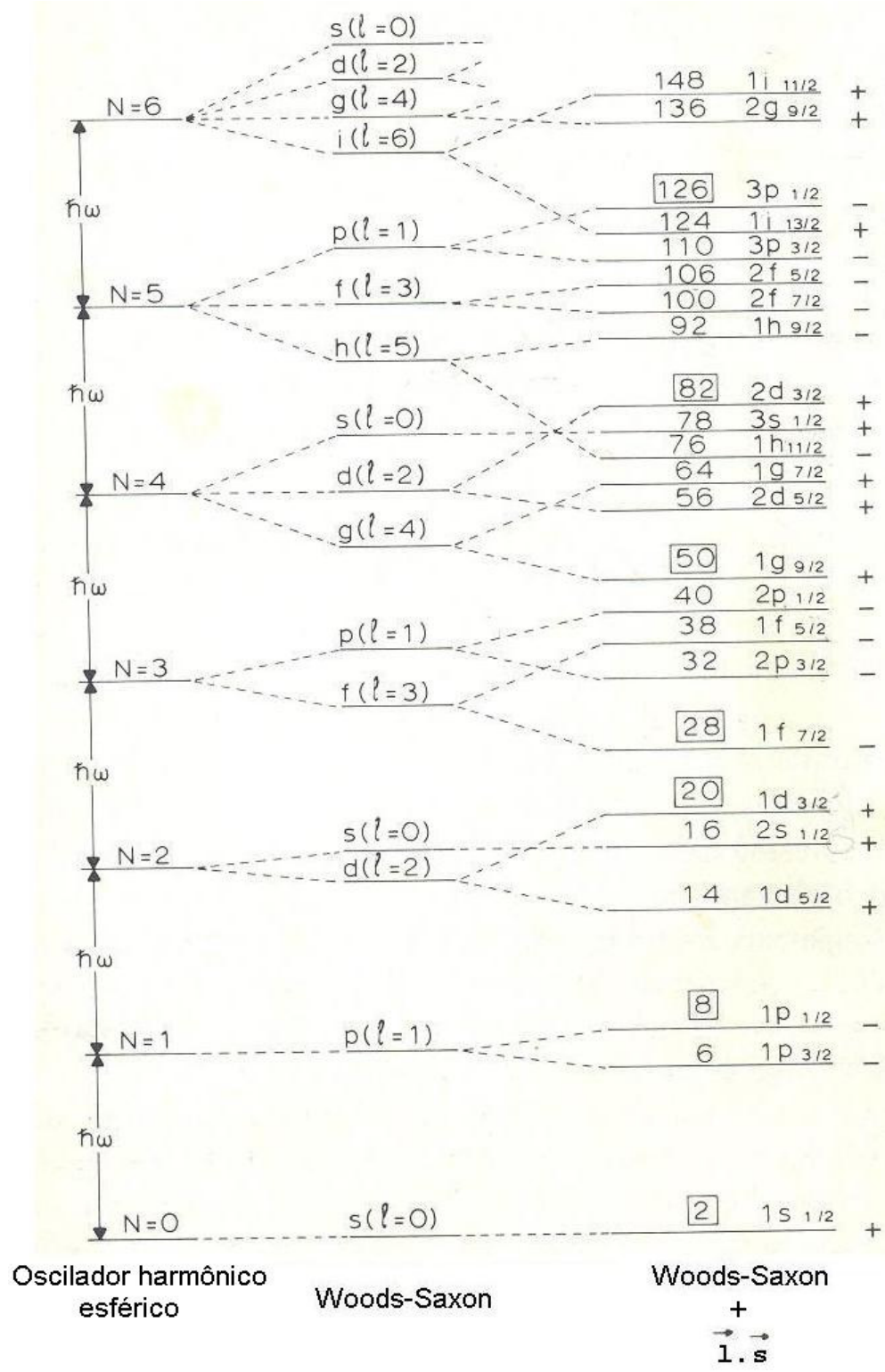

Figura 4.3: Níveis de energia de partícula única para o oscilador harmônico esférico, Woods-Saxon e WoodsSaxon acrescido de tempo de interação spin órbita(l.s), retirado de BRUSSAARD (1977).

No Modelo de Camadas de Larga Escala (LSSM - Large Scale Shell Model), procurase separar o potencial nuclear em duas partes: o potencial efetivo e o residual. Dessa forma, pode-se escrever a Hamiltoniana do problema como visto na Equação 4.1:

$$
\mathrm{H}=\mathrm{T}+\mathrm{V}=\mathrm{T}+\mathrm{V}_{\text {ef }}+\mathrm{V}_{\text {res }}
$$

O potencial efetivo pode ser aproximado por um dos potenciais analíticos discutidos anteriormente: Woods-Saxon modificado (Figura 4.2) ou Oscilador Harmônico modificado (Figura 4.3). Já o potencial residual pode ser tratado como uma perturbação, assumindo que 
este corresponde à interação residual de dois corpos apenas entre os núcleons de valência. Ou seja, assume-se que os núcleons do caroço inerte não são afetados pela interação residual.

Para que esse modelo seja eficiente é preciso conhecer muito bem a interação residual. Para isso, os elementos de matriz da interação residual são calculados especificamente para cada camada, a partir de dados experimentais de núcleos com núcleons de valência pertencentes à camada de interesse (CAURIER, 2005).

\subsection{INTERPRETAÇÃO DO ESTADO $10^{+}$DO ${ }^{54} \mathrm{Fe}$ ATRAVÉS DO LSSM}

Para os cálculos e previsões apresentadas nesta seção utilizou-se o código Antoine (CAURIER, 1999) e a GXPF1(HONMA, 2004) como interação residual. Esta interação foi desenvolvida recentemente para descrever núcleos pertencentes à camada pf. O núcleo ${ }^{40} \mathrm{Ca}$ foi utilizado como caroço inerte e as propriedades nucleares dadas ao programa como parâmetros de entrada foram:

Carga efetiva do nêutron: $\mathrm{q}_{\mathrm{eff}}=0,5 \mathrm{e}$.

Carga efetiva do próton: $\mathrm{q}_{\mathrm{eff}}=1,5 \mathrm{e}$.

Fator giromagnético de spin do próton: $\mathrm{g}_{\mathrm{s}}=5,586$.

Fator giromagnético de spin do nêutron: $\mathrm{g}_{\mathrm{s}}=-3,826$.

Fator giromagnético orbital do próton: $\mathrm{g}_{1}=1,000$.

Fator giromagnético orbital do nêutron: $\mathrm{g}_{1}=0,000$.

Os estados pertencentes à banda situada abaixo do estado isomérico $10^{+}$, vistos na Figura 3.2, foram calculados variando-se o número de partículas livres em toda a camada pf de um até oito para estudar a convergência do cálculo. Na Figura 4.4 são mostradas as energias experimentais dos primeiros estados excitados do ${ }^{54} \mathrm{Fe}$ e as calculadas pelo modelo considerando-se diferentes números de partículas livres que podem ser excitadas em toda a camada pf $(2,4,6$ e 8$)$. 


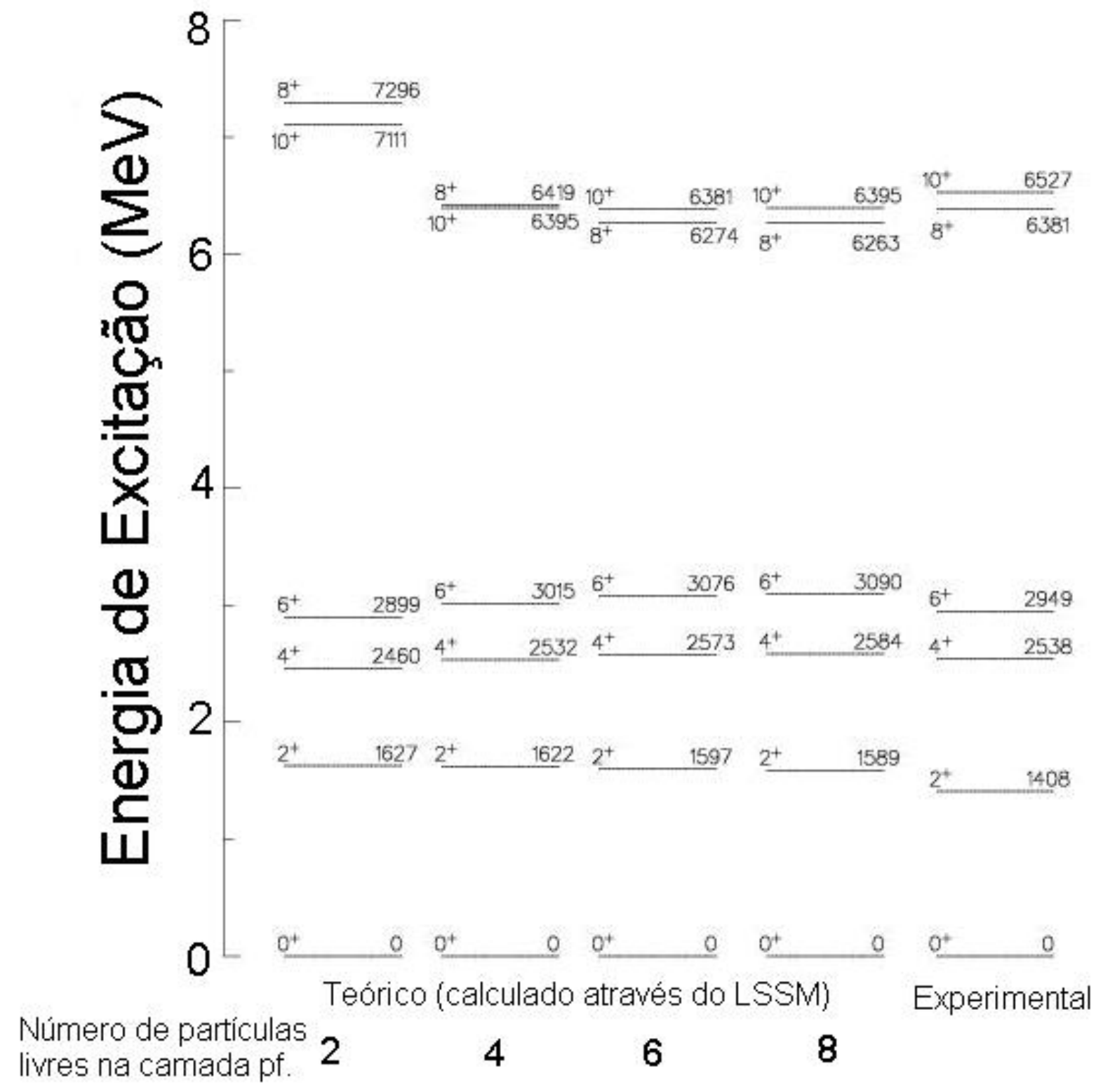

Figura 4.4: Comparação entre as energias previstas pelo LSSM com 2, 4, 6 e 8 partículas livres na camada pf e as energias experimentais dos primeiros estados excitados pertencentes a mesma banda do estado isomérico $10^{+}$

do ${ }^{54} \mathrm{Fe}$. Observa-se que a medida que se aumenta o número de partículas livres as previsões teóricas se aproximam do resultado experimental.

Pode ser visto, na Figura 4.4, que à medida que se aumenta o número de partículas livres, as previsões teóricas se aproximam do resultado experimental. Com apenas duas partículas livres o modelo descreve bem os resultados experimentais até o estado $6^{+}$, no entanto as energias dos estados $8^{+}$e $10^{+}$não são bem reproduzidas e apresentam-se invertidas em relação aos valores experimentais. Com quatro partículas livres as energias destes dois estados estão muito mais próximas dos valores experimentais, porém a ordem continua 
trocada. Com seis partículas livres, a ordem dos estados está correta, porém a diferença de energia entre os estados $8^{+}$e $10^{+}$(fator decisivo na meia vida do estado isomérico $10^{+}$) é pequena em relação ao conhecido. Já com oito partículas livres, essa diferença de energia aumenta, se aproximando mais do valor conhecido. Cálculos utilizando um número maior de partículas livres não podem ser realizados devido à sua inviabilidade computacional, uma vez que o número de elementos de matriz a serem tratados torna-se muito grande. Para o cálculo com oito partículas livres em toda a camada pf, são necessários aproximadamente 177 milhões de elementos de matriz, e cada caso demorou em torno de 140 horas em um computador Intel Xeon com 4 GB de memória RAM. Um cálculo com nove partículas livres em toda a camada pf utilizaria uma matriz com aproximadamente 261 milhões de elementos.

A função de ocupação dos estados da banda estudada na Figura 4.4 pode ser obtida diretamente do modelo LSSM. Essa função de ocupação fornece a função de onda de um estado através da ocupação dos orbitais pelos núcleons livres. Assim, um estado é interpretado como composto por uma mistura de configurações nucleares. A função de ocupação prevista para o estado isomérico $10^{+}$, utilizando até oito partículas livres na camada pf, é vista na Tabela 4.1. Observa-se nessa tabela que a contribuição predominante para o estado $10^{+}$ $(37,7 \%)$ vem da configuração $\left[v f_{7 / 2}^{-1} \pi f_{7 / 2}^{-2}\right] \otimes\left[v p_{3 / 2}{ }^{+1}\right]$, esta configuração já havia sido prevista por DAFNI (1978). 


\begin{tabular}{|c|c|c|c|c|c|c|c|c|}
\hline \multirow{2}{*}{ Porcentagem } & \multicolumn{3}{|c|}{$\mathrm{n}^{\text {o }}$ de nêutrons por camada } & \multicolumn{3}{|c|}{$\mathrm{n}^{\text {o }}$ de prótons por camada } \\
\cline { 2 - 9 } & $\mathrm{f}_{7 / 2}$ & $\mathrm{p}_{3 / 2}$ & $\mathrm{f}_{5 / 2}$ & $\mathrm{p}_{1 / 2}$ & $\mathrm{f}_{7 / 2}$ & $\mathrm{p}_{3 / 2}$ & $\mathrm{f}_{5 / 2}$ & $\mathrm{p}_{1 / 2}$ \\
\hline $4,10 \%$ & 7 & 0 & 0 & 1 & 6 & 0 & 0 & 0 \\
\hline $1,80 \%$ & 7 & 0 & 0 & 1 & 5 & 1 & 0 & 0 \\
\hline $14,00 \%$ & 7 & 0 & 1 & 0 & 6 & 0 & 0 & 0 \\
\hline $1,00 \%$ & 7 & 0 & 1 & 0 & 5 & 0 & 1 & 0 \\
\hline $3,30 \%$ & 7 & 0 & 1 & 0 & 5 & 1 & 0 & 0 \\
\hline $\mathbf{3 7 , 7 0 \%}$ & $\mathbf{7}$ & $\mathbf{1}$ & $\mathbf{0}$ & $\mathbf{0}$ & $\mathbf{6}$ & $\mathbf{0}$ & $\mathbf{0}$ & $\mathbf{0}$ \\
\hline $1,80 \%$ & 7 & 1 & 0 & 0 & 5 & 0 & 1 & 0 \\
\hline $4,70 \%$ & 7 & 1 & 0 & 0 & 5 & 1 & 0 & 0 \\
\hline $3,00 \%$ & 6 & 2 & 0 & 0 & 6 & 0 & 0 & 0 \\
\hline $1,90 \%$ & 6 & 2 & 0 & 0 & 5 & 1 & 0 & 0 \\
\hline $4,30 \%$ & 6 & 1 & 1 & 0 & 6 & 0 & 0 & 0 \\
\hline $1,50 \%$ & 6 & 1 & 1 & 0 & 5 & 1 & 0 & 0 \\
\hline $1,10 \%$ & 6 & 1 & 0 & 1 & 6 & 0 & 0 & 0 \\
\hline $1,20 \%$ & 6 & 0 & 2 & 0 & 6 & 0 & 0 & 0 \\
\hline
\end{tabular}

Tabela 4.1: Principais componentes da função de ocupação do estado $10^{+}$previstas pelo LSSM.

Através do LSSM também é possível calcular a probabilidade de transição reduzida quadrupolar elétrica, B(E2). Esta propriedade pode ser determinada utilizando os seguintes valores experimentais do estado excitado: energia do raio gama, branching ratio e vida média, através da Equação 4.2 (WONG, 1998):

$$
B(E 2)_{\exp }=\frac{1}{1,23 \times 10^{9} E_{\gamma}^{5} \tau} B
$$

Onde: $\mathrm{B}(\mathrm{E} 2)$ é a probabilidade de transição reduzida quadrupolar elétrica, $\mathrm{E}_{\gamma}$ é a energia do raio gama em $\mathrm{MeV}$, $\tau$ é a vida média do estado em ps e $B$ é o branching ratio da transição.

Os valores calculados de $\mathrm{B}(\mathrm{E} 2)$ para o estado isomérico $10^{+}$do ${ }^{54} \mathrm{Fe}$, variando o número de partículas livres em toda a camada pf de um até oito, e o valor experimental com respectiva incerteza são apresentados na Figura 4.5. Os dados experimentais $\left(\mathrm{E}_{\gamma}=146,2(2) \mathrm{keV}, B=0,9804(19)\right.$ e $\left.\tau=525(10) \mathrm{ns}\right)$ do estado $10^{+}$para o cálculo de $\mathrm{B}(\mathrm{E} 2)$, foram obtidos em JUNDE (2006). Observa-se nesta figura que o valor de B(E2) experimental 
é muito bem reproduzido pelo modelo ao se considerar pelo menos cinco partículas excitadas na camada pf.

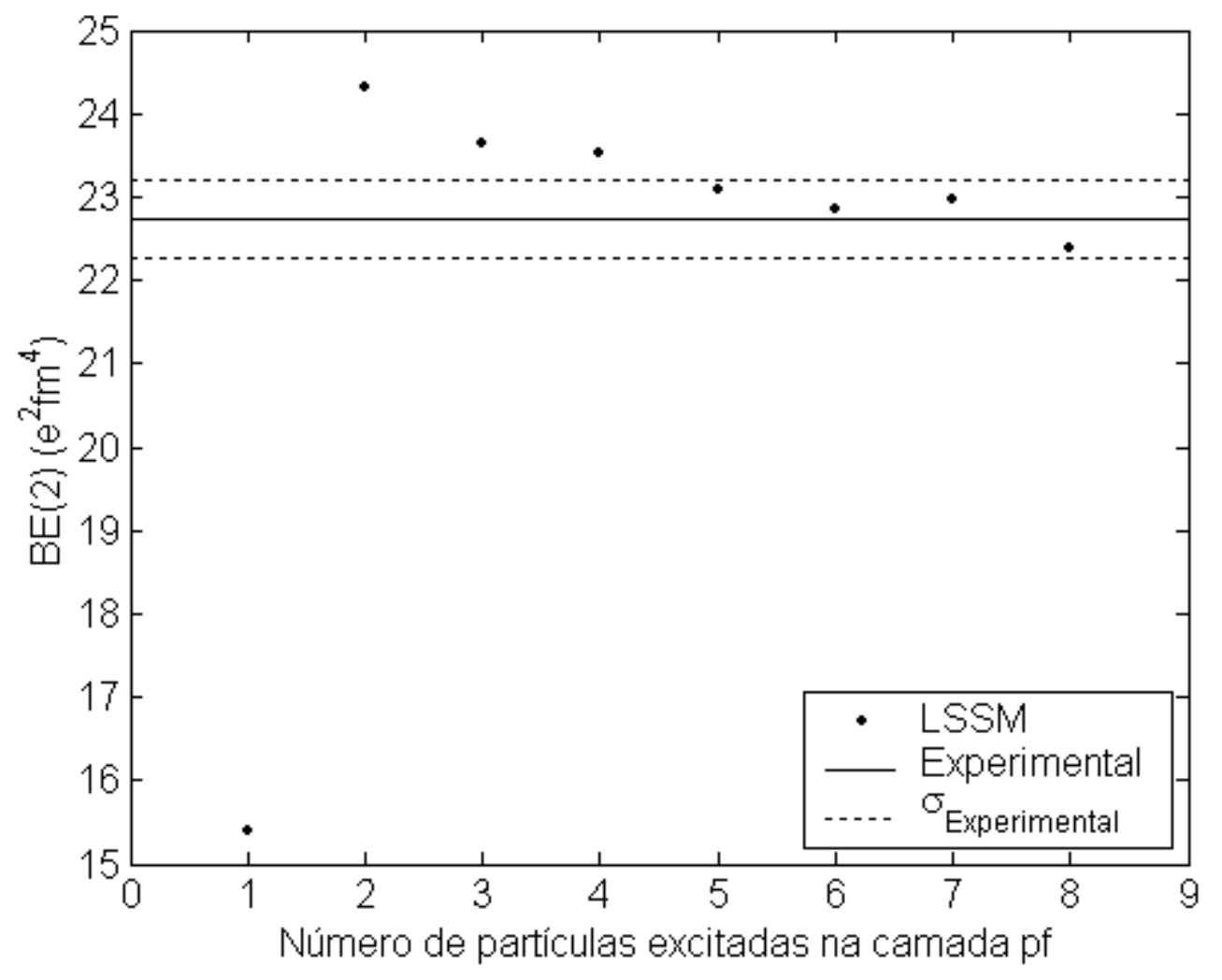

Figura 4.5: Comparação entre os valores de $\mathrm{B}(\mathrm{E} 2)$ do estado isomérico $10^{+}$do ${ }^{54} \mathrm{Fe}$, experimental e os teóricos previstos através do LSSM. São apresentados os valores calculados em função do número de partículas livres na camada pf. 


\section{CONCLUSÕES E PERSPECTIVAS}

Neste trabalho é apresentado o desenvolvimento de um sistema para medida de estados isoméricos com vida média na faixa de $10 \mathrm{~ns}$ a $10 \mu \mathrm{s}$, sem a utilização de feixe pulsado. Este sistema, batizado de SISMEI (SIStema de Medida de Estados Isoméricos), utiliza principalmente a técnica de coincidência atrasada entre partículas carregadas e raios $\gamma$. No SISMEI há uma separação espacial entre a região do alvo, onde as partículas carregadas são emitidas, e a região do stopper, onde os raios $\gamma$ atrasados são emitidos, permitindo assim uma diminuição do fundo aleatório.

O desenvolvimento deste sistema envolveu o projeto de peças mecânicas, algumas para alto vácuo, para serem adicionadas ao espectrômetro de raios $\gamma$ SACI-PERERE. Além disso, foi desenvolvida a eletrônica modular capaz de integrar a funcionalidade do SACI (Sistema Ancilar de CIntiladores) com a medida de diferenças de tempo entre partículas carregadas ou raios $\gamma$, emitidos na região do alvo, e raios $\gamma$, emitidos na região do stopper, de até $2 \mu \mathrm{s}$.

O SISMEI foi testado primeiramente através da reação de fusão-evaporação ${ }^{46} \mathrm{Ti}\left({ }^{11} \mathrm{~B}, 1 \mathrm{p} 2 \mathrm{n}\right){ }^{54} \mathrm{Fe}, \mathrm{E}_{\mathrm{F}}=30 \mathrm{MeV}$, para produzir o estado isomérico conhecido $10^{+}$do ${ }^{54} \mathrm{Fe}$ , $\mathrm{T}_{1 / 2}=364(7) \mathrm{ns}$, (DAFNI, 1978). Através deste teste foi possível concluir que o SISMEI é capaz de separar as transições rápidas das transições que estão abaixo do estado isomérico e, portanto, carregam a informação da vida média do estado. Neste experimento, utilizou-se o SISMEI para medir a meia vida deste estado isomérico através da construção de um espectro de tempo com coincidência com todas as transições que estão abaixo do estado isomérico $(146,411,1130,1408$ e $3431 \mathrm{keV})$. O resultado desta medida $\left(\mathrm{T}_{1 / 2}=375(16)\right.$ ns $)$ é compatível com o valor conhecido. 
Após este teste, o SISMEI foi ampliado com a colocação de um novo detector de raios $\gamma$ de GeHP na região do alvo, próximo ao SACI, sua eletrônica de coincidência foi ampliada e então o SISMEI pode ser novamente testado utilizando a mesma reação, mas com $\mathrm{E}_{\mathrm{F}}=33 \mathrm{MeV}$. Nesta experiência, foi verificada novamente a capacidade de separar as transições rápidas das transições que estão abaixo do estado isomérico. Utilizando o espectro de tempo do estado isomérico $10^{+}$do ${ }^{54} \mathrm{Fe}$ como calibração, mediu-se a meia vida do estado isomérico $5 / 2^{+}$do ${ }^{19} \mathrm{~F}, \mathrm{~T}_{1 / 2}=89,3(10)$ ns (TILLEY, 1995), e a meia vida encontrada , $\mathrm{T}_{1 / 2}=100(36) \mathrm{ns}$, é compatível com o valor conhecido. A grande incerteza desta medida está ligada principalmente ao baixo número de contagens do espectro de tempo, já que a experiência não foi otimizada para a produção do núcleo ${ }^{19} \mathrm{~F}$. Neste caso, o valor da meia vida foi extraído da análise do espectro em tempo da única transição $\left(\mathrm{E}_{\gamma}=197 \mathrm{keV}\right)$ que depopula o estado $5 / 2^{+}$de interesse. Neste experimento foi possível analisar também o espectro de tempo em coincidência com a transição de $351 \mathrm{keV}$ que depopula o estado $5 / 2^{+}$do ${ }^{21} \mathrm{Ne}$. Isso mostrou a capacidade do SISMEI em identificar transições que carregam meias vidas longas $\left(\mathrm{T}_{1 / 2}>10 \mu \mathrm{s}\right)$

Para interpretar a estrutura do núcleo ${ }^{54} \mathrm{Fe}$ abaixo do estado isomérico $10^{+}$foi utilizado o Modelo de Camada de Larga Escala (LSSM), através do código Antoine e da interação residual GXPF1. Foram calculados os estados que são populados no decaimento do estado isomérico $10^{+}(\mathrm{E}=6526 \mathrm{keV})$ e o modelo reproduziu muito bem as energias destes estados. $\mathrm{O}$ estado isomérico $10^{+}$foi interpretado utilizando as mesmas condições de cálculo, sendo que a configuração predominante determinada pelo modelo foi $\left[\mathrm{vf}_{7 / 2}{ }^{-1} \pi \mathrm{f}_{7 / 2}{ }^{-2}\right] \otimes\left[v \mathrm{p}_{3 / 2}{ }^{+1}\right]$, confirmando a configuração proposta por DAFNI (1978). A comparação entre os valores de B(E2) previstos utilizando o LSSM e obtido experimentalmente também mostrou que o modelo descreve muito bem os resultados experimentais, desde que seja utilizado um número suficiente de partículas livres na camada pf. 
O sistema deve ainda ser melhorado através de utilização de bases ativas em todos os detectores do SACI, de modo a permitir experimentos com taxa de eventos mais alta. Estas bases foram desenvolvidas para impedir a mudança de ganho em energia quando se varia a corrente de feixe e conseqüentemente a taxa de aquisição. Um novo módulo de BUSY também foi desenvolvido, de modo a minimizar o tempo morto do sistema de aquisição de dados.

O SISMEI está pronto e deverá ser utilizado proximamente para a procura e medida de estados isoméricos, através de reações fusão-evaporação e de espalhamento profundamente inelástico (deep inelastic). 


\section{REFERÊNCIAS}

ALCÁNTARA-NÚÑEZ, J.A. Sistema Ancilar de Cintiladores tipo "Phoswich" com

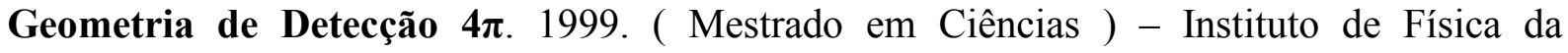
Universidade de São Paulo, São Paulo, 1999.

ALCÁNTARA-NÚÑEZ, J.A. et al. SACI - a $4 \pi$ plastic phoswich array ancillary detector system of a $\gamma$-ray spectrometer. Nuclear Instruments and Methods in Physics Research A, Amsterdam: Elsevier, v. 497, p. 429-439, 2003.

ALDER, K. et al. Study of Nuclear Structure by Electromagnetic Excitation with Accelerated Ions. Reviews of Modern Physics, Woodbury: American Institute of Physics, v. 28, n. 4, p. 432-542, 1956.

BAZZACCO, D. et al. Decay properties and magnetic moment of the $548 \mathrm{keV}$ level in ${ }^{136} \mathrm{Pr}$. Nuclear Physics A, Amsterdam: Elsevier, v. 562, p. 260-272, 1993.

BOWLER, M. G. Nuclear Physics. New York: Pergamon Press Ltd, 1973.

BRANDOLINI, F.; Precise DSAM ${ }^{50} \mathrm{Cr}$ as a lifetime measurements in ${ }^{48} \mathrm{Cr}$ and test of large scale shell model calculations. Nuclear Physics A, Amsterdam: Elsevier, v. 642, p. 387-406, 1998.

BRUSSAARD, P.J.; GLAUDEMANS, P.W.M. Shell-model applications in nuclear spectroscopy. New York: North-Holland Publishing Company, 1977.

CASTEN, R. F. Nuclear Structure from a Simple Perspective. $2^{\circ}$ ed. New York: Oxford University Press, 2005.

CAURIER, E.; NOWACKI, F. Present Status of Shell Model Techniques, Acta Physica Polonica B, Cracow: Jagellonian University, v. 30, n. 3, p. 705-714, 1999.

CAURIER, E. et al. The Shell Model as a Unified View of Nuclear Structure. Reviews of Modern Physics. Woodbury: American Institute of Physics, v. 77, n. 2, p. 427-488, 2005.

CHUNG, K.C. Introdução à Física Nuclear. Rio de Janeiro: EdUERJ, 2001.

COHEN, B. L. Concepts of Nuclear Physics. New York: McGraw-Hill Book Company, 1971.

COOK, N.D. Models of the Atomic Nucleus. Berlin: Springer-Velag, 2006.

DAFNI, E. et al. Static moments of ${ }^{54} \mathrm{Fe}$ and perturbed angular distributions with combined dipole and quadrupole interactions. Physics Letters B, Amsterdam: Elsevier, v. 76, n. 1, p. 51-53, 1978. 
DINCA, D. et al. Reduced transition probabilities to the first $2^{+}$state in ${ }^{52,54,56} \mathrm{Ti}$ and development of shell closures at $N=32$, 34. Physical Review C. Ridges: American Physics Society, v. 71, p. 041302(R), 2005.

ELECTRONICS Equipment Pool Catalog. Fermilab Equipament Information. 2005. Disponível em: <http://www-esd.fnal.gov/esd/catalog/>. Acesso em: 05 fev 2008.

ENSDF: Evaluated Nuclear Structure Data File. NNDC : National Nuclear Data Center. Disponível em: < http://www.nndc.bnl.gov/ensdf/>. Acesso em: 06 jun 2008.

FIRESTONE, R. B. Nuclear Data Sheets, Orlando: Elsevier, v. 103, p. 269, 2004.

GAVRON, A. Statistical Model calculations in heavy ion reactions. Physical Review C. Ridge: American Physical Society, v. 21, n. 1, p. 230-236, 1980.

HUBBELL, J. H.; SELTZER, S. M. Tables of X-Ray Mass Attenuation Coefficients and Mass Energy-Absorption Coefficients. NIST - National Institute of Standards and Technology. 2004. Disponível em: <http://physics.nist.gov/PhysRefData/ XrayMassCoef/tab3.html>. Acesso em: 22 jan 2008.

HONMA, M. et al. New effective interaction for $p f$-shell nuclei and its implications for the stability of the $N=Z=28$ closed core. Physical Review C. Ridges: American Physics Society, v. 69, p. 034335-034369, 2004.

IONESCU-BUJOR, M. et al. $g$ factors of the $7 / 2^{+}$and $14^{+}$isomers in ${ }^{175,176} \mathrm{~W}$. Physics Letters B, Amsterdam: Elsevier, v. 495, p. 289-284, 2000.

JUNDE, H.; SU, H. Nuclear Data Sheets, Orlando: Elsevier, v. 107, p. 1393, 2006

KNOLL, G. F. Radiation Detection and Measurement. $2^{\circ}$ ed. New York: John Wiley \& Sons, 1989.

KONDEV, F. Experimental Nuclear Structure - Part I. In: Workshop on "Nuclear Structure and Decay Data: Theory and Evaluation", 2006, Trieste. Disponível em: < www-nds.iaea.org/workshops/ictp2006/Lectures/F.Kondev/Trieste1.ppt >. Acesso em: 21 junho 2008.

LAFN - LABORATÓRIO ABERTO DE FÍSICA NUCLEAR. DEPARTAMENTO DE FÍSICA NUCLEAR - IFUSP. Disponível em: < http://www.dfn.if.usp.br/paginalafn/index.html >. Acesso em: 03 out 2008.

MARTIN, M. J. Nuclear Data Sheets, Orlando: Elsevier, v. 70, p. 315, 1993.

MILNER, W. T. Holifield Heavy Ion Research Facility Computer Handbook. Oak Ridge National Lab, Oak Ridge, Tennesse, USA, 1987.

MORINAGA, H. and YAMAZAKI, T. In-Beam gamma ray spectroscopy. New York: North-Holland Publishing Company, 1976. 
RIBAS, R. V. A camac data acquisition system based on PC-linux. Nuclear Instruments and Methods in Physics Research A, Amsterdam: Elsevier, v. 483, p. 830-832, 2002.

RUDOLPH, D. et al. High-spin shell-model states near 56Ni. The European Physical Journal A. Heidelberg: Springer-Verlag, v.4, p. 115-145, 1999.

SILVEIRA, M. A. G. ${ }^{58}$ Co: Estudo de um núcleo ímpar-ímpar na camada pf. 2004. (Doutorado em Ciências) - Instituto de Física da Universidade de São Paulo, São Paulo, 2004.

SINGH, B. Nuclear Data Sheets, Orlando:Elsevier, v. 108, p. 197, 2007.

TANIGAKI, M. et al. Lifetime measurement of the first excited state of ${ }^{64} \mathrm{Ga}$. The European Physical Journal A. Heidelberg: Springer-Verlag, v. 6, p. 119-120, 1999.

TILLEY, D. R. et al. Energy levels of light nuclei $A=18-19$. Nuclear Physics A, Amsterdam: Elsevier, v. 595, p. 1-170, 1995.

TOUFEN, D. L. et al. Isomeric States Measurement System. Anais da XXX Reunião de Trabalho sobre Física Nuclear no Brasil, 2007. Artigo aceito para publicação. São Paulo: Editora Livraria da Física, p.52-55, 2008.

TRIUMPHO, T. H. et al. Active Photomultiplier Bases for the Saci Perere Spectrometer. Anais da XXVIII Reunião de Trabalho sobre Física Nuclear no Brasil, 2005. São Paulo: Editora Livraria da Física, p.391-398, 2007.

HELENE, O. A. M., VANIN V. R. Tratamento Estatístico de Dados em Física Experimental. 2a ed. São Paulo: Edgard Blucher LTDA, 1991.

WINTHER, A. e ALDER, K. Relativistic Coulomb Excitation. Nuclear Physics A, Amsterdam: North-Holland Publishing Company, v. 319, p. 518-532, 1979.

WONG, S.M.S. Introdutory Nuclear Physics. 2a ed. New York: John Wiley \& Sons, 1998.

WU S.C. Nuclear Data Sheets, Orlando: Elsevier, v. 106, p. 367, 2005.

YAO, W.M. et al. Review of Particle Physics. Jornal of Physics G, Bristol: IOP Publishing, v. 33, p. 1, 2006. 


\section{APÊNDICE A: Bases ativas para as fotomultiplicadoras dos detectores cintiladores do saci.}

Para permitir ao Sistema Ancilar de Cintiladores (SACI) trabalhar de forma confiável com taxas mais elevadas de contagens, foram desenvolvidas bases ativas para as fotomultiplicadoras dos seus detectores cintiladores. A descrição da eletrônica e dos testes utilizando um primeiro modelo para estas bases pode ser vista em (TRIUMPHO, 2007). Este primeiro modelo, apesar de seu funcionamento satisfatório apresenta duas características indesejadas:

- O tamanho do circuito é excessivamente grande, tornando difícil uma substituição simples das antigas bases passivas pelas novas bases ativas;

- O transistor utilizado (MPSU-10) encontra-se fora de fabricação, o que dificulta muito a sua aquisição em maior escala e aumenta o custo de fabricação das bases.

Para contornar estas características inconvenientes, um novo circuito foi proposto para a construção das bases ativas. Este circuito apresenta duas mudanças fundamentais: a troca do transistor MPSU-10 pelo MJE340 e a redução de um estágio ativo (de 4 estágios ativos para 3

estágios ativos). Este novo transistor pode trabalhar com tensões elevadas $\left(\mathrm{V}_{\text {ce_max }}=300 \mathrm{~V}\right)$, assim como o MPSU-10. No entanto, esse transistor não apresenta uma resposta em freqüência tão boa quanto o MPSU-10. Já a redução de um estágio ativo tem por objetivo principal reduzir o tamanho do circuito para permitir que este seja montado de modo a ocupar o mesmo espaço físico do circuito da base passiva. O novo circuito para a base ativa é visto na Figura A. 1, Onde: $\mathrm{R}=820 \mathrm{k} \Omega-1 / 8 \mathrm{~W}, \mathrm{R} 1=270 \mathrm{k} \Omega-1 / 8 \mathrm{~W}, \mathrm{R} 2=560 \mathrm{k} \Omega-1 / 8 \mathrm{~W}$, $\mathrm{D}=1 \mathrm{~N} 4148, \mathrm{C}=100 \mathrm{nF}-100 \mathrm{~V}, \mathrm{Q}=$ MJE340, K é o catodo e D1 à D10 são os dinodos. 


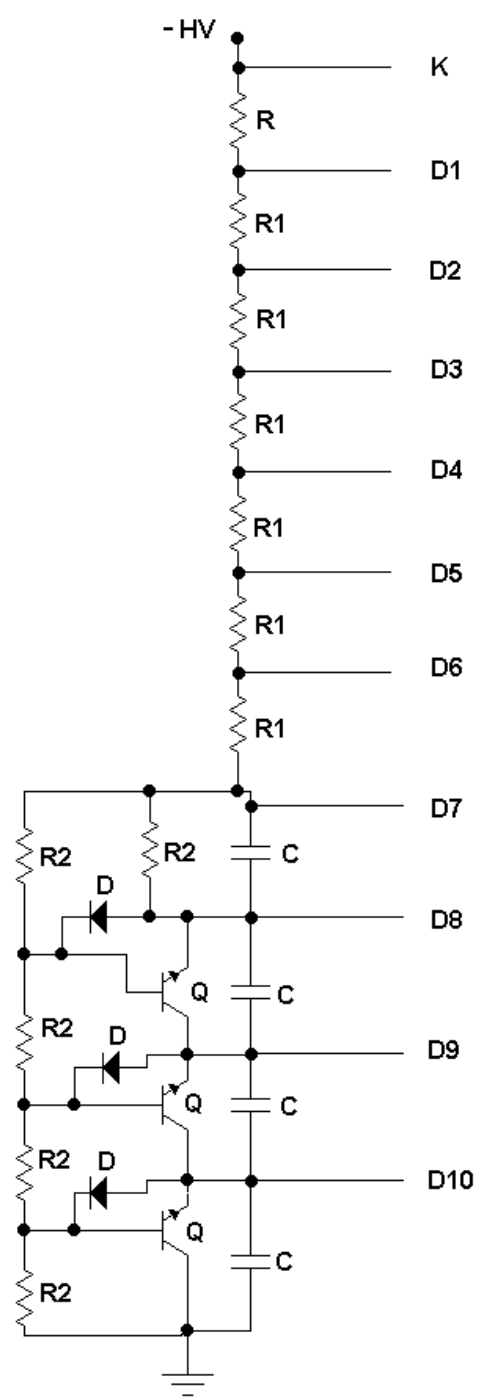

Figura A. 1. Circuito Elétrico para base ativa com 3 estágios ativos.

Para que a base ativa ocupasse o mesmo espaço físico da base passiva, desenvolveu-se um layout não tradicional para o circuito. Nesta nova configuração, os componentes não ficam junto à placa de circuito impresso, como normalmente, mas sobrepostos e isolados individualmente com isolante termo-contrátil. O layout do circuito é visto na Figura A. 2, à esquerda, e a posição dos componentes no layout é vista na Figura A. 2, à direita. Os pontos marcados com "nc" não devem ser conectados ao soquete que liga a base com a fotomultiplicadora. 

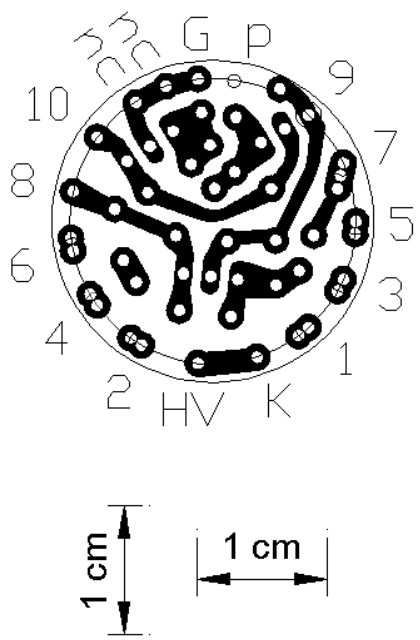
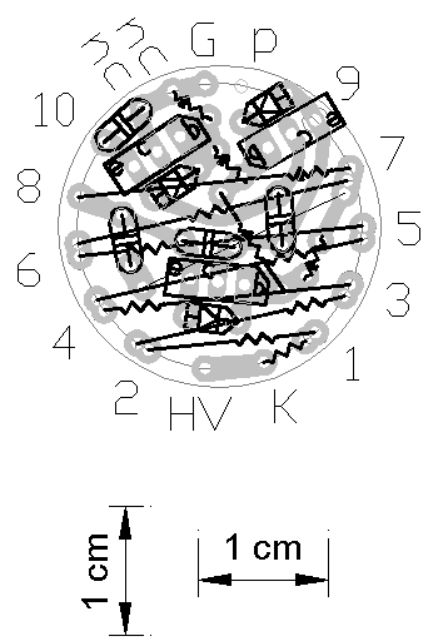

Figura A. 2. Layout do circuito impresso utilizado para a construção da base ativa (à esquerda) e posição dos componentes no layout (à direita). Os pontos marcados com "nc" não devem ser conectados ao soquete que liga a base com a fotomultiplicadora.

Como o circuito da base ativa foi modificado de forma relativamente drástica, com reduções de suas funcionalidades, fez-se necessário um outro teste para confirmar o desempenho deste novo circuito. Este teste foi realizado através da reação ${ }^{11} \mathrm{~B}+{ }^{58} \mathrm{Ni}$, $\mathrm{E}_{\mathrm{F}}=35 \mathrm{MeV}$. Neste teste, variou-se a corrente de feixe para ambos os modelos de base e manteve-se constante o detector cintilador, a fotomultiplicadora e o ângulo de detecção. A comparação entre os espectros de perda de energia das partículas carregas no detector plástico $\Delta \mathrm{E}$, para 3 correntes de feixe, é apresentada na Figura A. 3. Observa-se nestes espectros que o ganho da base passiva, à esquerda, muda consideravelmente com a variação de corrente enquanto o novo modelo de base ativa, à direita, mantém o ganho constante para correntes de feixe de até $35 \mathrm{nA}$, comprovando que o novo modelo da base é eficiente e pode ser implementado para todos os detectores cintiladores do SACI. 

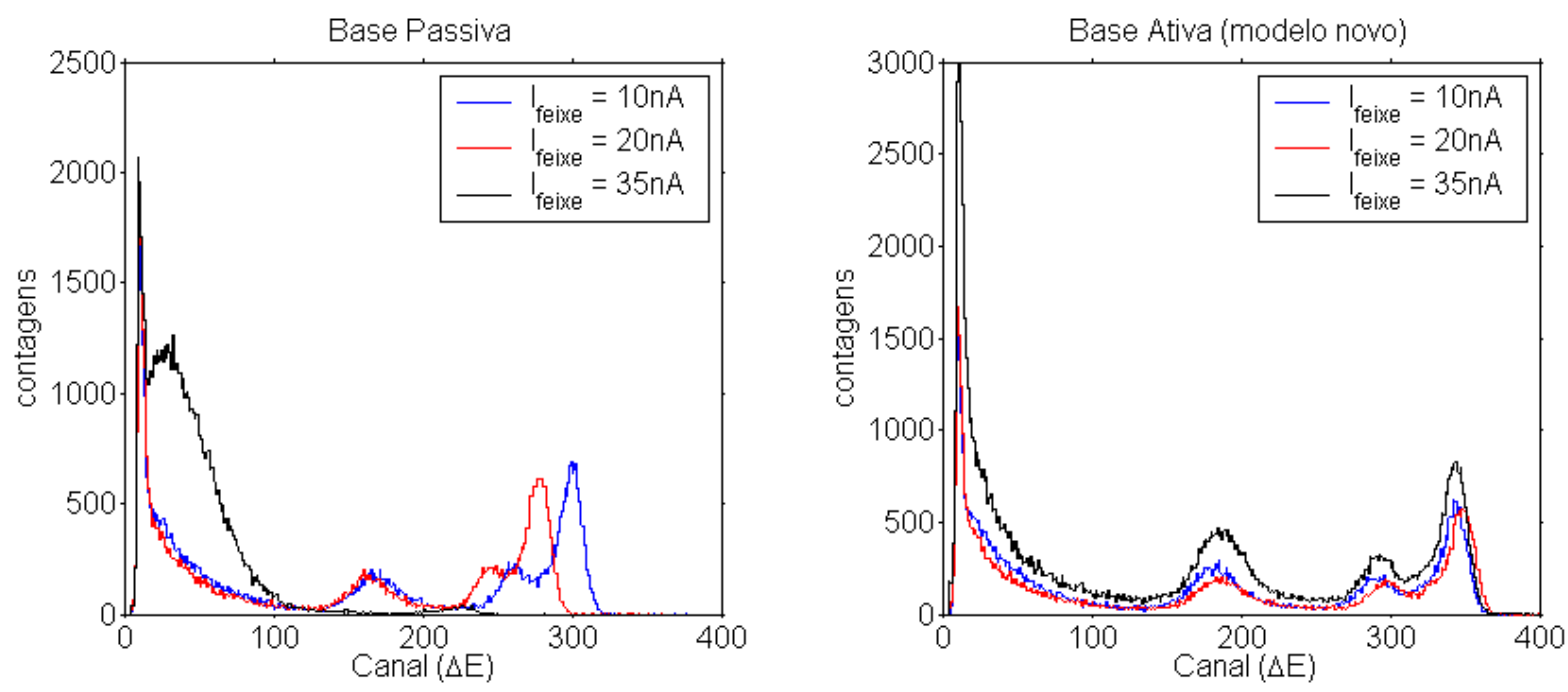

Figura A. 3: Espectros da perda de energia das partículas carregas no detector plástico $\Delta \mathrm{E}$ posicionado no ângulo de $0^{\circ}$ do SACI para 3 correntes de feixe diferentes. Observa-se que o ganho da base passiva, à esquerda, muda consideravelmente com a variação de corrente enquanto o novo modelo de base ativa, à direita, mantém o ganho constante para correntes de feixe de até $35 \mathrm{nA}$. 


\section{APÊNDICE B: Módulo CAMAC de BUSY comandado via arquivo de aquisição.}

Na eletrônica do SACI os módulos de aquisição e conversão de informações (ADCs e QDCs) necessitam de tempos relativamente longos para realizar suas conversões corretamente. O módulo de $B U S Y$ tem a função de informar à eletrônica que os módulos de aquisição estão ocupados e conseqüentemente inibir a entrada de uma nova informação.

Antes deste trabalho o módulo de BUSY era um módulo Gate \& Delay Generator (GG) com largura de pulso grande o suficiente para garantir o tempo necessário para a conversão de todos os módulos de aquisição. Porém, como o tempo de aquisição de cada evento nem sempre é o mesmo, na maior parte do tempo o sistema fica ocioso, em BUSY, por um tempo desnecessário, aumentando o tempo morto total do sistema. O módulo de $B U S Y$ desenvolvido neste trabalho elimina esse problema. Este novo módulo é muito semelhante a um GG, fornecendo um sinal lógico ativado por um pulso de entrada. Neste caso, a diferença é que o sinal de saída é desativado através de um comando proveniente do programa SPMlinux (RIBAS, 2002), que controla o sistema de aquisição de dados. Com isso, pode-se desativar o sinal de BUSY logo após a conversão do último módulo da aquisição de dados, eliminando assim o tempo morto causado pelo sinal de $B U S Y$ antigo, que era fixado em $400 \mu$ s. O circuito do novo módulo de BUSY é visto na Figura B. 1.

O novo módulo BUSY utiliza dois circuitos integrados: 74LS27 (TRI 3-INPUT NOR GATE), utilizado para detectar quando CAMAC está enviando um comando para desativar o sinal de BUSY (no caso: NAF N,0,8) e CD4027 (CMOS Dual J-K Master-Slave Flip-Flop), que é responsável por enviar o sinal de BUSY de acordo com os comandos vindos da entrada do módulo (SET BUSY) e do CI 74LS27 (CLEAR BUSY). 


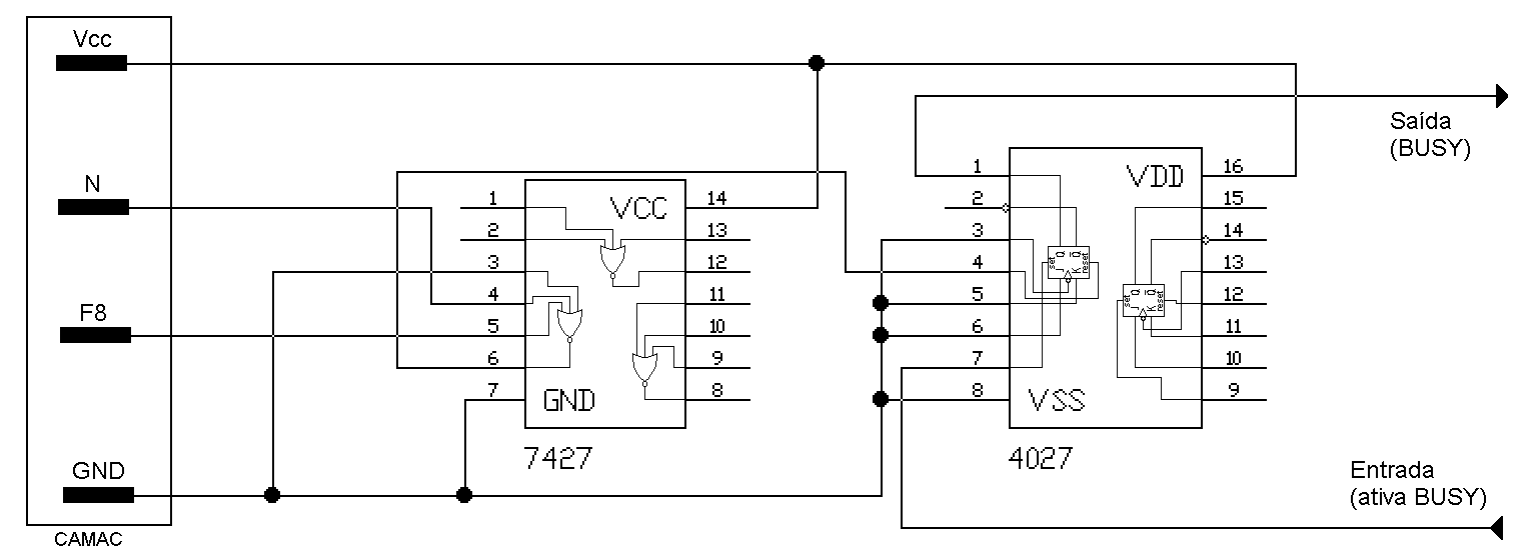

Figura B. 1: Circuito do novo módulo de BUSY. 